\title{
Alexandre Munhoz
}

\section{Metodologia para detecção de obstáculos para navegação de embarcações autônomas usando visão computacional.}

Dissertação apresentada à Escola de Engenharia de São Carlos da Universidade de São Paulo, como parte dos requisitos para obtenção do título de Mestre em Ciências, Programa de Pós-Graduação em Engenharia Elétrica (Área de Concentração em Processamento de Sinais e Instrumentação) 

AUTORIZO A REPRODUÇÃO E DIVULGAÇÃO TOTAL OU PARCIAL DESTE TRABALHO, POR QUALQUER MEIO CONVENCIONAL OU ELETRÔNICO, PARA FINS DE ESTUDO E PESQUISA, DESDE QUE CITADA A FONTE.

Ficha catalográfica preparada pela Seção de Tratamento

da Informaçãọ do Serviço de Biblioteca - EESC/USP
Munhoz, Alexandre
Metodologia para detecção de obstáculos para navegação de embarcações autônomas usando visão computacional / Alexandre Munhoz; orientador Valentin Obac Roda. -- São Carlos, 2010.

Dissertação (Mestrado-Programa de Pós-Graduação em Engenharia Elétrica e Área de Concentração em Instrumentação) -- Escola de Engenharia de São Carlos da Universidade de São Paulo, 2010.

1. Robótica. 2. Detecção de obstáculos. 3. Visão computacional. 4. Navegação autônoma. 5. Lago. 6. Rio. I. Título. 



\section{FOLHA DE JULGAMENTO}

\section{Candidato: Bacharel ALEXANDRE MUNHOZ.}

Dissertação defendida e julgada em 03/09/2010 perante a Comissão Julgadora:
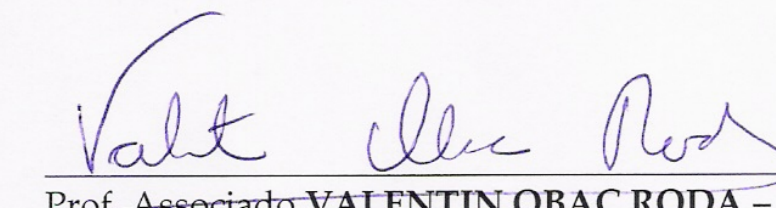

APROUADO

Prof.Associado VALENTIN OBAC RODA - (Orientador)

(Escola de Engenharia de São Carlos/USP)

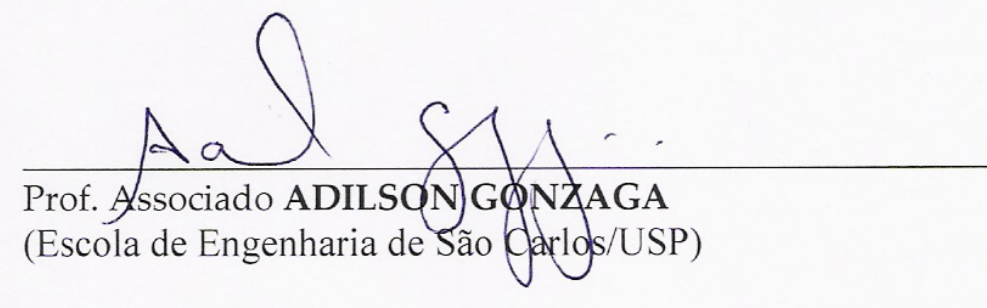

APRUUADO

(Escola de Engenharia de São Carlog/USP)

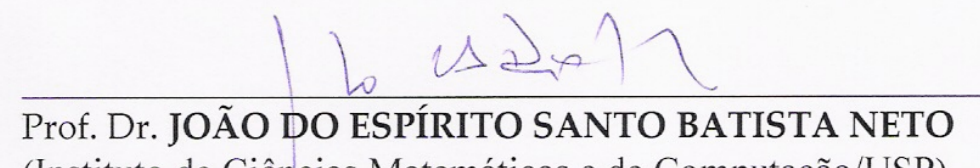

(Instituto de Ciências Matemáticas e de Computação/USP)

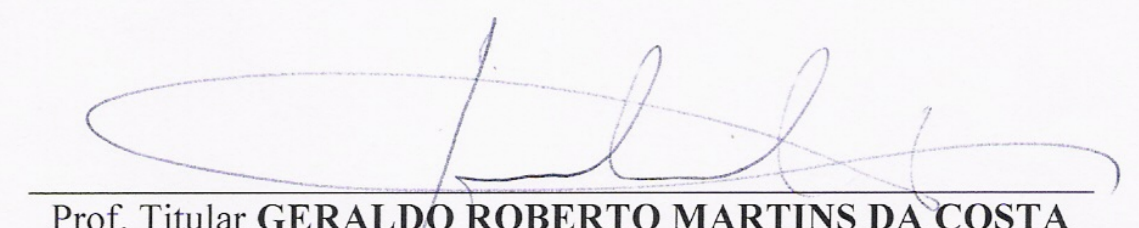

Coordenador do Programa de Pós-Graduação em Engenharia Elétrica e Presidente da Comissão de Pós-Graduação 



\section{Agradecimentos}

Um bom motivo para o leitor se interessar por esta seção de agradecimentos, é conhecer o ótimo ambiente de estudos e pesquisas que é o Departamento de Engenharia Elétrica da Universidade de São Paulo, no campus de São Carlos.

Sou testemunho da melhor qualidade das relações sociais que já presenciei em toda a minha vida acadêmica, e sou eternamente agradecido pelo que isso proporcionou ao meu trabalho e a minha formação.

Todos os professores de que convivi são transparentes em suas opiniões e posturas, com perfeita clareza na transmissão de idéias. Aquele que mais se destaca nestas características, é sem duvida o prof. Dr. Adilson Gonzaga, cuja liderança me cativou à seguílo em suas disciplinas e alguns workshops de visão computacional.

Me impressionou muito o esforço da prof.a. Dra. Maria Stela Veludo de Paiva, ao vêla realizar um bom levantamento de literatura, apenas para responder à curiosidade de um

aluno. É sem dúvida nenhuma um exemplo raro no qual eu sou grato em ser uma testemunha ocular e poder me guiar, copiando esta postura.

Agradeço também ao prof. Dr. Marcelo Andrade da Costa Vieira, pela virtude de sempre transmitir aos alunos com paciência e entusiasmo sem importar-se com os desafios que a literatura vai nos levar. Este é a postura exata e necessária que os alunos precisam para atingir o estado de arte.

Testemunhei durante meu convívio com uma bondade incondicional do prof. Dr. Denis V. Coury, que me permitiu acompanhar algumas de suas aulas e explicações no qual o único vínculo era um pedido verbal que eu havia feito.

Agradeço também ao prof. Dr. Ivan Nunes da Silva, cuja habilidade didática pode ser demonstrada pela multidão que o procura, e estas palavras já tem força para um seguro ponto final. 
O ambiente também foi excepcional devido à turma de amigos que frequentaram as cadeiras junto comigo. Eles mantinham um nível de debates precisamente adequados ao desenvolvimento do grupo. Todos os questionamentos levantados sempre auxiliavam no desenvolvimento dos colegas e da comunidade. Havia sempre a sensibilidade para que as questões fossem colocadas de maneira correta a não ceifar o desenvolvimento de uma mosca e ao mesmo tempo estimular o raciocínio de divindades. É o caso de Luiz Marcelo Chiesse da Silva e Gustavo Teodoro Laureano. Lembro também de companheiros que colaboravam muito com idéias e questões, mas ficaram apenas o primeiro nome : Antônio e André (da disciplina de processamento de imagens ministrada pelo prof. Dr. Marcelo Andrade da Costa Vieira). As vezes acho que o Antônio não queria que nesta homenagem, houvessem nomes por alguma filosofia que transcende rótulos, mas aí está.

Finalmente, meu orientador, professor e amigo prof. Dr. Valentin Obac Roda, que manteve desde o primeiro dia que conheci, o inalterável comportamento de paciência, respeito, sapiência... portando sempre os conselhos mais seguros para atravessar esta fase única de minha vida.

À todos, obrigado. 


\section{Epígrafe}

“... dois objetos podem, inadvertidamente, ocupar o mesmo lugar no espaço."

Massola, A.M.G et al Fundamentos de Computação Gráfica

Rio de Janeiro; São Paulo: Livros Técnicos e Científicos

Editora S.A., 1987, p 265 



\section{RESUMO}

Este trabalho apresenta um novo método de deteç̧ão de obstáculos usados para navegação de um barco autônomo. O método desenvolvido é baseado em visão computacional e permite medir a distância e direção do obstáculo à câmera de video. A distância do possível obstáculo à câmera de vídeo, e o vetor de contorno predominante da imagem são os parâmetros usados para identificar os obstáculos.

Imagens estereoscópicas adquiridas nas margens da lago do clube Náutico de Araraquara, usando bóias de navegação como obstáculos, foram usadas para extrair as características significantes das experiências. Para validar a experiência, foram utilizadas imagens do Reservatório do Broa (Itirapina, SP). A proposta desenvolvida mostrou ser mais eficiente que o método tradicional usando a teoria de Campos Potencias.

As imagens foram propositadamente tomadas contra o sol, onde o brilho das ondas são erroneamente indicadas como obstáculos pelo método de campos potenciais. Esta proposta filtra as ondas de forma a diminuir sua interferência no diagnóstico.

Palavras-chave: Robótica. Detecção de obstáculos. Visão computacional. Navegação autônoma, Lago. Rio. 



\begin{abstract}
This work presents the results of new obstacle detection methods used for an autonomous boat navigation. The developed method is based on computer vision and allows to measure the distance and direction of the obstacle to the boat. The distance of the possible obstacle to the camera, and the obstacle outline predominant vector are the parameters used to identify the obstacles.

Stereo images acquired from the margins of the Nautical Araraquara lake, using navigation buoys as obstacles, were used to extract the meaningful characteristics of the experiments. To validate the experiment, images from the Broa Reservoir (Itirapina, SP) where used. The developed proposal showed to be more efficient than the traditional method using the potential fields theory.

The images were taken willfully against the sun, where the brightness of the waves are erroneously identified as obstacles by the method of potential fields. This method filters the waves so as to reduce its interference in the diagnosis.
\end{abstract}

Keywords: : Robótics. Obstacle avoidance. Computer vision. Autonomous navigation, Lake. River. 



\section{Ilustrações}

Figura 1. - Pesquisas primordiais em reconhecimento de padrões visuais 23

Figura 2. - Diagrama geral do trabalho ................................................................. 26

Figura 3. - Diagrama do experimento principal ............................................... 28

Figura 4. - Diagrama de câmeras montadas ................................................................. 36

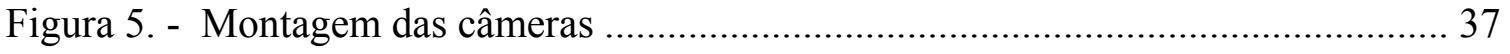

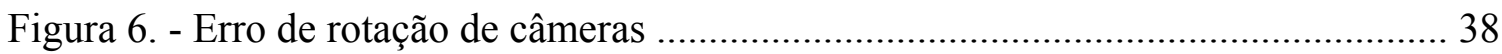

Figura 7. - Sobreposição de imagens desalinhadas e de imagens alinhadas por erro de rotação da câmera ................................................................................ 38

Figura 8. - Tratamento de imagens para correção do erro de inserção ........................... 41

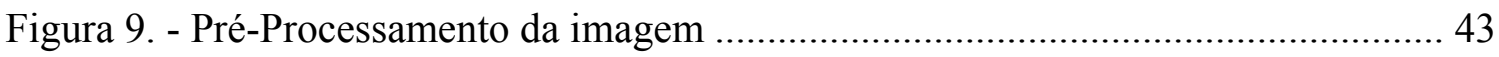

Figura 10. - Exemplo de levantamento de Blobs ...................................................... 44

Figura 11. - Imagens capturadas para extração de características -1 ............................45

Figura 12. - Imagens capturadas para extração de características -2 .............................46

Figura 13. - Imagens capturadas para extração de características -3 ........................... 47

Figura 14. - Boias de navegação tomadas como obstáculos ...................................... 48

Figura 15. - Exemplo de cálculo de vetor predominante de contorno .......................... 51

Figura 16. - Espaço de características para análise de validação de disparidade ........... 53

Figura 17. - Figura de transferidor utilizada para calcular o angulo relativo a

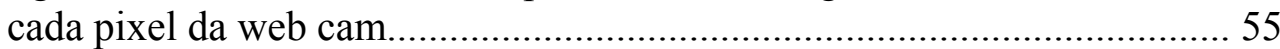

Figura 18. - Disposição da câmera e alfinetes sobre painel do transferidor e a imagem capturada por esta câmera ...................................................... 56

Figura 19. - Triângulo relativo à disposição das duas câmeras e um ponto do objeto analisado

Figura 20.- Diagrama genérico de representação geométrica do espaço entre câmeras e o objeto em estudo

Figura 21. - Diagrama de cálculo de $\boldsymbol{\alpha e}$ para pixels à direita da imagem 61

Figura 22. - Diagrama de cálculo de $\boldsymbol{\alpha e}$ para pixels à esquerda da imagem 
Figura 23. - Diagrama de cálculo de $\boldsymbol{\alpha d}$ para pixels à direita da imagem 64

Figura 24. - Diagrama de cálculo de $\boldsymbol{\alpha d}$ para pixels à esquerda da imagem .65

Figura 25. - Representação das variáveis para cálculo de distância .66

Figura 26. - Teste de campo para cálculo de distância 67

Figura 27.- Erros do calculo de distância gerados pela discretização da imagem ......... 68

Figura 28. - Estacas de madeira gerando erros de medida de distância

Figuras 29. - Blobs não filtrados em um espaço de características

Distância X Vetor

Figura 30. - Blobs filtrados por validação $>30$ dispostos em um espaço de características Distância X Vetor

Figura 31. - Amostragem para validade externa comparando método proposto com método de Snyder(2004)

Figura 32. - Amostragem para validade externa comparando método proposto com método de Snyder(2004) .78

Figura 33.- Amostragem para validade externa comparando método proposto com método de Snyder(2004)

Figura 34. - Blobs presentes nas imagens ........................., ;........... 80

Figura 35.- Amostragem para validade externa comparando método proposto com método de Snyder(2004)

Figura 36.- Amostragem para validade externa comparando método proposto com método de Snyder(2004)

Figura 37.- Amostragem para validade externa comparando método proposto com método de Snyder(2004)

Figura 38.- Amostragem para validade externa comparando método proposto com método de Snyder(2004) 84

Figura 39. - GPS GT-272. 89

Figura 40. - Bússola V2XE 90

Figura 41. - Conversor de tensão Bússula - TTL 90

Figura 42. - Adaptador de USB para Bússula 90

Figura 43. - Pontos de borda da represa 


\section{Tabelas}

Tabela 1 - Teste de cálculo de distância .68

Tabela 2 - Legenda de cores utilizada nos gráficos de distribuição de características

Tabela 3 - Desempenho do método de Snyder em comparação com o método proposto. 



\section{Lista de símbolos e abreviaturas utilizados}

Convenções - Os símbolos apenas em negrito são considerados variáveis utilizadas. Os símbolos em negrito e itálicos, são considerados imagens.

angdesl - Angulo obtido pelo desvio entre o angulo de 90 graus do pixel central e o ângulo de incidência do ponto do objeto em análise.

AUV - Veículo Autônomo Submerso (Autonomous Underwater Vehicle).

coordh - Coordenada horizontal de um pixel em análise.

deslpixdir - Desvio em pixels do ponto analisado sobre o centro horizontal original da imagem direita.

deslpixesq - Desvio em pixels do ponto analisado sobre o centro horizontal original da imagem esquerda.

distância_margem - Distância entre o ponto de captura da imagem e a margem do lago exibida pela mesma imagem. Esta distância é calculada a partir de um GPS, uma bússola e coordenadas de contorno do lago.

distância_ponto-cursor - Distância entre um ponto da margem do lago e um cursor móvel para procura de distância_margem. Esta variável tem como propósito detectar se o cursor móvel chegou à margem.

distância_testada - Distâncias em que serão procuradas a distância_margem.

hp - Deslocamento horizontal da imagem propiciado por erro de inserção da câmera no seu suporte.

im - Imagem pré-processada.

Nim - Imagem pós-processada.

palf - Distância média em pixels entre cada alfinete de referência. Medida em pixels, utilizada para calcular angulo de incidência da luz sobre cada pixel da imagem.

pixa - Graus de incidência de luz entre 2 pixels vizinhos horizontalmente na imagem.

pmesq - Pixel cuja coordenada horizontal corresponde ao centro da câmera, e cujo raio de incidência da luz é de 90 graus

ponto_margem - Pontos de contorno da margem, para fins de mapear as coordenadas na margem no sistema.

rot - Rotação da imagem propiciado por erro de inserção da câmera no seu suporte.

sdob - Distância entre o ponto do objeto analisado e o centro do diafragma da câmera direita 
sed - Distância entre o centro do diafragma da câmera direita e o centro do diafragma da câmera esquerda

seob - Distância entre o ponto do objeto analisado e o centro do diafragma da câmera esquerda.

$\mathbf{v p ~ - ~ D e s l o c a m e n t o ~ v e r t i c a l ~ d a ~ i m a g e m ~ p r o p i c i a d o ~ p o r ~ e r r o ~ d e ~ i n s e r c ̧ a ̃ o ~ d a ~ c a ̂ m e r a ~ n o ~ s e u ~}$ suporte

$\mathbf{X}$ - Eixo horizontal de rotação da câmera de vídeo.

xcursor - Coordenada x de um cursor móvel utilizado com objetivo de procurar a distância da margem ao ponto onde a imagem foi capturada. Esta procura é feita utilizando um GPS, uma bússola e pontos de mapeamento do contorno do lago.

xdir - Coordenada x do ponto em análise da imagem real refletido na câmera direita.

xesq - Coordenada $\mathrm{x}$ do ponto em análise da imagem real refletido na câmera esquerda.

xmargem - coordenada $\mathrm{x}$ de cada ponto ao longo da margem do lago.

Y - Eixo vertical de rotação da câmera de vídeo.

ycursor - Coordenada y de um cursor móvel utilizado com objetivo de procurar a distância da margem ao ponto onde a imagem foi capturada. Esta procura é feita utilizando um GPS, uma bússola e pontos de mapeamento do contorno do lago.

ymargem - coordenada y de cada ponto ao longo da margem do lago.

$\mathbf{Z}$ - Eixo de rotação da câmera de vídeo situado no sentido do fluxo de raio luminoso para o centro da imagem.

aalf - Ângulo entre alfinetes de referência, tomados para medir ângulo de incidência da luz sobre cada pixel da imagem.

$\boldsymbol{\alpha d}$ - Ângulo sobre a câmera direita refletindo a abertura entre a câmera esquerda e o ponto do objeto analisado

$\boldsymbol{\alpha e}$ - Ângulo sobre a câmera esquerda refletindo a abertura entre a câmera direita e o ponto do objeto analisado

aob - Ângulo sobre o ponto do objeto analisado refletindo a abertura entre a câmera direita e a câmera esquerda.

apix - Pixels de distância entre cada grau de incidência de luz sobre a imagem, em varredura horizontal.

$\sigma \mathbf{x n}$ - Desvio Padrão das coordenadas x do ponto $\mathrm{n}$.

бyn - Desvio Padrão das coordenadas y do ponto n. 


\section{Sumário}

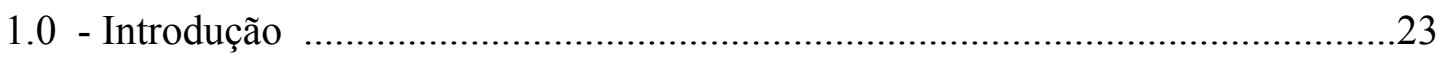

1.1 - Motivação ………………………………………………………... 23

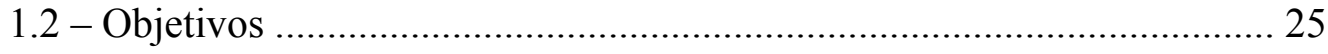

1.3 - Organização da dissertação ................................................................ 26

2.0 - Detecção de Obstáculos por visão computacional .............................................29

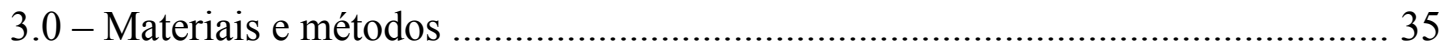

3.1 - Procedimentos de calibração das câmeras ……………………………. 38

3.1.1 - Detecção de erros ................................................................ 38

3.1.2 - Correção de erros .................................................................. 41

3.2 - Pré-processamento das Imagens ......................................................... 43

3.3 - Imagens capturadas para definição de classes …………………………. 45

3.4 - Atribuição de classes .............................................................................. 48

3.5 - Atribuição de características ................................................................... 50

3.6 - Disparidade de Imagens ………………………………………..... 52

3.6.1 - Cálculo de disparidade .......................................................... 52

3.6.2 - Validação da análise de disparidade do blob............................ 53

3.7 - Cálculo de distância ............................................................................ 55

3.7.1 - Cálculo pixel-grau .................................................................. 55

3.7.2 - Diagrama de cálculo de distância ............................................. 57

3.7.3 - Calculando ae ................................................................... 59

3.7.3.1 - Cálculo de ae para pixels situados à direita ............. 61

3.7.3.2 - Cálculo de ae para pixels situados à esquerda ......... 62

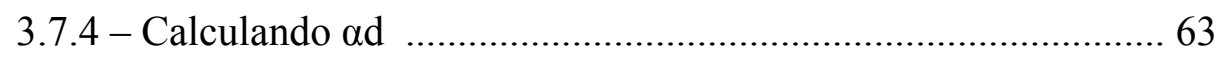

3.7.4.1 - Cálculo de $\alpha$ d para pixels situados à direita ........... 64

3.7.4.2 - Cálculo de $\alpha$ d para pixels situados à esquerda ......... 65

3.7.5 - Finalização do cálculo da distância ........................................... 66

3.7.6 - Aferição do cálculo de distância ................................................ 67

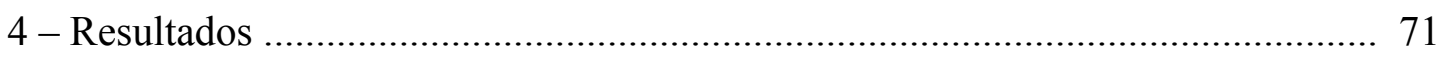

4.1 - Determinação da região de classificação de obstáculos ........................ 71

4.2 - Teste de desempenho em comparação com Snyder (2004) ................... 75 


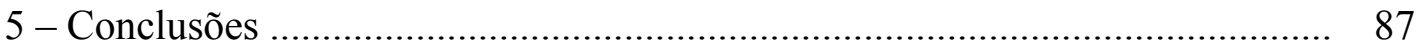

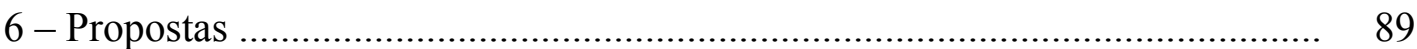

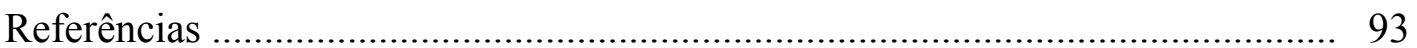

Apêndice A - Rotinas desenvolvidas ............................................................ 99

Apêndice B - Erros proporcionados pela discretização ………................................ 105 


\section{Capítulo 1}

\section{Introdução}

\section{1 - Motivação}

Muito tempo antes de haver computadores, ou mesmo da eletrônica digital, já havia investigações sobre padrões de reconhecimento visual. Em um trabalho pioneiro na área de etologia, Timbergen e Perdeck (1950 apud Manning, Aubrey 1977) já fazia alguns experimentos para identificar estímulos visuais em animais. Em seu trabalho, era descrito o comportamento de filhotes de gaivotas no ninho, que abriam o bico em coordenação motora para receber comida toda vez que se aproximava um graveto com a ponta pintada de vermelho. Nesta espécie, a mãe possuía uma mancha vermelha na ponta do bico, logo deduziu-se que bastaria a presença de qualquer cilindro de dimensão próxima e com a ponta vermelha para que a imagem fosse reconhecida pelos filhotes como sendo a imagem da mãe.

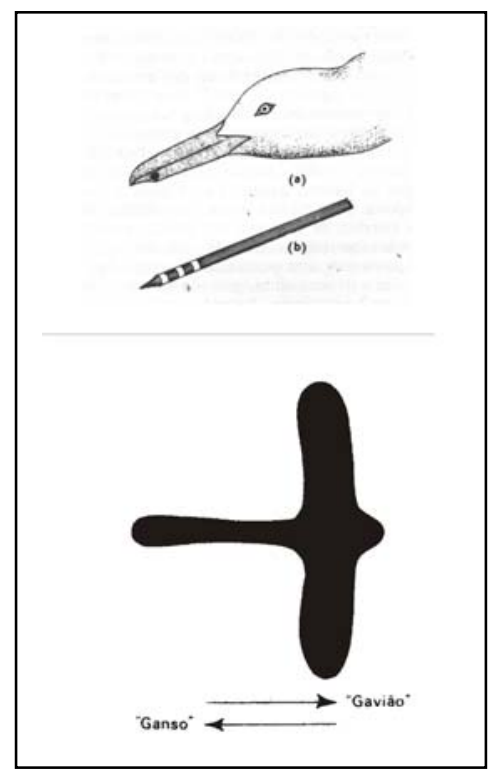

Figura 1. Experimentos primordiais em reconhecimento de padrões em imagens. (ilustração segundo, Timbergen e Perdeck (1950 apud Manning, Aubrey 1977) e Timbergen (1951 apud Manning, Aubrey 1977) )

Em outro experimento clássico de Timbergen (1951 apud Manning, Aubrey 1977) sobre reconhecimento de imagens, descrito neste mesmo livro, é recortada em cartolina uma silhueta, conforme a Figura 1. Este recorte possui um formato que pode lembrar tanto um 
gavião quanto um ganso, dependendo apenas do sentido de seu deslocamento. Foi suspensa então a cartolina por fios e deslocada sobre ninhos de diversas espécies de aves que se aninham no chão. Quando o recorte era deslocado no sentido que faz lembrar um ganso, os filhotes em seu ninho permaneciam tranqüilos, sem nenhuma atenção ao estímulo visual. No entanto, quando a cartolina era deslocava no sentido que lembra um gavião, os filhotes apresentavam comportamento de alarde. Este experimento, mostra que nos primórdios da etologia, já era estudada a influencia do movimento no reconhecimento de imagens.

Hoje, com a presença disseminada dos computadores em nossas vidas, as investigações sobre reconhecimento de padrões visuais cresceu. No ano de 2008 a base de dados Scopus registrou 5962 artigos publicados com as palavras-chave "computer vision"

Um interesse particular surgiu no Laboratório de Instrumentação Virtual e Microprocessada, do Departamento de Engenharia Elétrica da Universidade de São Paulo Campus de São Carlos. Neste local, se desenvolveu um barco com navegação autônoma, onde se verificou o interesse por um sistema de reconhecimento automático de obstáculos fortuitos.

Primordialmente, neste laboratório, Stavarengo (2006) desenvolveu um sistema de navegação autônoma com uma embarcação em sua dissertação de mestrado "Telemetria de Dados e Imagens para Plataforma Autônoma para Coleta de Dados Hidrológicos “. Dispondo então o laboratório deste material, percebemos a oportunidade do desenvolvimento do presente trabalho. 


\section{2 - Objetivos}

Pretende-se com o presente trabalho, apresentar soluções adaptadas à embarcações para detecção de obstáculos, utilizando visão computacional. A imagem desejada é a de perspectiva da superfície do corpo de água aonde a embarcação irá navegar. Desta forma, as câmeras poderão ser apoiadas sobre o próprio barco.

Os obstáculos que se pretendem detectar, são aqueles fortuitos, já que este projeto está integrado à outras rotinas de navegação, onde o planejamento de rota e propulsão já é estabelecida pela rotina principal.

Como a rotina em si apenas se comunica com o programa de planejamento de rota, não compete à ela o plano de fuga. Com isso esta passa a ser responsável em determinar a distância e direção do obstáculo para que o programa principal possa tomar as decisões cabíveis.

O padrão das ondas depende da direção e intensidade dos ventos, e principalmente da superfície ao qual a água se expõe à estes ventos. Sendo os lagos ligados ao projeto, de superfície pequena em relação ao mar, não se espera ondas das proporções encontradas nos oceanos. Por esta razão, os testes realizados neste experimento são em ambientes com ondas de pequeno tamanho.

Esta pesquisa tem cunho investigativo. Sendo uma aplicação nova não se pretende indicar o método para todos os obstáculos possíveis, mas medir o desempenho para detecção dos obstáculos encontrados em campo.

Este trabalho se propõe a ser um método mais eficiente do que o proposto por Snydera, F. D. (2004), que trata do reconhecimento de obstáculos por visão computacional sobre a superfície em perspectiva de um lago. Verificamos que os métodos por ele defendidos são pouco efetivos para imagens coletadas contra o sol em condições de ondas sobre a superfície do lago. 


\section{3 - Organização da dissertação.}

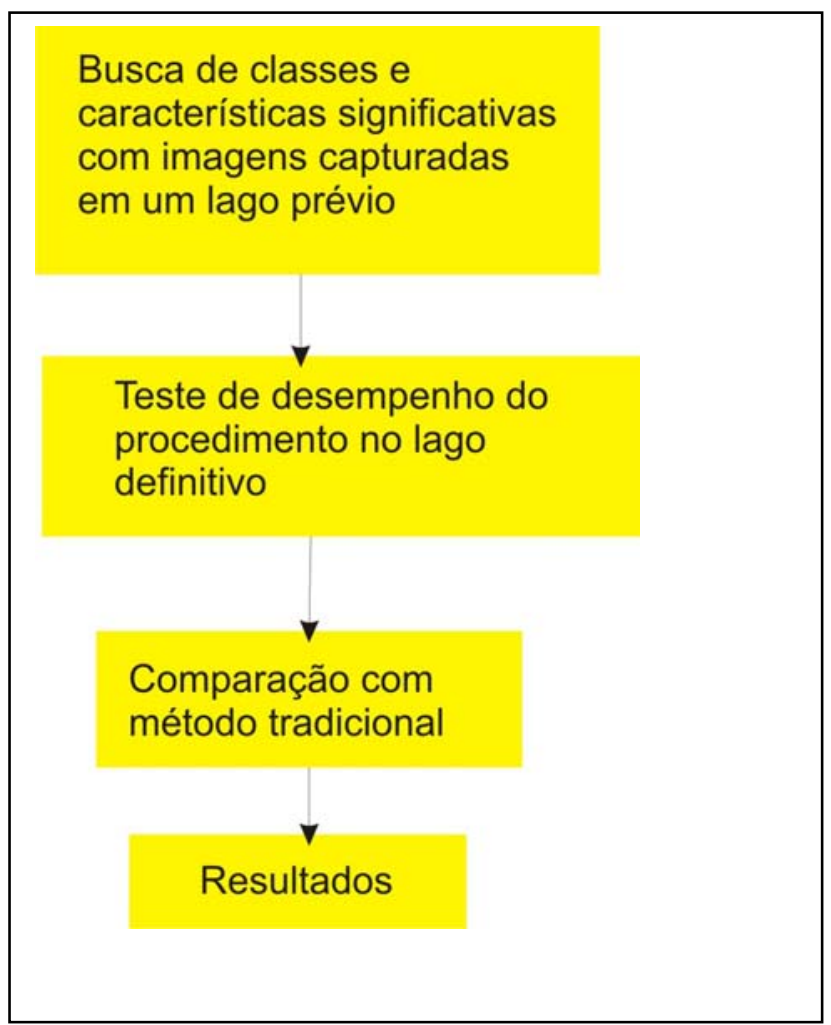

Figura 2. - Diagrama geral do trabalho

Esta breve introdução que procurou descrever a motivação inicial do trabalho, e a determinação dos objetivos, se preocupa agora em mostrar como se distribui o presente trabalho a fim de facilitar a compreensão geral do leitor.

Um histórico sobre reconhecimento de obstáculos é apresentado no capítulo 2. Como os trabalhos sobre reconhecimento de obstáculos sobre a superfície da água utilizando-se de visão computacional não são muitos, procurou-se inicialmente descrever o estado em reconhecimento de obstáculos por visão computacional estéreo em ambientes não aquáticos. Posteriormente é descrito o estado de arte em reconhecimento de obstáculos em ambiente aquático em geral.

No diagrama geral do experimento, conforme ilustrado na figura 2, procuramos inicialmente coletar classes de contornos sobre imagens em estéreo coletadas à margens do clube Náutico de Araraquara - SP. Estes contornos rastreados (blobs) foram divididos manualmente em diversas classes. Observou-se então, as principais características envolvidas nas classes deste banco de imagens preliminar. 
Como teste de validação externa, procurou-se então verificar se estas características estavam presentes também em um novo banco de imagens coletados em um outro lago. Por esta razão, tomamos novas imagens na represa do Broa em Itirapina - SP.

Por constatarmos que o método de Snyder et al. (2004), é pouco eficiente em imagens contra o sol, todas as imagens capturadas neste experimento são tomadas tendo o sol como fundo.

No capítulo 3, onde são abordados os materiais e métodos utilizados, há uma ênfase especial à presença de duas câmeras com uma distância não convencional entre elas. Por conta desta característica peculiar, achou-se conveniente aplicar uma técnica alternativa para calibragem de seus parâmetros .

O diagrama do experimento é exposto na figura 3.

O capítulo 4 mostra os resultados, comparando o desempenho de nossas rotinas com o método proposto por Snyder et al. (2004). Esta comparação é apresentada tanto através de uma tabela de desempenho numérico. Também são apresentadas imagens indicando onde estariam os resultados falso-positivos de obstáculos detectados pelo método de campos potenciais.

As conclusões de que o método proposto é superior, descrevendo as limitações do estado de arte geral para imagens coletadas neste perfil são detalhadas no capítulo 5 .

Este método utiliza como variável necessária para o processamento, a distância da margem do lago de fundo para cada imagem coletada. Por se tratar de um procedimento experimental, esta distância foi tomada por medidas realizadas a partir de imagens de satélite. Pretende-se que em eventual uso da técnica no futuro, a distância da margem de fundo do lago à câmera seja obtida automaticamente. Para isso, no capítulo 6 , é feita uma proposta que ainda não foi implementada, mas que pode ser tomada como guia. Neste projeto, esta distância poderá ser recuperada a partir de coordenadas de um GPS e da direção da imagem fornecida com uma bússola, utilizando para cálculo um conjunto de pontos coletados ao longo do contorno do lago. 


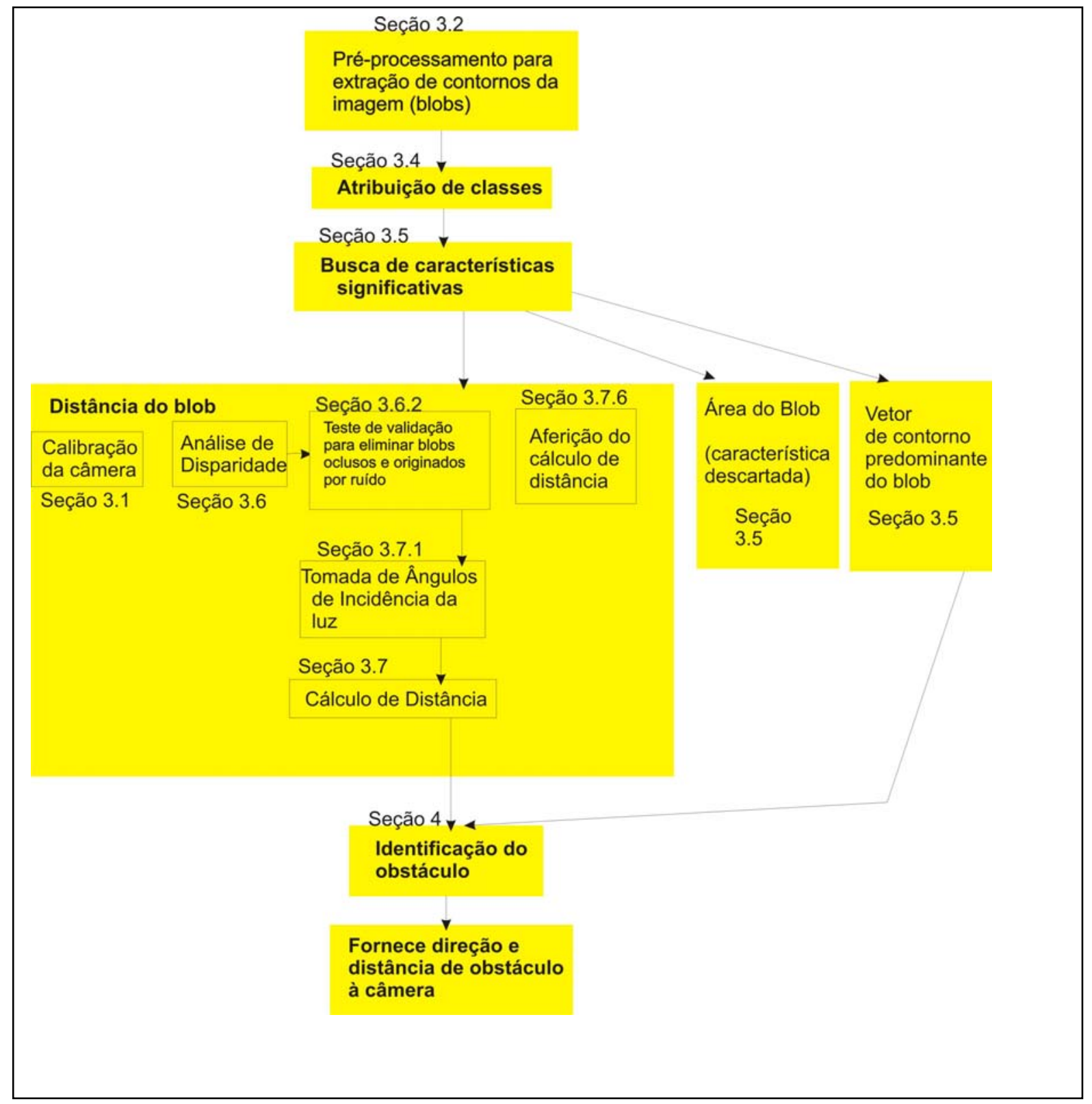

Figura 3. - Diagrama do Experimento principal 


\section{Capítulo 2}

\section{Deteç̧ão de obstáculos em ambiente aquático por visão computacional}

Entre as propostas iniciais de reconhecimento de obstáculos utilizando visão estéreo, foi projetado um sistema de navegação autônoma para um automóvel em meados da década de 70 e este trabalho só foi publicado décadas depois por Tsugawa (1994). Neste sistema, as imagens são coletadas por um par de câmeras e segmentadas por filtro derivativo, a fim de procurar as bordas laterais de uma pista para navegação de um veículo à $10 \mathrm{~km} / \mathrm{h}$.

As aplicações desta área, já se estendem à uma diversidade de veículos autônomos. A detecção de obstáculo por visão estéreo foi utilizada desde em veículos extra-terrestres à cadeira de rodas. Dur (2009) desenvolveu sistemas para detecção de obstáculos em um veículo da NASA para exploração de Marte, enquanto Oda e Shimizu (2006) construiu um sistema para cadeira de rodas, ambos os projetos utilizando-se da visão estéreo.

Os métodos de detecção de obstáculos por análise espacial não necessita necessariamente de 2 câmeras. Alguns trabalhos utilizam-se de uma única câmera capturando 2 imagens após um movimento de translação entre cada imagem. É o caso de de Wekel, Kroll-Peters, e Albayrak (2008) e Molton e Brady (2000). Bhanu et al. (1994) desenvolveram um trabalho que se utilizava de duas câmeras, porém combinava os dados estéreo destas duas câmeras, com duas imagens seqüenciais providas por uma das suas câmeras para melhorar a percepção espacial. A detecção destes obstáculos também pode ser feita por 3 câmeras, como por exemplo Li e Brady (2006) que utilizou-se de um FPGA para processar as três imagens na detecção de obstáculos. Ainda pode ser realizada por diversas câmeras onidirecionais, como fez Koyasu, Miura e Shirai. (2001 , 2003) .

Em muitos casos, aliados à visão computacional estéreo, são combinados outros sensores que integrados melhoram a percepção de obstáculo, quando comparados à cada sensor individualmente ou à visão computacional em si. Wallner e Dillmann (1995) integrou 
um sistema de visão computacional à um sistema de sonar para refinar o mapeamento. Esta integração também está presente em Nara e Takahashi (2006) e Moghadam, Wijesoma e Feng (2008) que integraram visão computacional estéreo com sensor de varredura à laser. A Identificação por rádio freqüência (RFID) também foi integrada à visão computacional estéreo para identificar obstáculos por Songmin et al. (2007), onde a região de interesse para processamento de imagem é definida por uma seleção feita por RFID.

Stiller et al. (2000) e Polycronopoulos et al. (2004) integraram ainda mais sensores. Ambos adicionaram à visão estéreo, a varredura à laser e sensores de sonar para mapear obstáculos .

Diversos métodos já foram desenvolvidos para que os obstáculos sejam detectados nas imagens em estéreo. Ho (2010) detecta pontos característicos de Harris em ambas imagens, a fim de ter uma triangulação entre cada par de pontos que permitam calcular a distância. No artigo de Svasta e Hapenciuc (2009), as formas encontradas nas imagens são tratadas por correlação cruzada e é feito um casamento de características. Hubber e Kortenkamp (1998) faz uso de frames anteriores das imagens para prever a região de maior probabilidade de encontrar características correspondentes em um par de imagens. Na proposta de Patnaik, Konar, e Mandal (2002) as coordenadas 3D são reconstruídas em um plano de obstáculo utilizando o filtro de Kalman

Muitos autores dão importância em localizar o plano do chão no método. Assim fez Li e Jia (1998) que buscavam seus obstáculos a partir da localização de um plano de chão em imagens estéreo. Encontramos 3 algorítmos para cada uma das 3 situações no artigo de Zhang, Weiss e Hanson (1997) : 1) Plano de chão conhecido, 2) Plano de chão desconhecido, 3) estimativa do plano de chão. Yoon, Roh e Shim (2008) desenvolveram um método de invariantes projetiva, onde se define um polígono interligando 4 pontos onde ocorre a maior probabilidade de se encontrar obstáculos, a partir de um par de imagens.

O método mais utilizado para se detectar obstáculos a partir de visão computacional estéreo é a teoria de campos potenciais. Neste método é estimado o fluxo ótico entre um par de imagens. Temos então como resultado uma matriz de vetores de deslocamento de regiões de pixels de uma imagem em relação à outra. A rota de fuga seria aquela que possui os 
menores vetores de deslocamento. Exemplos de utilização de campos potenciais são Vicent e Tjahjadi (2005), Ohnishi e Imiya (2007), Guldner e Utkin (2005) e Ge e Cui (2000)

Hrabar e Sukhatme (2009) utilizaram a teoria de campos potenciais para um veículo terrestre e um veículo aéreo . Estes veículos trocavam dados dos dois pares de imagens coletados a fim de se integrarem e ter um mapa mais preciso das rotas de fuga comum para ambos.

Outro método quase tão utilizado quanto a teoria dos campos potenciais é a análise de disparidade entre as imagens. Nesta proposta, em uma varredura podemos encontrar uma seqüência de pixels de uma imagem em uma outra imagem pareada. Porém, ao invés de vetor, temos o deslocamento exato em número de pixels deslocados de um campo em relação à outro. Mingxiang e Yunde (2006) apresentam em seu artigo um exemplo típico desta técnica. Através de visão bi-ocular, Saurav (2009) utilizou-se deste método para montar uma representação estocástica do mapa de navegação, para ambientes internos (laboratório com luz artificial) e externos (ambiente externo sob luz solar). Li e Brady (2006) já citado por ter se utilizado de 3 câmeras, também se utilizou de análise de disparidade. Uma aplicação de utilização de disparidade para imagens com veículos aéreos, foi proposta por Hannal, Straznicky e Goubran (2008) onde a disparidade foi analisada sobre contornos segmentados. Quek, Ibañez-Guzmán e Lim (2005) utilizaram-se de análise de disparidade para um veículo que seguia outro por visão, a partir de um par de imagens segmentadas por lógica Fuzzy aplicado à coloração.

Laureano (2008), realizou um bom levantamento sobre o estado da arte e métodos de análise de disparidade.

Em ambiente aquático, os trabalhos sobre detecção de obstáculos são muitos, porém aqueles que se utilizam de visão computacional para este fim são raros. Principalmente aqueles com tomada de imagens sobre a superfície da água em vista sob perspectiva conforme a disponível em um barco.

A grande maioria dos veículos de navegação autônoma em ambiente aquático presentes em literatura são submersos, conhecidos como AUV (Autonomous Underwater Vehicle). 
O trabalho mais antigo de detecção de obstáculos em AUV encontrado, foi o de Khanmohammadi et al. (1988). Os obstáculos são fixos, em posições previstas e é proposto um sistema de 6 equações lineares e não lineares dimensionais para movimentação e controle de motores para desvio dos obstáculos sub-aquáticos.

Em 2001 Antonelli e Chiaverini. utilizaram visão computacional para detecção de obstáculos fortuitos submersos. Este sistema de percepção se baseia em redes neurais com desempenho em tempo real.

Kanakakis, Valavanis e Tsourveloudis (2004) desenvolveram em um submarino, um sistema de percepção de obstáculos com base em um sonar baseado em algoritmo de lógica Fuzzy. O sistema de percepção submarina de Nolan, Toal e Ewald (2005) já era mais sensível, pois este construiu um sonar com emissor de formato curvo para aumentar o ângulo de procura.

O sistema de percepção de lógica Fuzzy sobre o sonar submarino foi aperfeiçoado por Bui e Kim (2006), onde foi implementado em produtos B-K ( Bandler and Kohout's Triangle Subproduct) de relação Fuzzy.

O uso de sonar para detecção de obstáculos submersos chegou a ser simulado por Bouxsein et al. (2006). Outras variantes de detecção acústica de obstáculos por veículos submersos é a de $\mathrm{Wu}$ et al. (2006) que incluiu junto ao veículo, uma linha-guia para navegação. Um sonar de custo muito baixo, foi o objetivo de Xu et al. (2006). Pebody (2008) utilizou de sonar para submarino de exploração no Ártico para navegação e detecção de obstáculos em ambiente abaixo de uma camada de gelo.

Outra tecnologia para detecção de obstáculos em ambientes aquáticos, é a percepção destes por sensores táteis. Dobbins e Samways (2003) desenvolveram este sistema em um barco que navega por um canal, onde correntezas e ventos podem desvia-los de seu curso. A indicação da necessidade de correção de rota ocorre assim que algum sensor toca uma borda do canal. 
Toal e Flanagan (2005) desenvolveram um sensor próprio utilizando fibras óticas. O obstáculo submerso, quando muito próximo do submarino (distância tátil), desvia os raios luminosos, acusando sua presença.

Sensores de infravermelho (IR) foram utilizados por Ye et al. (2007) para submarinos. O sensor segue uma fonte de luz IR que é o alvo de direção do veículo. Assim que a fonte de luz é interrompido pelo obstáculo, ele busca a direção da fonte mais próxima, efetuando o desvio.

Para barcos, os obstáculos também foram detectados por ultra-som Zeng, Ito e Shimizu (2000) e por sensor à laser por Ruiz e Granja (2009)

A visão computacional acompanhou pouco os veículos submersos. Barisic, Vukic e Miskovic (2007) utilizaram a teoria de campos potenciais, que é muito usada para robôs terrestres, no planejamento de rota do veículo autônomo sub-aquático. Também utilizou desta metodologia Gao et al. (2008) para AUV.

Pouca literatura foi encontrada sobre detecção de obstáculos em embarcações de superfície utilizando visão computacional. Na superfície da água temos como problema as variações de brilho e luminosidade do sol.

$\mathrm{Na}$ grande parte dos casos, os experimentos com detecção de obstáculos com robôs terrestres são realizadas em ambientes fechados, com iluminação artificial e obstáculos prédefinidos em um universo finito de situações. As queixas sobre ambiente externo sobre iluminação solar estão relacionadas com variações bruscas da iluminação e também com a hiper-segmentação da imagem (NABBE, B. Et al., 2006) .

Um único trabalho localizado, o de Snyder et al. (2004), identifica os obstáculos de um barco de navegação autônoma por visão através da teoria de campos potenciais, para navegação em um rio. Imagens mostradas pelo autor sugerem a presença de águas calmas e espelhadas, quase sem ondas. Ocasionalmente observa-se ondas que poderiam influenciar como falso-positivo na teoria dos campos potenciais, mas que não foram tomadas como fonte do experimento. Estas ondas se tornariam um problema ainda mais significativo se as 
imagens fossem capturadas contra o sol, onde seu brilho se tornariam contrastante a ponto de se confundir com um obstáculo.

Diferente de submarinos, o barco navega sobre a superfície do lago, necessitando então de imagens de perspectiva deste ambiente. Propomos para melhor determinação de distância e angulação do obstáculo, a análise de disparidade de imagens.

Toda vez em que se trabalha com câmeras para captura de imagem bi-ocular, é necessário calibrá-las para eliminar erros de rotação durante a inserção destas sobre o substrato, conforme será descrito no capítulo seguinte. Bouguet,. (2008), desenvolveu rotinas de calibragem de fácil uso. 


\section{Capítulo 3}

\section{Materiais e Métodos}

Com o objetivo de capturar imagens e processá-las à margem de um lago, as rotinas desenvolvidas em Matlab, foram executadas em um microcomputador portátil, marca Toshiba com processador AMD64 Turion com 2.0 Ghz. As imagens foram obtidas através de um par de câmeras webcam modelo 11123 fabricadas pela Clone.

Apesar de não termos utilizado em nosso experimento, recomendamos o uso de uma bússola eletrônica e um GPS para detectar a distância da margem do lago ao barco. Neste trabalho, como as imagens foram coletadas de um ponto fixo, a distância da margem foi determinada por imagens de satélite.

As câmeras foram apoiadas em um suporte feito com chapa de aço 16 por ser resistente e suficientemente leve. As dimensões desta chapa são de $1500 \mathrm{~mm}$ x $55 \mathrm{~mm}$, e foi dobrada em 90 graus longitudinalmente para eliminar qualquer possibilidade de flexão.

Sobre este suporte foram coladas as duas web-cams. Como desejamos detectar obstáculos à grande distâncias, desejamos que a distância entre elas seja a maior possível. A distância entre as web-cams é de 1,4m, por ser a largura do barco.

As web-cams tem por características o ajuste automático do brilho e contraste, assim que ligadas. Por esta razão, quando o Matlab faz a captura de uma imagem, estas são ligadas, e a imagem é imediatamente transferida ao computador antes mesmo que este ajuste seja efetuado. Como consequência disso, as primeiras imagens tomadas em ambiente aberto, tem brilho altíssimo por influência da luminosidade solar. Experimentalmente, observou-se que as imagens chegam a ser totalmente brancas, o que não ocorre quando a captura é realizada em ambiente protegido, como no interior de uma casa ou escritório. Não foi encontrada webcam onde o ajuste de brilho e contraste não seja automático.

Para capturar imagens com brilho adequado, foram adicionados ao suporte dois adaptadores para que se coloque à frente da câmera filtros óticos atenuadores, construídos 
com vidros cobertos com insulfilm. Estes adaptadores permitem que se troquem os filtros da frente da câmera, dependendo da luminosidade. Foram preparados 4 pares de placas de vidros, o primeiro par com uma camada de insulfilm para autos com 5\% de transmitância, o segundo par de placas possui 2 camadas deste mesmo insulfilm, o terceiro possui três camadas e o quarto quatro camadas.

Este suporte foi fixado em um tripé para máquina fotográfica VPT-20 fabricado pela Tron. Assim, o suporte com as duas câmeras podem ser rotacionadas em sincronia para que possa ser coletadas imagens em estéreo de diversas direções.

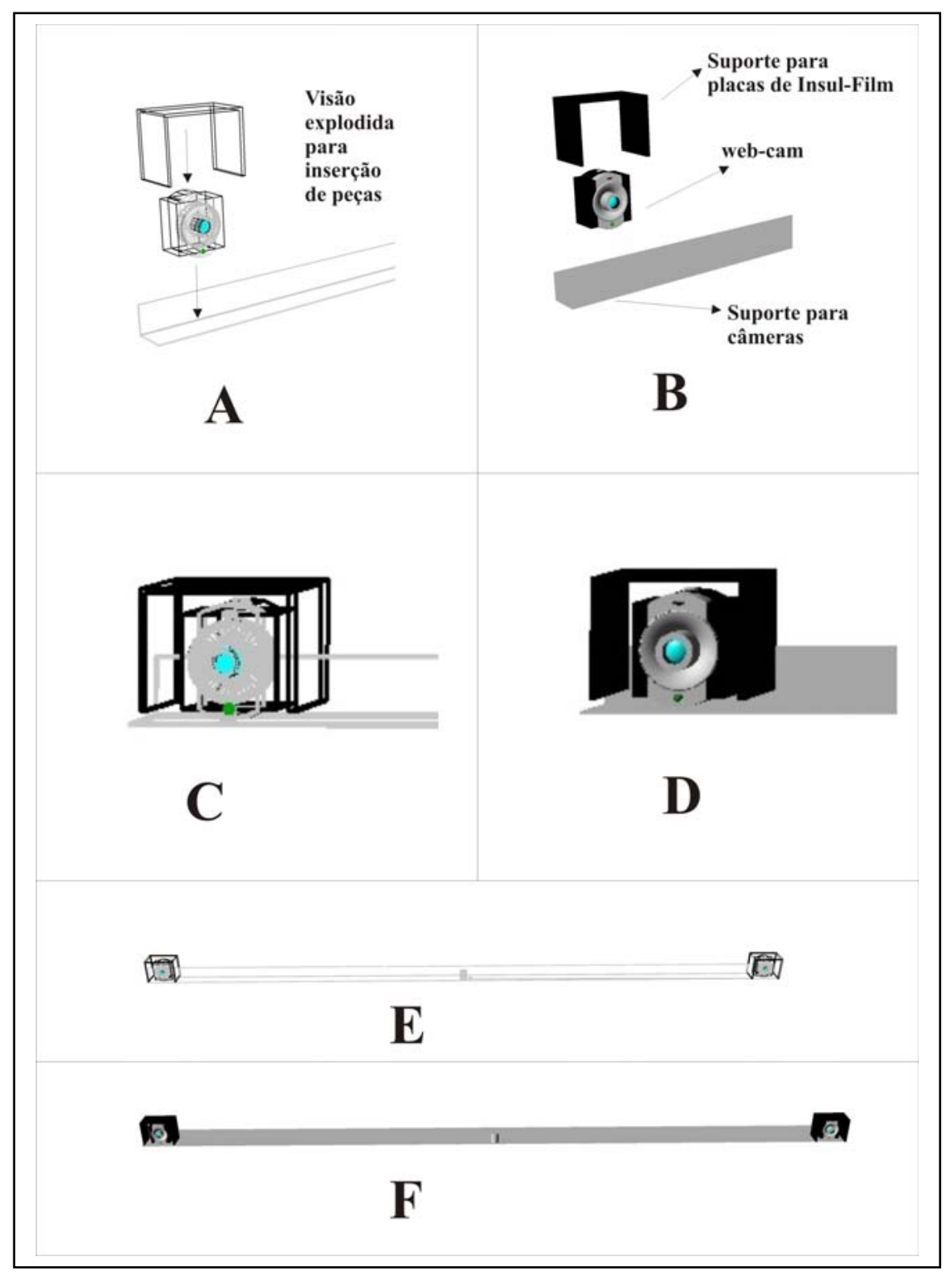

Figura 4. (A) Diagrama de inserção de peças em wireframe. (B) Diagrama com nome das peças em imagem renderizada. (C) Peças montadas em imagem wireframe. (D) Peças montadas em imagem renderizada. (E) Suporte das câmeras com as duas câmeras montadas em imagem wireframe (F) Conjunto total com as duas câmeras montadas em imagem renderizada. 
Este aparato físico montado, ilustrado nas figuras 4 e na 5, foi conectado ao microcomputador de forma a capturar e processar as imagens utilizando o aplicativo Matlab 2008, com as ferramentas Image Acquisition toolbox e Image Processing toolbox.

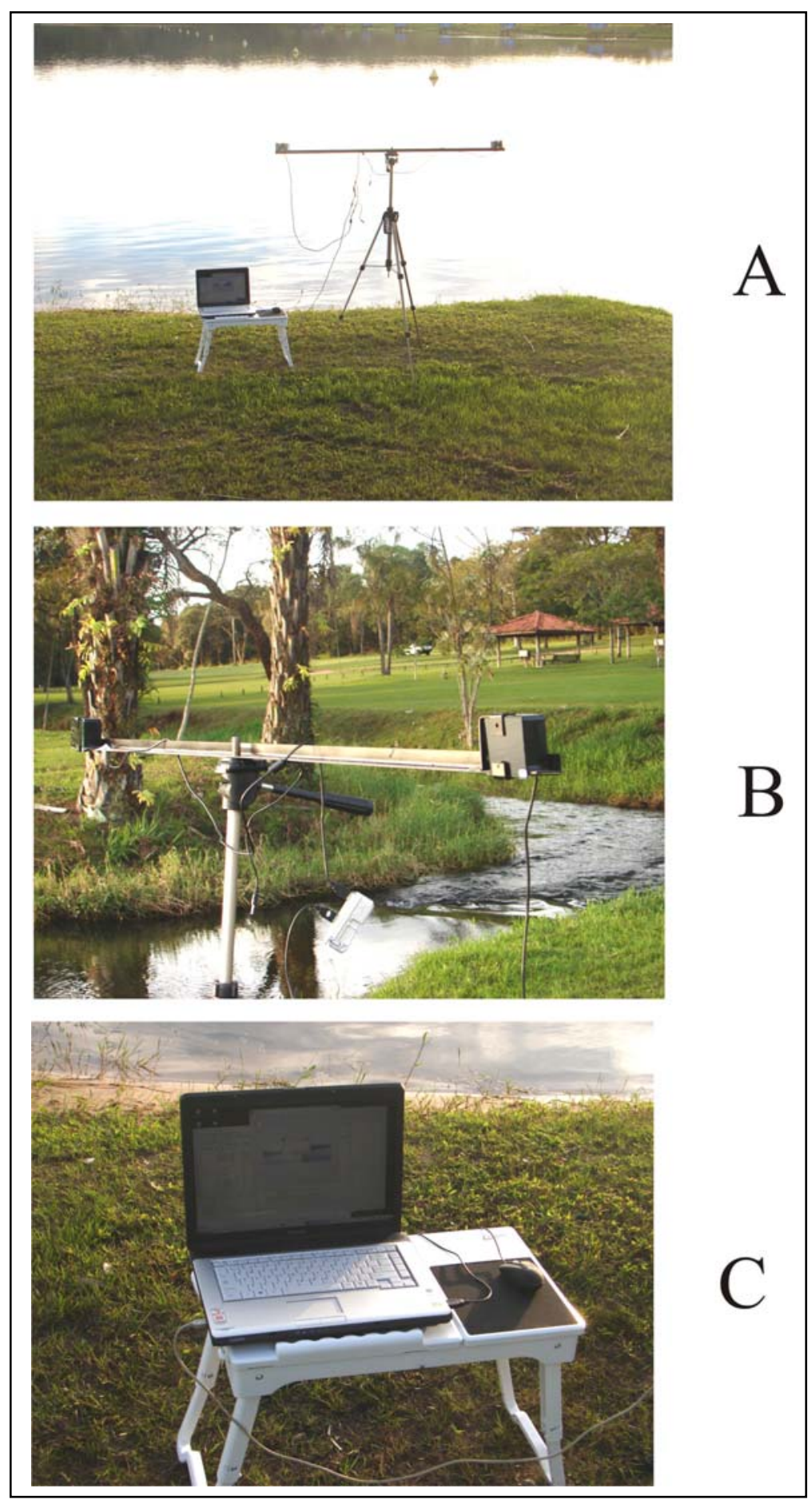

Figura 5. Imagens do acessório montado. (A) Equipamento total, com suporte das câmeras apoiado sobre tripé para máquinas fotográficas. (B) Imagem ampliada do suporte das câmeras com o suporte de placas, contendo um par de placas com 4 camadas de insulfilm. (C) Laptop com uma pequena mesa de apoio para operação em campo. 


\section{1 - Procedimentos de calibração das câmeras}

\subsection{1. - Detecção de erros}

Quando fixamos as câmeras sobre o suporte, podem ocorrer desalinhamentos entre estas, causados por rotação de uma câmera em relação à outra em os diversos eixos possíveis de seu espaço. Estes casos estão ilustrados na figura 6, onde temos em A um diagrama das câmeras alinhadas. Em $\mathrm{B}$ temos a rotação de uma câmera em relação à outra relativo do eixo X. Em C é exibido um desalinhamento entre câmeras proporcionado por uma rotação no eixo Y, e em D temos uma rotação de uma das câmeras ao longo do eixo Z.

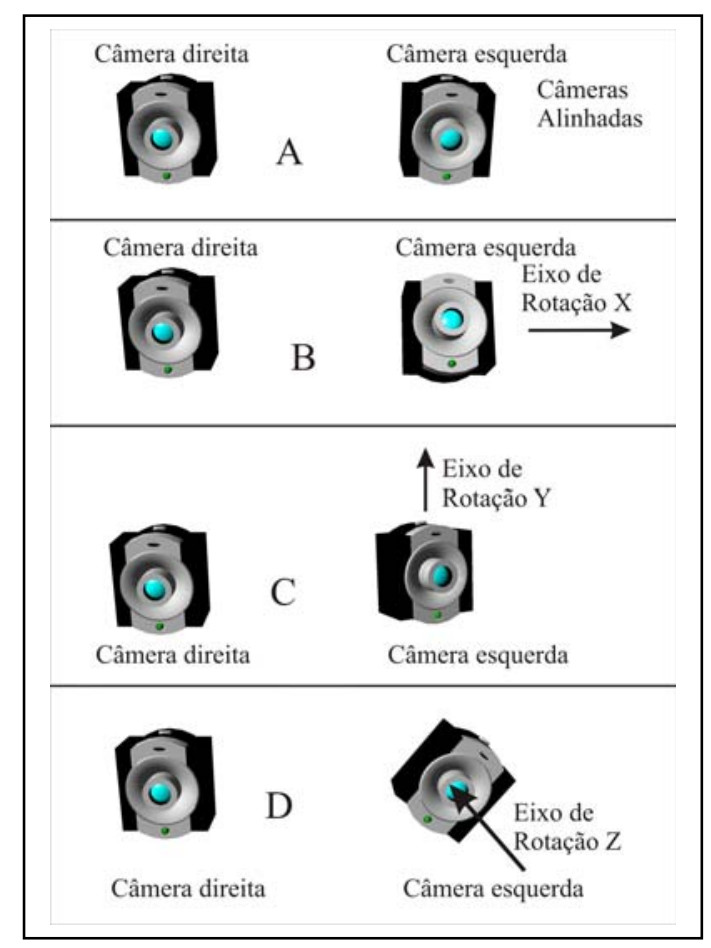

Figura 6. - Rotações possíveis da câmera por erro de inserção.

Os erros gerados pela rotação do eixo $\mathrm{X}$ acarretam em um deslocamento vertical da imagem de uma câmera em relação à outra, enquanto os erros gerados pela rotação no eixo Y acarretam em um deslocamento horizontal da imagem de uma câmera em relação à outra. Os erros gerados pela rotação do eixo $\mathrm{Z}$ acarretam em uma rotação real da imagem de uma câmera em relação à outra.

As rotinas de calibração como as propostas por Bouguet (2009), necessitam de um gabarito que é melhor adaptado à um par de câmeras com pequena distância entre si. Quando a distância entre câmeras é grande, como no nosso caso, situar o gabarito em um campo comum entre as câmeras é um problema significativo. O gabarito ficaria tão longe 
das câmeras, ao atingir o campo comum entre elas, que teria o tamanho de sua imagem reduzida. Também estaria reduzida a resolução da imagem deste gabarito.

Baseado nesta constatação, foi desenvolvida uma rotina simples para detectar o deslocamento de uma imagem em relação à outra, por consequência de rotação dos eixos $\mathrm{x}$ e y entre as câmeras, e também detectar a rotação entre as imagens por consequência da rotação do eixo $\mathrm{z}$ entre as câmeras

Como referência, as câmeras já fixadas em seu suporte comum, foram direcionadas à Lua por ser a imagem mais distante possível. Desta forma o deslocamento de pixels de uma imagem em relação à outra não deve acontecer pela distância entre as câmeras, mas unicamente pela rotação das mesmas.

Obtendo então duas imagens da lua, a rotina cria uma imagem fruto da alternância de pixels entre as imagens da câmera direita (figura 7 B) e da câmera esquerda (figura 7 A). Resulta-se assim uma imagem com as bordas da lua desalinhadas (figura $7 \mathrm{C}$ ).

Através de comandos do teclado podemos deslocar uma das imagens à esquerda, ou direita, ou acima, ou abaixo. Este deslocamento pode ser no passo de 1 pixel ou de 10 pixels. Quando as imagens já estiverem alinhadas ( por comando manual (figura 7D), encerramos o programa, que fornece o deslocamento horizontal (hp) e vertical (vp) atingido depois do alinhamento.

O programa também permite rotacionar uma das imagens para detectar rotação do eixo z sobre a câmera. Porém este comando não foi utilizado, por se verificar que este tipo de rotação não foi significativa durante a inserção das câmeras sobre seu suporte. A rotina desenvolvida encontra-se no Apêndice A.

O programa principal extrai bordas das imagens com o propósito de alinhá-las, para posterior processamento. 


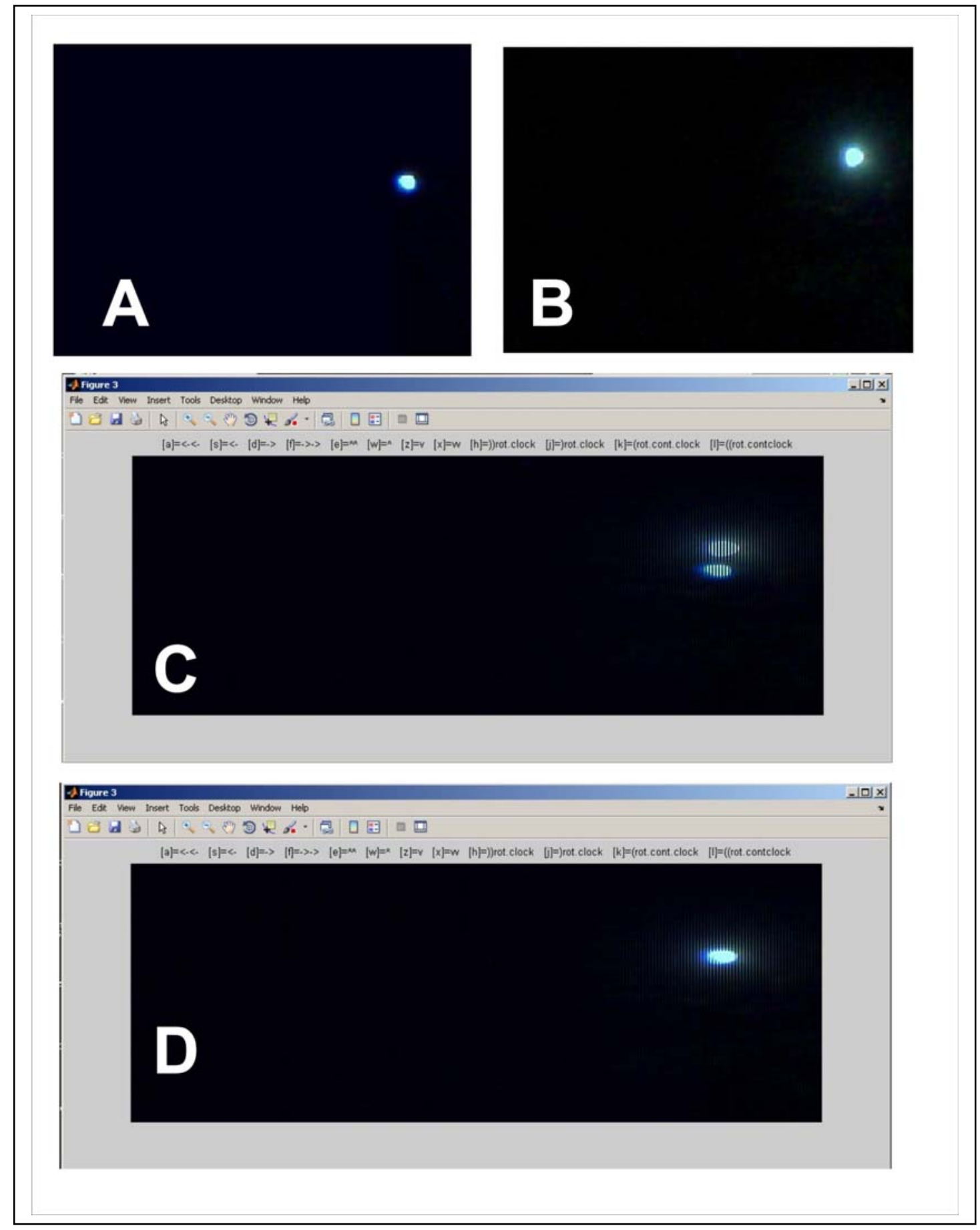

Figura 7. Imagens obtidas com o programa de calibração de posição da câmera. 


\subsection{2 - Correção de erros}

Sobre os deslocamentos horizontais e verticais detectados na inserção das câmeras, temos as seguintes situações, conforme ilustrado na figura 8 .

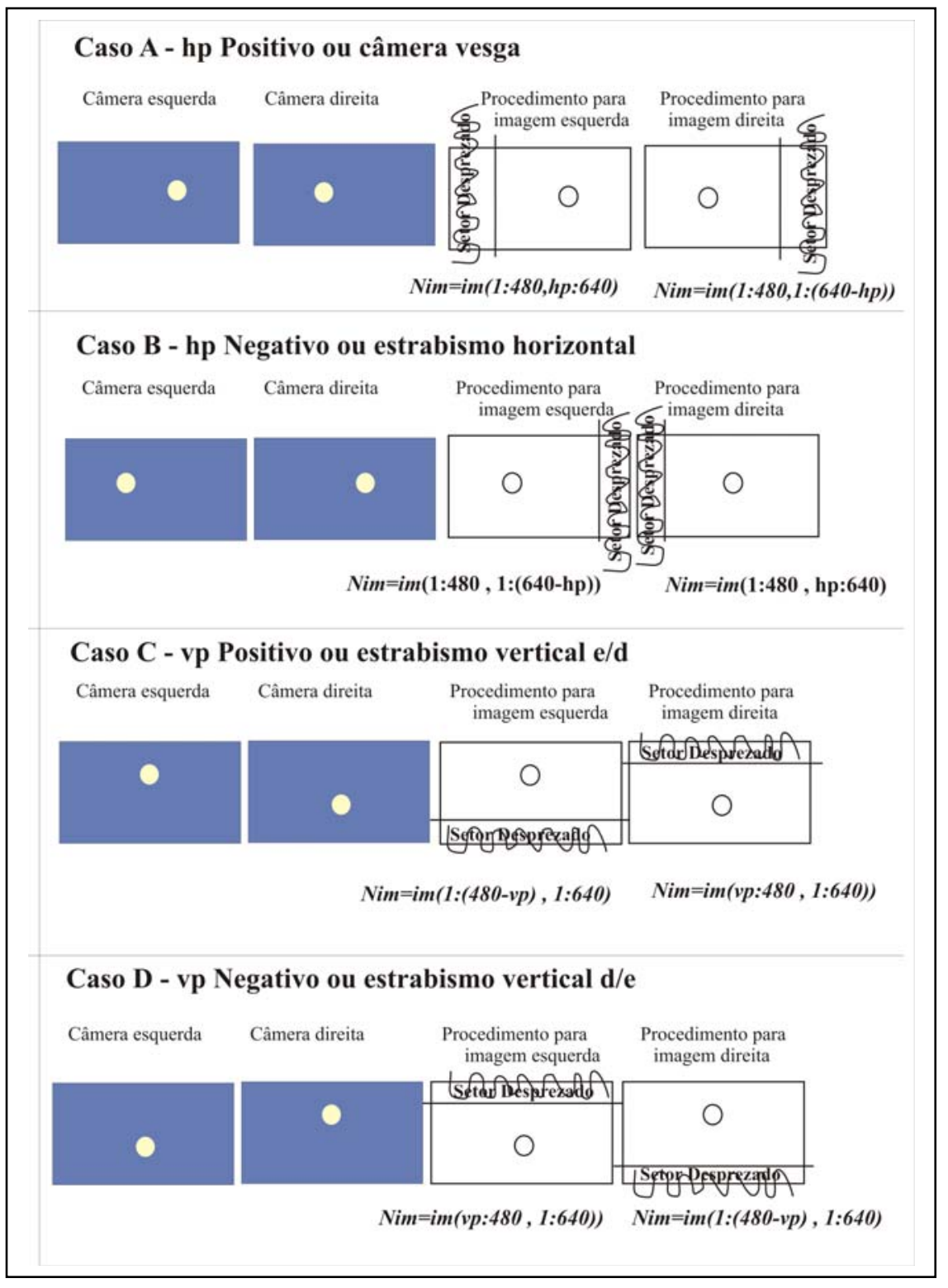

Figura 8. Tratamento de imagens para correção do erro de inserção. Nim= imagem corrigida. im=imagem com erro. 
No caso A, com o deslocamento horizontal (hp) positivo, há um corte na borda esquerda da imagem esquerda, e um corte na borda direita da imagem direita. A nova imagem esquerda será $\quad \boldsymbol{N i m}=\boldsymbol{i m}(1: 480, \mathbf{h p}: 640)$, onde $\boldsymbol{N i m}$ é a nova imagem, e im é a imagem com erro de deslocamento. A nova imagem direita será :

$$
\operatorname{Nim}=\operatorname{im}(1: 480,1:(640-\mathbf{h p}))
$$

No caso B, com o deslocamento horizontal (hp) negativo, há um corte na borda direita da imagem esquerda, e um corte na borda esquerda da imagem direita. A nova imagem esquerda será $\operatorname{Nim}=\boldsymbol{i m}(1: 480,1:(640-\mathbf{h p}))$ e a nova imagem direita será

$$
\operatorname{Nim}=\operatorname{im}(1: 480, \mathbf{h p}: 640)
$$

No caso C, com o deslocamento vertical (vp) positivo, há um corte na borda inferior da imagem esquerda, e um corte na borda superior da imagem direita. A nova imagem esquerda será $\mathbf{N i m}=\boldsymbol{i m}(1:(480-\mathbf{v p}), 1: 640)$ e a nova imagem direita será

$$
\operatorname{Nim}=\operatorname{im}(\mathbf{v p}: 480,1: 640))
$$

No caso D, com o deslocamento vertical (vp) negativo, há um corte na borda superior da imagem esquerda, e um corte na borda inferior da imagem direita. A nova imagem esquerda será $\mathbf{N i m}=\boldsymbol{i m}(\mathbf{v p : 4 8 0 , 1 : 6 4 0 ) )}$ e a nova imagem direita será

$$
\operatorname{Nim}=\operatorname{im}(1:(480-\mathbf{v p}), 1: 640)
$$




\section{2 - Pré-processamento das imagens}

As imagens que tiveram suas bordas recortadas com o objetivo de corrigir erros de alinhamento, serão agora processadas para que extração de polígonos. Estes polígonos conhecidos como blobs, serão nossa principal ferramenta de análise da imagem.

Cada imagem esquerda foi transformada em monocromática com 4 níveis de cinza, para facilitar a segmentação.

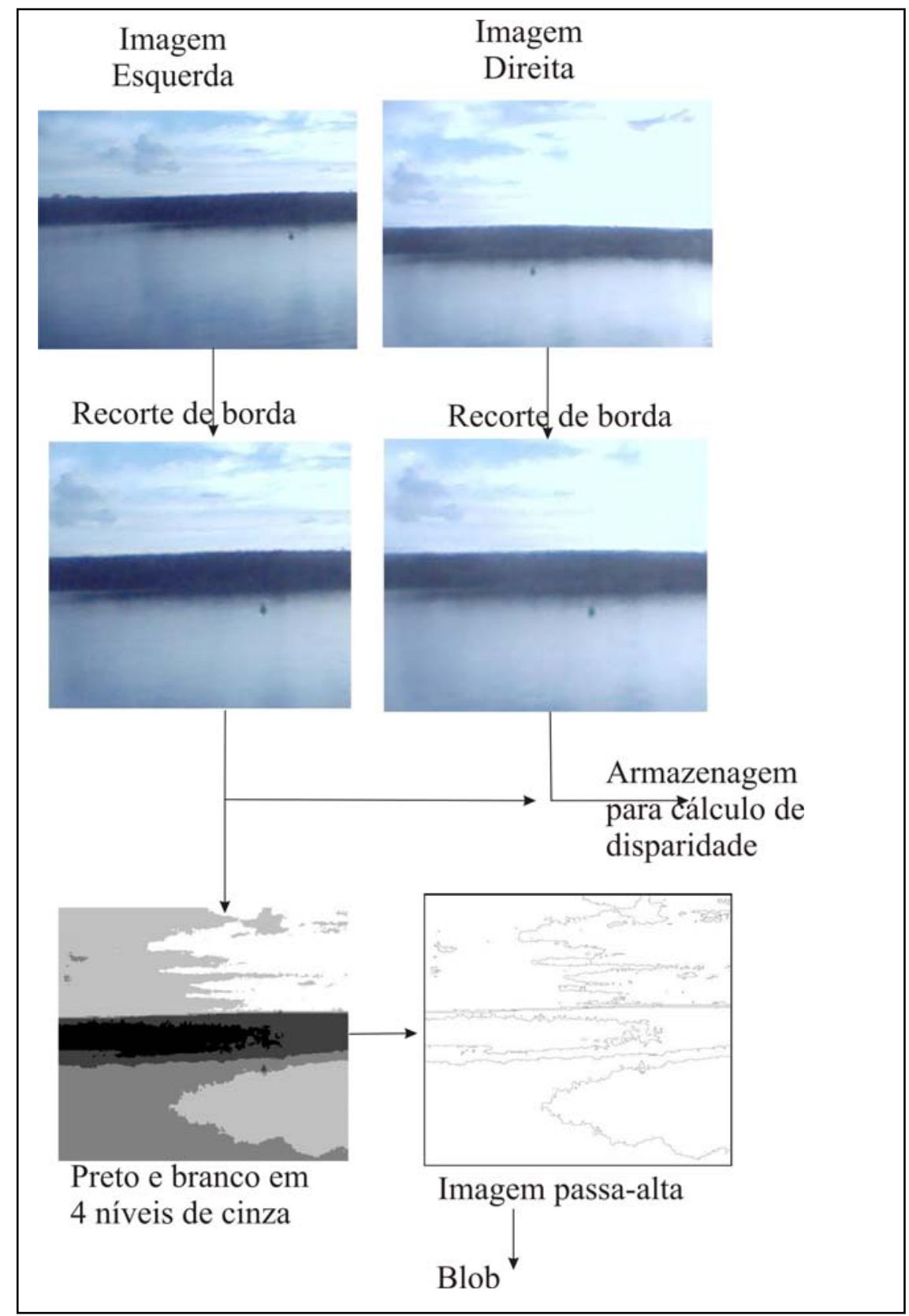

Figura 9. Diagrama do pré-processamento das imagens 
Em seguida, cada imagem esquerda foi submetida a um filtro passa-alta Laplaciano. Os blobs são então obtidos rastreando as coordenadas x e y ao longo de cada polígono da imagem resultante. As imagens exemplo deste processamento estão ilustradas na figura 9.

Na figura 10, temos um exemplo de identificação dos Blobs. Ao longo da varredura da imagem são encontrados diversos polígonos pelo caminho. A cada polígono encontrado, percorre-se todos os pontos de seu contorno, registrando as coordenadas encontradas. Estes polígonos, ao qual se tem uma tabela com as coordenadas de todos os pontos de seu contorno são chamados de Blobs, e são o principal elemento deste trabalho.

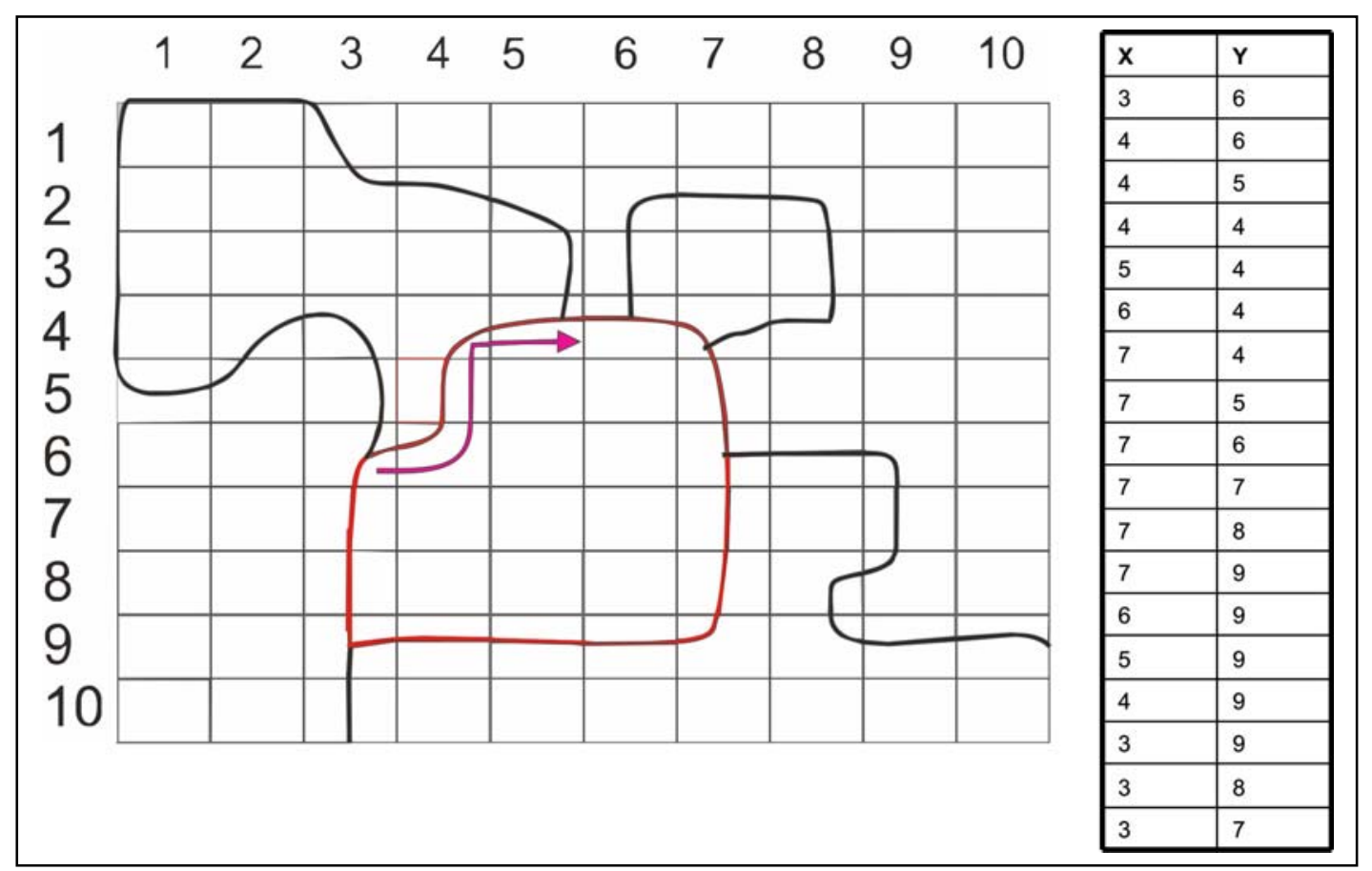

Figura 10. - Exemplo de levantamento dos Blobs de uma imagem passa-alta. 


\section{3 - Imagens capturadas para definição de classes em validade Interna}

Com o objetivos de pré-definir as classes envolvidas em cada blob, foram capturadas uma série de 11 pares de imagem estéreo das margens do Clube Náutico de Araraquara-SP. Estas imagens foram pré-processadas, segundo os procedimentos descritos na seção 3.2.

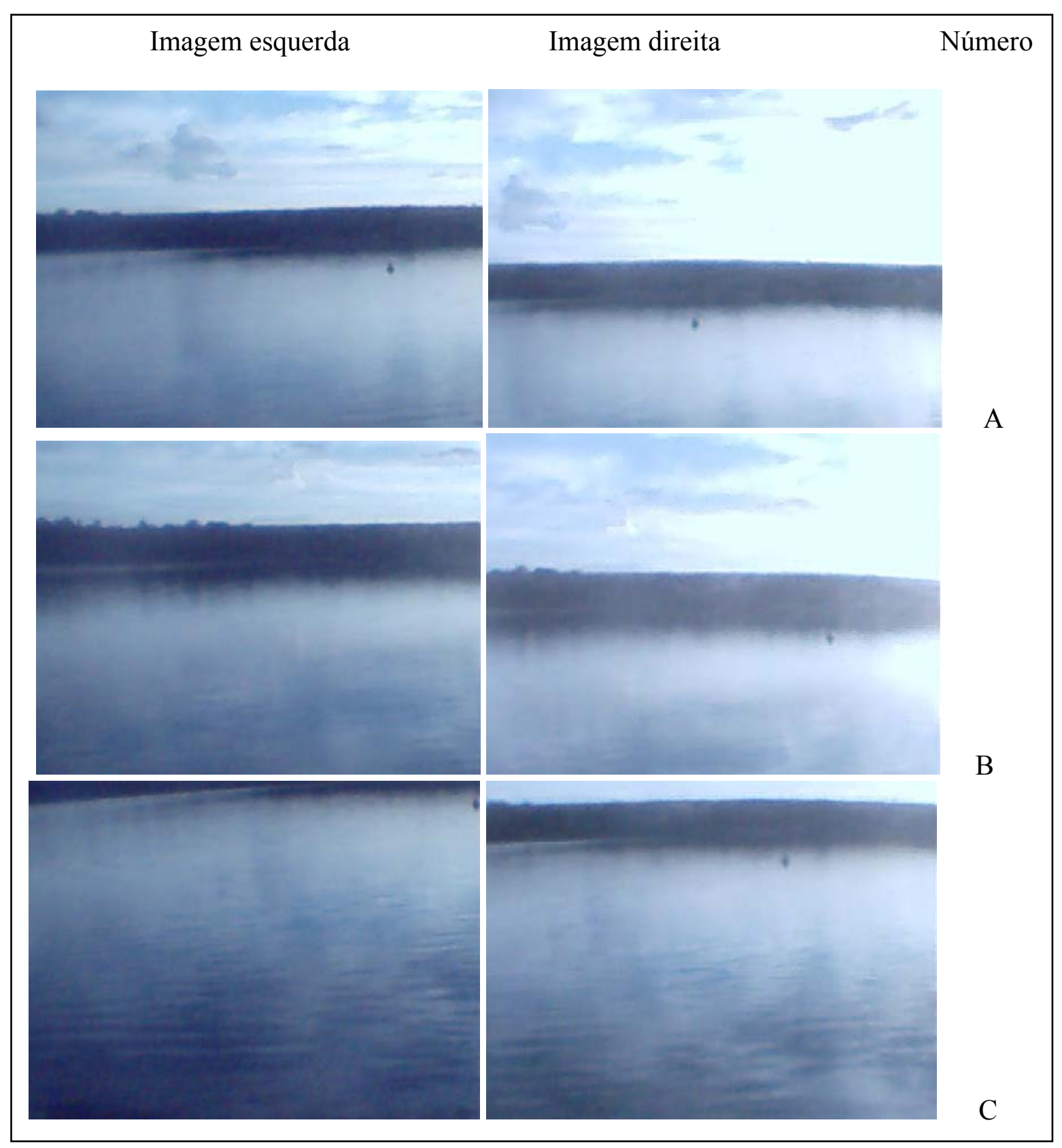

Figura 11. Imagens capturadas para definição de classes

Foram tomados como obstáculos as bóias de navegação indicadas como exemplo na figura 14 . 


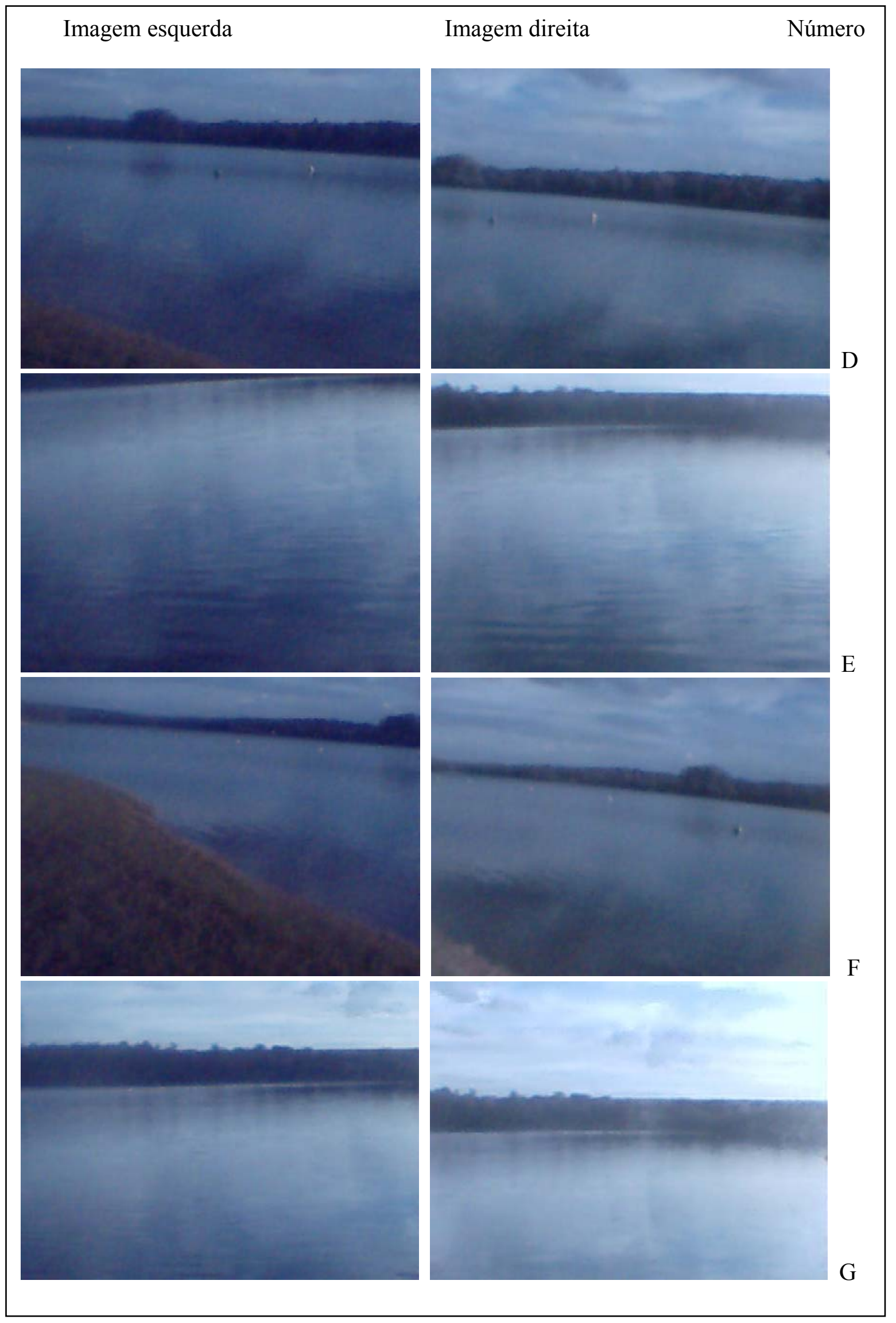

Figura 12. Imagens capturadas para definição de classes 


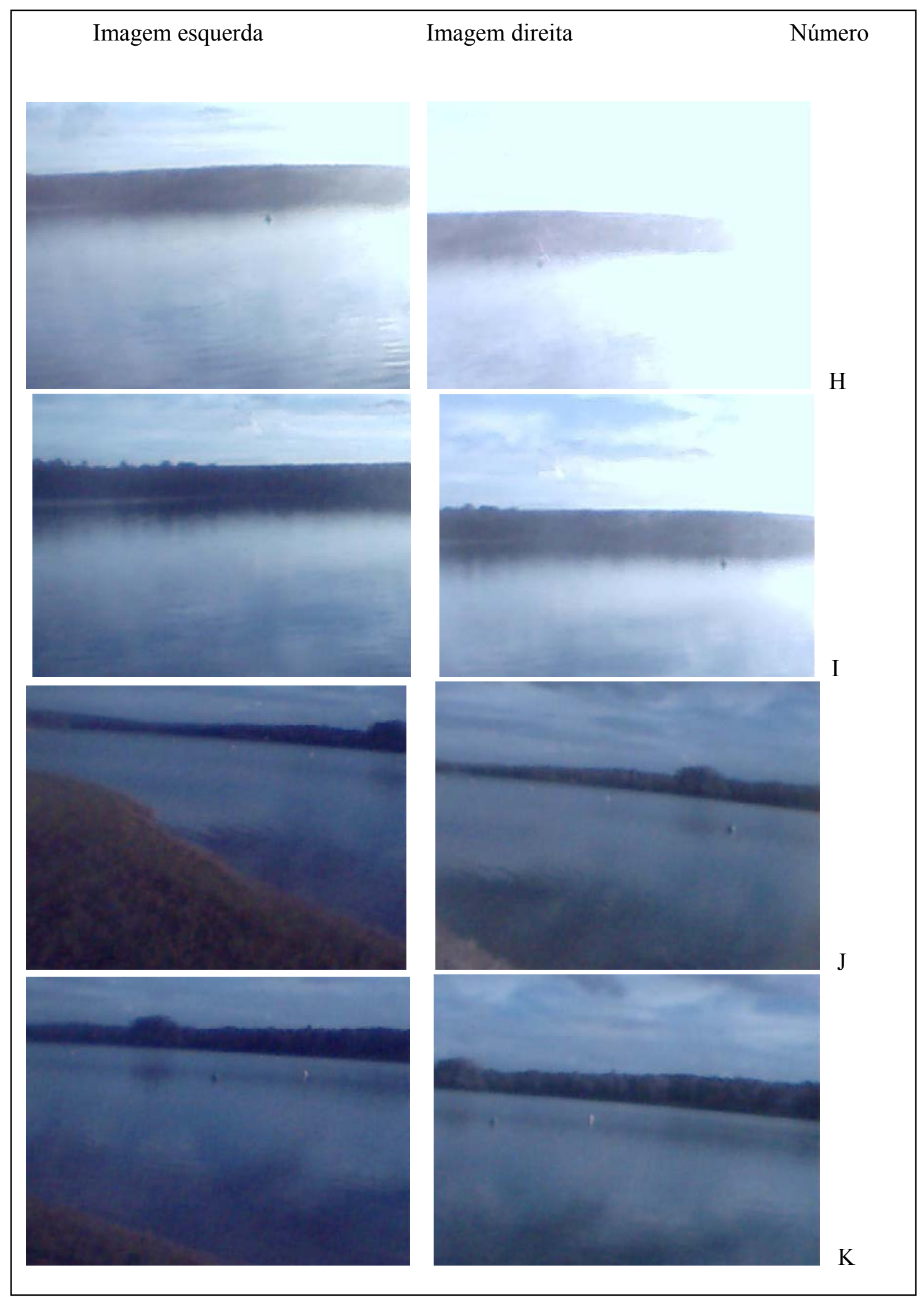

Figura 13. Imagens capturadas para definição de classes 


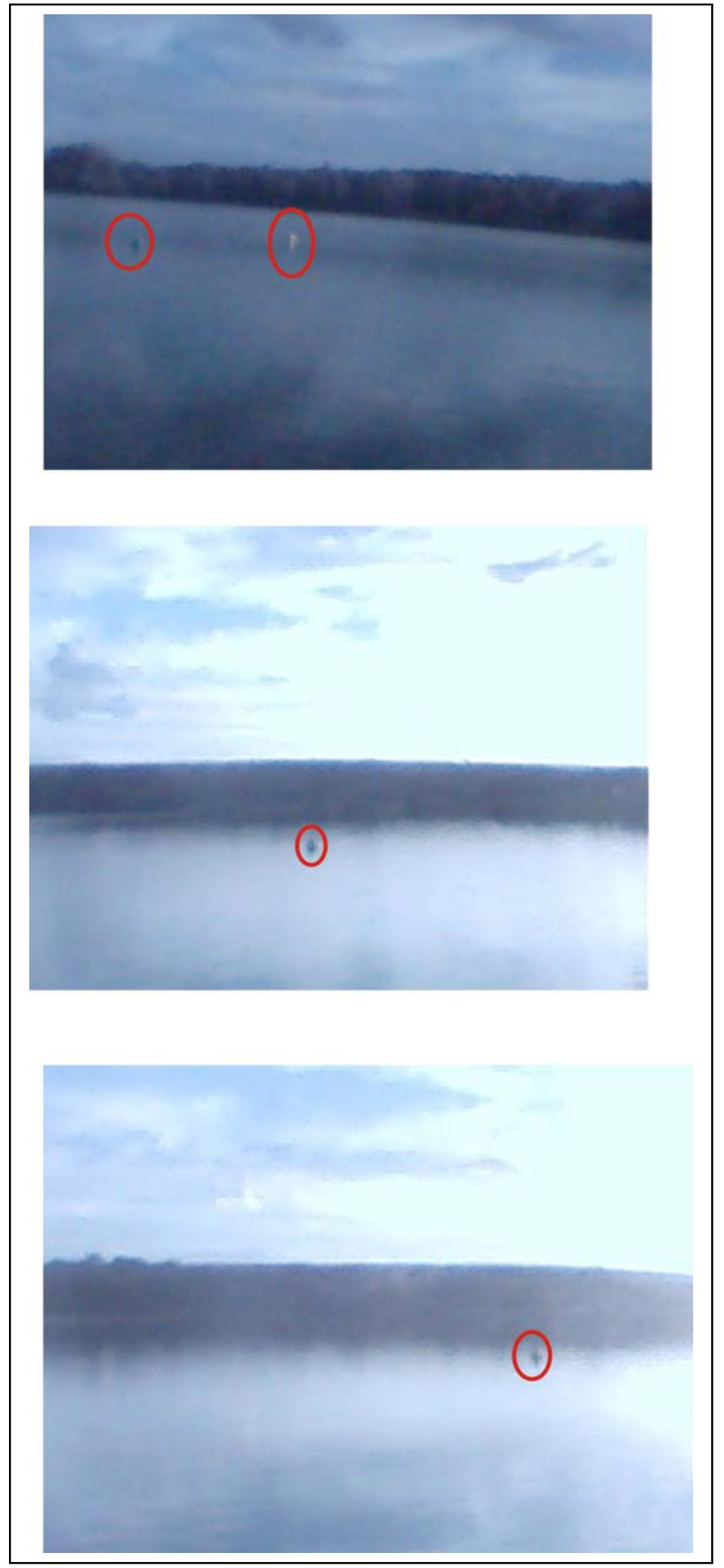

Figura 14. - Boias de navegação tomadas como obstáculos para extração de características. 


\section{4 - Atribuição de classes}

As imagens esquerdas da sequência de imagens das figuras 11-13 quando préprocessadas geraram 1674 blobs. Estes blobs foram classificados manualmente a fim de obter características que pudessem ser agrupadas. Observou-se nestes contornos as seguintes classes de dados :

A) Nuvens - Nesta classe notamos contornos com distância superior à distância da margem oposta do lago. Sua área e vetor de contorno predominante podem ser diversificados.

B) Margem - Nesta classe notamos contornos com distância compatível à distância esperada para margem oposta do lago. Não foram distinguidas variações de área e vetor de contorno predominante significativas

C) Reflexo de imagem da margem sobre o lago. Nesta classe notamos características como distância, área e vetor de contorno predominante similares à classe Margem. Pelo fato do presente trabalho se dedicar à detecção de obstáculos, não temos interesse em diferenciar esta classe da classe Margem.

D) Luminosidade da água proveniente do sol. - Nesta classe encontramos as maiores distâncias, sendo distância superior à distância da margem e das nuvens. A área ocupada por este blob é relativamente grande. Ocasionalmente, a luminosidade do sol pode refletir sobre ondas, gerando contorno de pequenas áreas, mas este caso é identificado como sendo a classe a seguir.

E) Onda - Classe com área sempre bem definida. Espera-se que esta área possa sofrer mudanças dependendo da altura das ondas nas condições ambientes, mas mesmo mudando teremos uma área constante para aquelas condições. O vetor de contorno predominante deste blob é próximo de 90 graus, ou seja, este se aproxima de retas horizontais. A distância destes contornos envolve os obstáculos, podendo ser diferenciados apenas pelo vetor e pela área.

F) Obstáculo - Entende-se como obstáculo o blob que possui distância inferior à margem oposta do lago, com vetor diferente à 90 graus e com área diferente à atribuída às ondas. 


\section{5 - Atribuição de características .}

Com o objetivo de caracterizar os blobs gerados, foram extraídas as seguintes características para cada blob esquerdo gerado :

A) Area - A área do blob foi definida em pixels. Depois de levantada a área de todos os blobs, esta característica foi descartada por se verificar de que não é significativa para a caracterização.

B) Distância - Cada blob foi quebrado em suas diversas linhas no qual este contorna. Cada linha teve a sequência de pixels recuperada a partir da imagem esquerda original e executada a estimativa de disparidade. Em seguida, foi calculada a distância desta linha à câmera esquerda. Como um blob pode agrupar diversas linhas, está sujeito à obter variações espúrias do cálculo de distância sobre eventual linha. A distância de um blob é então definida como sendo a distância de maior ocorrência entre suas linhas.

C) Vetor predominante do contorno. Foi analisado se o contorno tem tendência de achatamento em que inclinação. Vetores próximos de 90 graus indicam que o contorno tem um achatamento vertical, ou seja, se aproxima de uma linha horizontal. Vetores próximos de 0 graus indicam que o contorno tem um achatamento horizontal, ou seja, este se aproxima de uma linha vertical

Para determinar este vetor, tomemos como exemplo um blob em formato de círculo, como o ilustrado na figura 15 no alto. A cada quadrante que o blob percorre em sua trajetória A-B-C-D-E ... etc., marcamos o mesmo deslocamento no gráfico da figura 15 abaixo. A única diferença é que quando o quadrante do blob desce, como no deslocamento $\mathrm{H}$ e J, o gráfico abaixo por tomar sempre o módulo do deslocamento sobe um quadrante. $\mathrm{O}$ mesmo ocorre quando na varredura do blob, o deslocamento passa à um quadrante à esquerda, por exemplo, no deslocamento $\mathrm{M}$ e $\mathrm{O}$. Por tomar sempre o módulo, no gráfico abaixo, o deslocamento $\mathrm{M}$ e $\mathrm{O}$ será à direita. Terminada a varredura, o vetor predominante será o angulo entre o primeiro e o último ponto. Curiosamente, para figuras achatadas verticalmente, o ângulo predominante será próximo de 90 graus, enquanto figuras achatadas lateralmente, o ângulo predominante será de 0 graus. Como o contorno das ondas são na maioria achatadas verticalmente, este vetor predominante poderá medir o formato geral destas. 
Com o objetivo de testar as características de cada classe, foram pré-processadas as imagens relativas as figuras 11,12 e 13 para se extrair as imagens passa-alta e o blob destas imagens. Os 1674 blobs obtidos de todos os pares de imagens foram classificados manualmente através de uma inspeção visual. Em seguida estes elementos foram plotados em um gráfico para exposição de suas características de vetor de deslocamento de contorno e distância.

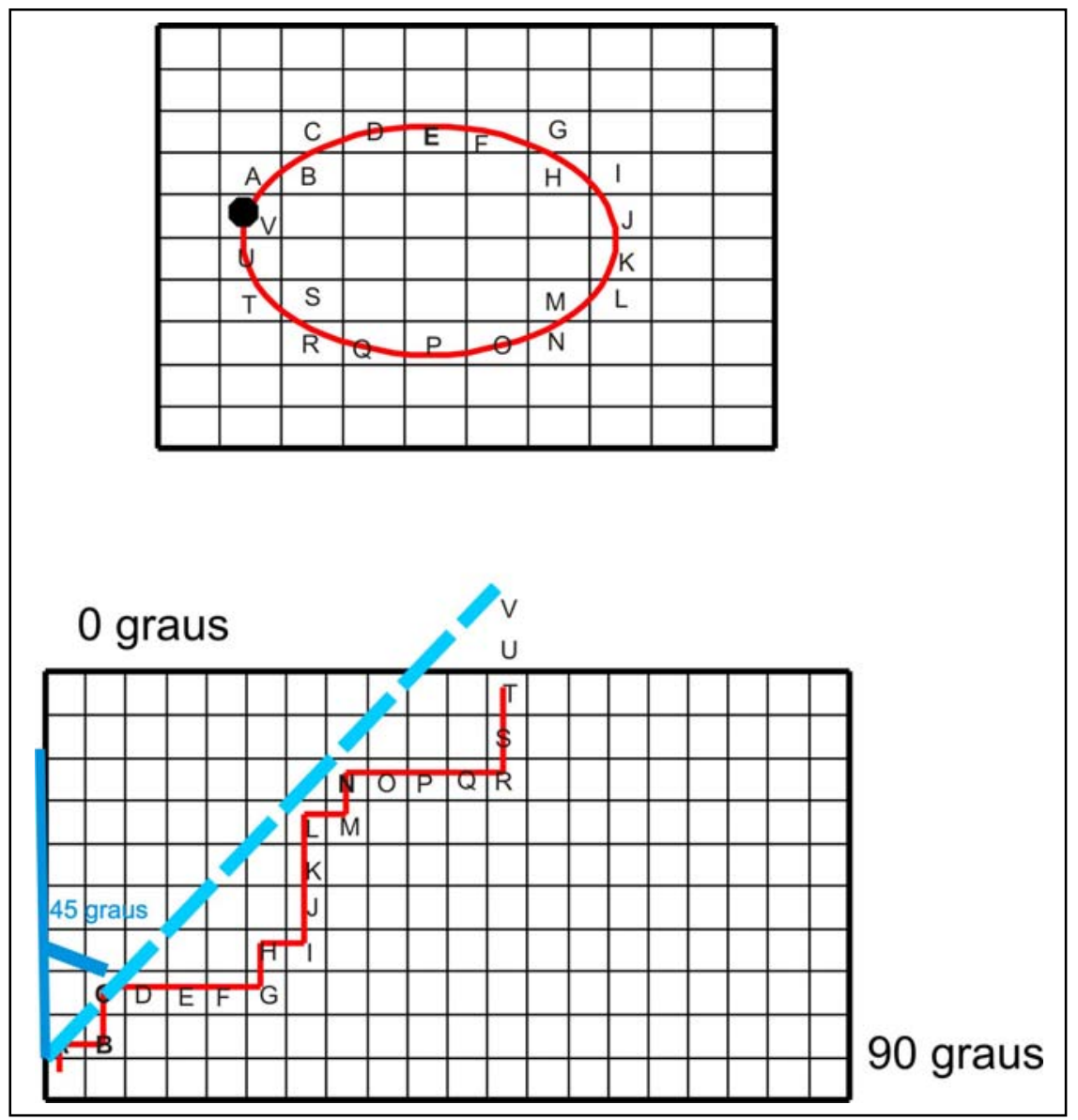

Figura 15. - Exemplo de determinação de vetor predominante de contorno.

Observou-se que a distância é a característica mais significativa que separa as classes de blobs : Nuvem, Margem, Reflexo e Luminosidade da classe Obstáculo. A única classe que não pode ser separada da classe Obstáculo pela distância é a classe Onda. Para isso, se torna significativa a classe de vetor de contorno predominante. 


\section{6 - Disparidade de imagens}

\subsection{1 - Cálculo de disparidade de imagens}

Os métodos de disparidade consistem em procurar uma seqüência de pixels de uma imagem em seu par estéreo. Esta procura é realizada deslocando uma janela de mesmo tamanho desta sequência de pixels sobre a imagem complementar. Enquanto se desloca a janela é verificada em qual posição as sequências de ambas as imagens são mais semelhantes.

Esta comparação de semelhança é feita subtraindo cada croma de cada pixel da imagem janela original de cada croma de cada pixel da janela complementar deslocada. Dos valores subtraídos é extraído seus módulos para eliminar o sinal negativo de algumas destas subtrações. É obtido um índice da diferença somando todos os módulos destas diferenças .

A disparidade será a diferença de coordenadas entre a sequência de pixels da imagem direita e a sequência mais semelhante na imagem esquerda.

O método aqui desenvolvido trabalha com blobs. Havendo cada blob diversas linhas, estamos sujeitos à encontrar alguns erros de disparidade entre cada linha de pixels contida no interior de cada blob.

A disparidade do blob é então tomada como sendo a disparidade de maior ocorrência entre as suas linhas. 


\subsection{2 - Validação da análise de disparidade do blob.}

Ocasionalmente, obtemos alguns campos da imagem direita que não aparecem na imagem esquerda por consequência do deslocamento entre câmeras. Este caso são chamados de oclusão de imagem. Casos de oclusão geram blobs não correspondentes.

A presença de blobs sem correspondência entre imagens direita e esquerda também podem ocorrer devido e eventuais ruídos, ou diferenças de brilho do sol na onda visto em diferentes câmeras. Mas ao calcular a disparidade como sendo o conjunto de pixels mais semelhantes, o programa vai a princípio tomar o blob mais próximo da coordenada calculada na imagem esquerda como sendo o blob correspondente. É preciso verificar o blob verdadeiramente correspondente existe.

Para verificar se existe o mesmo contorno em ambas imagens foi desenvolvida uma rotina que procura se o blob em estudo da esquerda é coerente com o blob da direita localizado pela disparidade entre eles. Este índice é calculado medindo a distância euclidiana entre os dois blobs em um espaço de características tetra-dimensional. Para melhor entender como esta distância é medida, vamos rever a fórmula para medidas de distância para um espaço tri-dimensional :

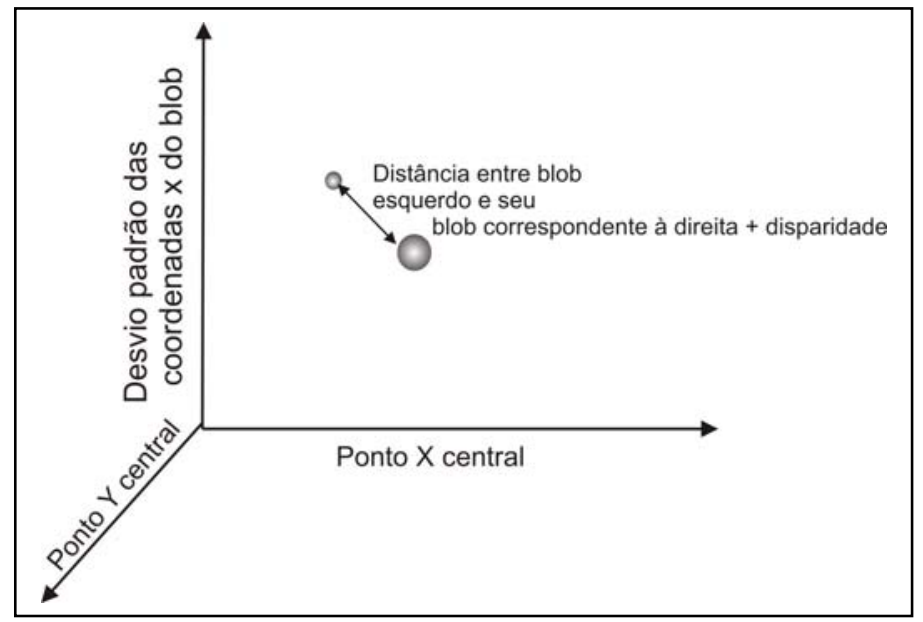

Figura 16. - Gráfico do espaço de características para análise de validação de disparidade, apresentando apenas 3 eixos.

Uma das esferas do gráfico da figura 16 representa o local do espaço de características do blob esquerdo analisado. A outra esfera é o blob em análise da imagem direita. Todos os 
blobs da imagem direita são comparados por este método para verificar se existe mesmo um blob correspondente.

Quando comparamos a coordenada $\mathrm{x}$ do ponto central entre os blobs direito $\mathrm{e}$ esquerdo, já devemos saber que elas não coincidirão por causa da disparidade entre as imagens. Por causa disso, o blob da imagem direita é situado em um espaço de características onde a coordenada x é somada à disparidade.

Se o gráfico tivesse apenas estes 3 eixos de características, conforme ilustrado na figura 16, a fórmula para calcular a distância entre dois pontos no espaço tri-dimensional é :

$$
d:=\sqrt{(x 2-x 1)^{2}+(y 2-y 1)^{2}+(\sigma x 2-\sigma x 1)^{2}}
$$

Onde $\mathrm{d}=$ distância entre os pontos

$\mathrm{x} 2=$ coordenada $\mathrm{x}$ do centro do blob esquerdo

$\mathrm{x} 1$ = coordenada $\mathrm{x}$ do centro do blob direito - disparidade

y2 $=$ coordenada y do centro do blob esquerdo

y1 = coordenada y do centro do blob direito

$\sigma \times 2=$ desvio padrão das coordenadas $\mathrm{x}$ do blob esquerdo

$\sigma \times 1=$ desvio padrão das coordenadas $\mathrm{x}$ do blob esquerdo

Porém tomamos 4 eixos em nosso espaço de características, pois levamos em conta também o desvio padrão das coordenadas y dos blobs. A figura 16 desenhou apenas 3 eixos por ser o limite do que se pode representar neste impresso. A fórmula para calcular a distância entre os blobs utilizada neste nosso experimento é :

$$
d:=\sqrt{(x 2-x 1)^{2}+(y 2-y 1)^{2}+(\sigma x 2-\sigma x 1)^{2}+(\sigma y 2-\sigma y 1)^{2}}
$$

Onde :

бy2 = desvio padrão das coordenadas y do blob esquerdo

$\sigma y 1=$ desvio padrão das coordenadas y do blob esquerdo

Experimentalmente, constatamos que todos os blobs inválidos apresentam uma distância euclidiana menor que 30. A rotina de validação encontra-se no apêndice A. 


\section{7 - Cálculo de distância}

Para se calcular a distância de obstáculos à câmera é fundamental conhecer, a princípio o ângulo de incidência de cada raio luminoso que proporciona cada pixel. Como a disparidade entre as imagens se refere à um deslocamento de blobs em sentido horizontal, estes ângulos serão levantados ao longo de uma distribuição horizontal.

\subsection{1 - Cálculo pixel-grau}

Foi calculado o grau de incidência dos raios luminosos na web-cam, para cada pixel produzido por esta.

Para isso foi desenhado um transferidor e plotado em um painel de tamanho A0, conforme desenhado na figura 17. Este pôster foi apoiado em uma folha de isopor e ao longo do perímetro deste transferidor foram inseridos alfinetes com cabeça de esferas coloridas. Nos graus múltiplos de 10, foram inseridos alfinetes com cabeças azuis, enquanto nos graus com valores terminados em 5 foram inseridos alfinetes de cor branca. No ponto de grau 0 foi inserido um alfinete com cabeça de cor dourada.

A câmera foi posicionada com centro focal situado no centro do transferidor, e fixada com fita crepe. Desta forma foi capturada uma imagem contendo o eixo dos diversos alfinetes ao longo do transferidor

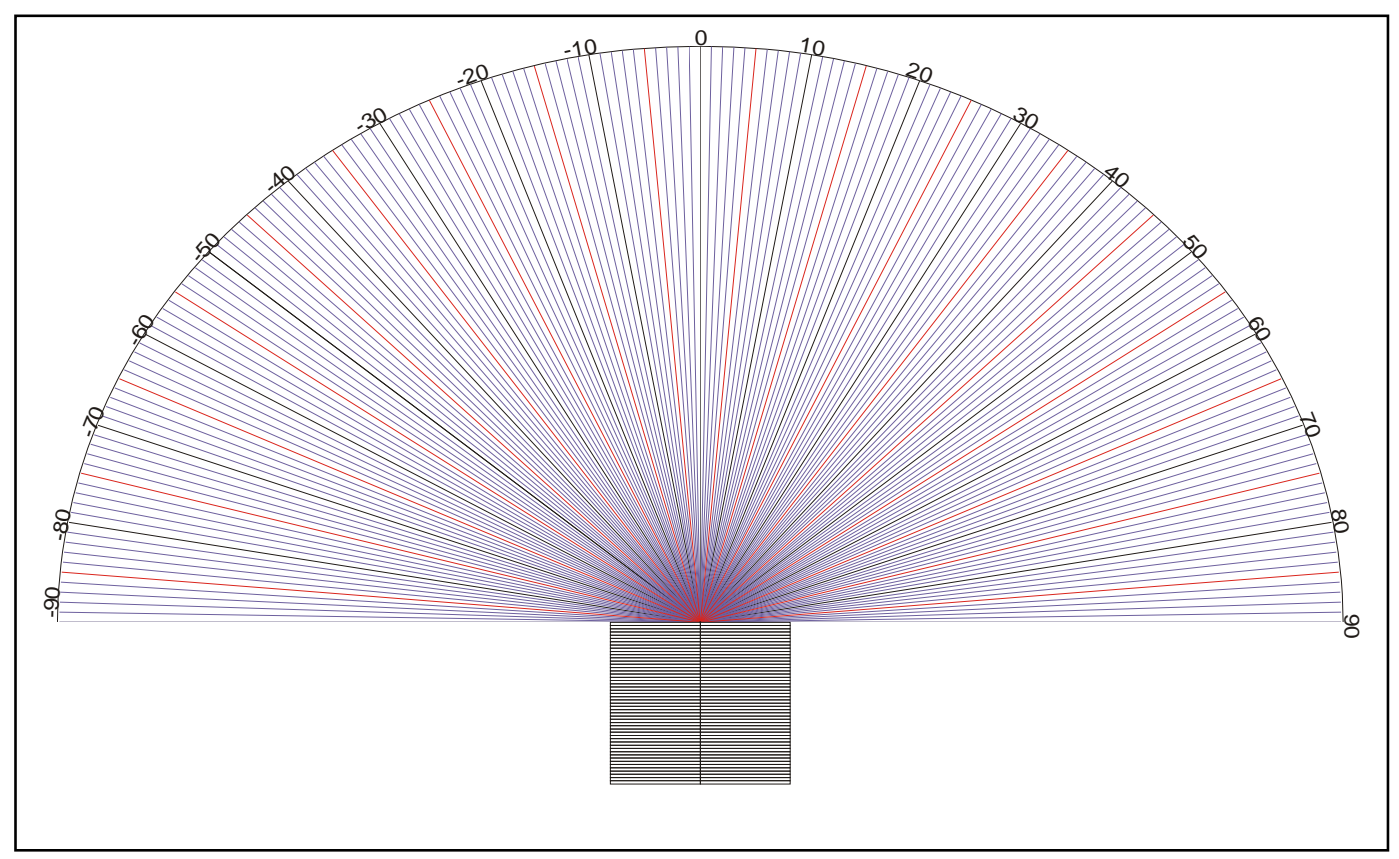

Figura 17. Transferidor plotado sobre um painel. 


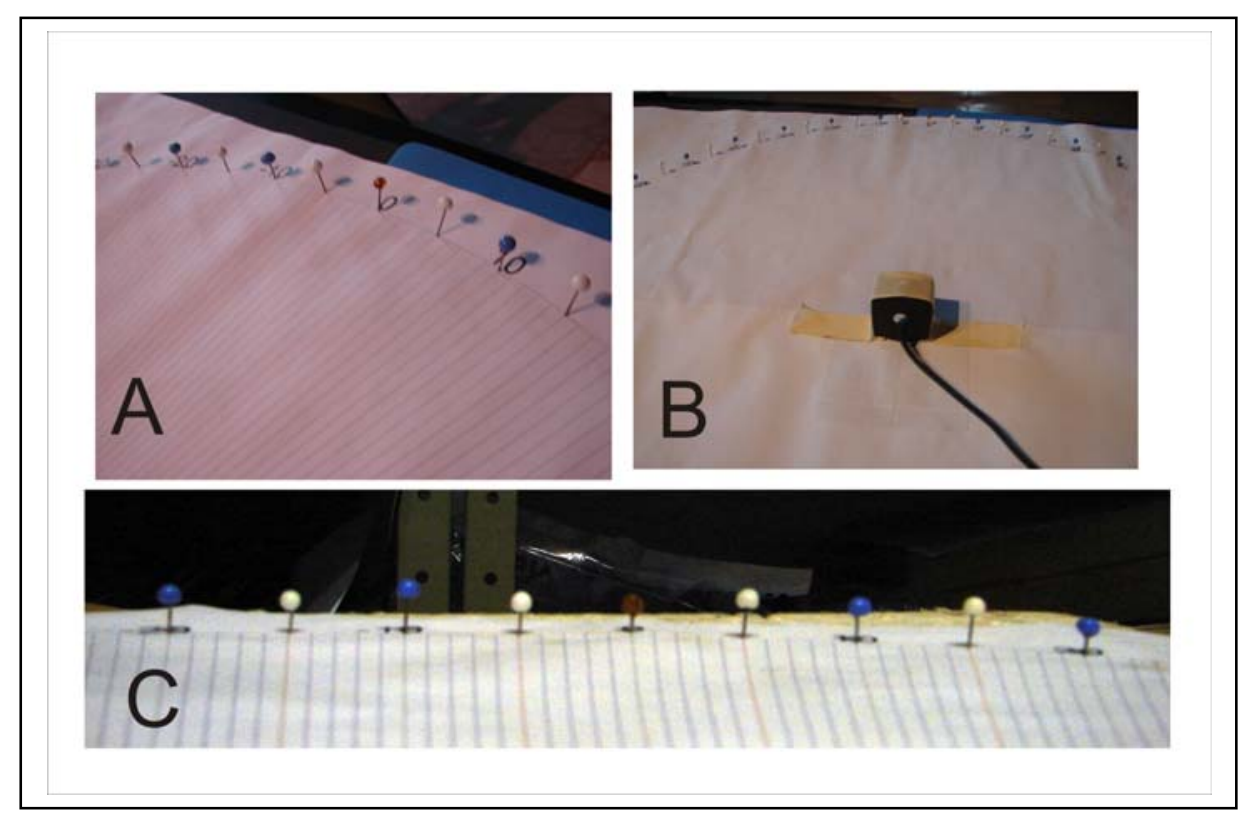

Figura 18. Câmera apoiada em transferidor com alfinetes.

Todos os alfinetes da imagem $\mathrm{C}$ da figura 18 possuem um ângulo ( $\boldsymbol{\alpha a l f}$ ) de 5 graus cada um, e uma distância média (palf) de 67,5 pixels.

A relação de pixels por cada grau (apix) será :

$$
\alpha \text { pix }:=\frac{\text { palf }}{\alpha \text { alf }}
$$

Ou seja, cada $\alpha$ pix $=13,5$ pixels por grau

A relação de graus por pixel (pixa) será o inverso de (1), ou seja

$$
\text { pix } \alpha:=\frac{1}{\alpha \text { pix }}
$$

Segundo nossos resultados, $\mathbf{p i x} \boldsymbol{\alpha}=0,074074$ graus para cada pixel 


\subsection{2 - Diagrama do cálculo de distância}

A disposição espacial das câmeras e o objeto se situa conforme ilustrado na figura 19. Um ponto da imagem do objeto, refletido sobre a imagem da câmera esquerda e sobre a imagem da câmera direita, formam um triângulo.

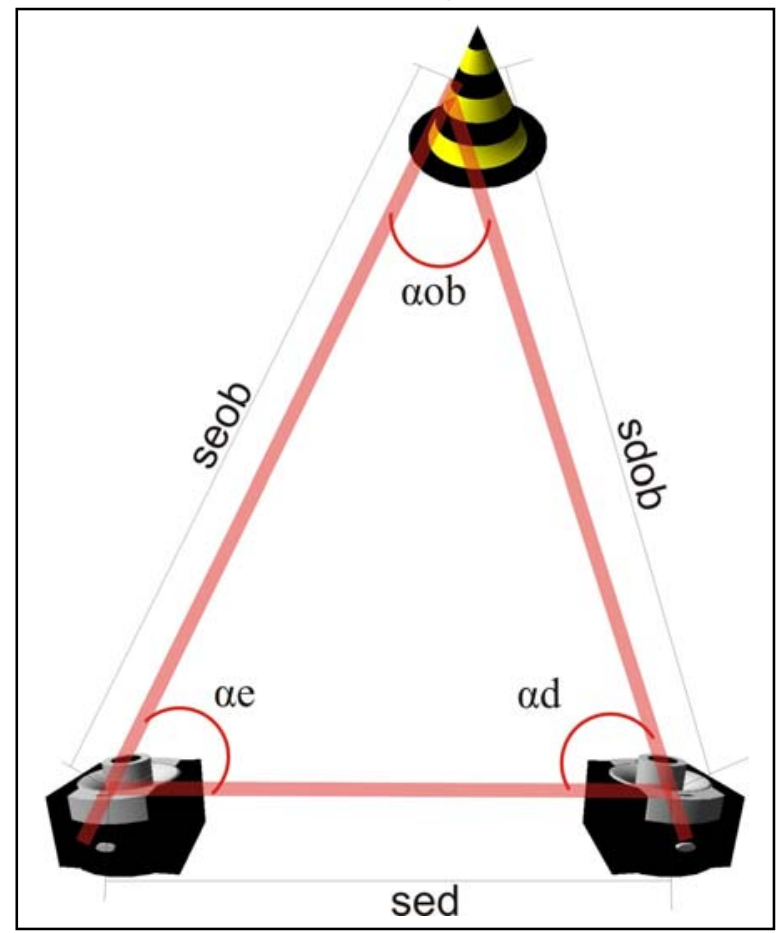

Figura 19. Triângulo relativo à disposição das duas câmeras e um ponto do objeto analisado.

Neste triângulo as variáveis significativas são :

sed - distância entre o centro do diafragma da câmera direita e o centro do diafragma da câmera esquerda

ae - ângulo sobre a câmera esquerda refletindo a abertura entre a câmera direita e o ponto do objeto analisado.

ad - ângulo sobre a câmera direita refletindo a abertura entre a câmera esquerda e o ponto do objeto analisado.

$\boldsymbol{\alpha o b}$ - ângulo sobre o ponto do objeto analisado refletindo a abertura entre a câmera direita e a câmera esquerda.

seob - distância entre o ponto do objeto analisado e o centro do diafragma da câmera esquerda.

sdob - distância entre o ponto do objeto analisado e o centro do diafragma da câmera direita. 
Um dado que possuímos a priori é a distância entre as câmeras (seb), que no nosso caso tomamos o cuidado de apoià-las sobre um suporte que corresponde à largura do barco, que é $1,4 \mathrm{~m}$.

A imagem original possui 640 pixels de largura. Quando o pixel está no centro desta imagem, ou seja, na coordenada horizontal 320, sabemos que o ângulo de incidência da luz sobre as câmeras é de 90 graus.

Porém, não podemos tomar como 90 graus o centro da imagem já processada, pois conforme descrito na seção 3.1.2, ela teve suas bordas retiradas e passa a ter um centro irreal para a trajetória de raios luminosos. O pixel que corresponde ao ângulo de 90 graus é o do centro horizontal da imagem original antes de perder esta borda.

A nova coordenada do centro horizontal da imagem é :

pmesq $=320-\mathbf{h p}$, onde :

hp é o deslocamento da imagem proporcionado pelo erro de inserção da câmera sobre o suporte. Este deslocamento pode ser positivo ou negativo. 


\subsection{3 - Calculando $\alpha \mathrm{e}$}

Preliminarmente, podemos considerar que todo pixel presente no centro horizontal da imagem original, ou seja, na coordenada horizontal pmesq, possui um ângulo de inclinação de seus raios luminosos igual a 90 graus.

No entanto, os cálculos para determinação de $\alpha e$ podem divergir nos casos em que o pixel está à direita do centro pmesq, em relação aos casos em que o pixel analisado está à esquerda do centro pmesq. Isso se deve ao fato do desenho geométrico ser diferente para cada caso.

Para facilitar a compreensão das disposições geométricas desenhadas nos próximos tópicos, a figura 20 descreve uma disposição geométrica genérica onde está representada a imagem final, a imagem dentro da câmera, o diagrama, os ângulos de interesse em cada questão, e o objeto contendo o pixel analisado.

Nesta figura 20, em J, temos a imagem capturada, K define o deslocamento do pixel entre o centro da imagem e o pixel analisado. I mostra a imagem rotacionada, refletida no interior da câmera. Em G temos o diafragma (ou pinhole) da câmera, onde os raios luminosos se cruzam. A Região F mostra os ângulos de interesse discutidos em cada seção, e a Região E mostra o objeto que emite o raio luminoso do pixel analisado. A representação da câmera $\mathrm{H}$, refere-se à uma câmera cuja metade superior foi removida, conforme exposto em A, B e C. Esta câmera foi rotacionada de forma a observarmos sua vista do topo para baixo (D). 


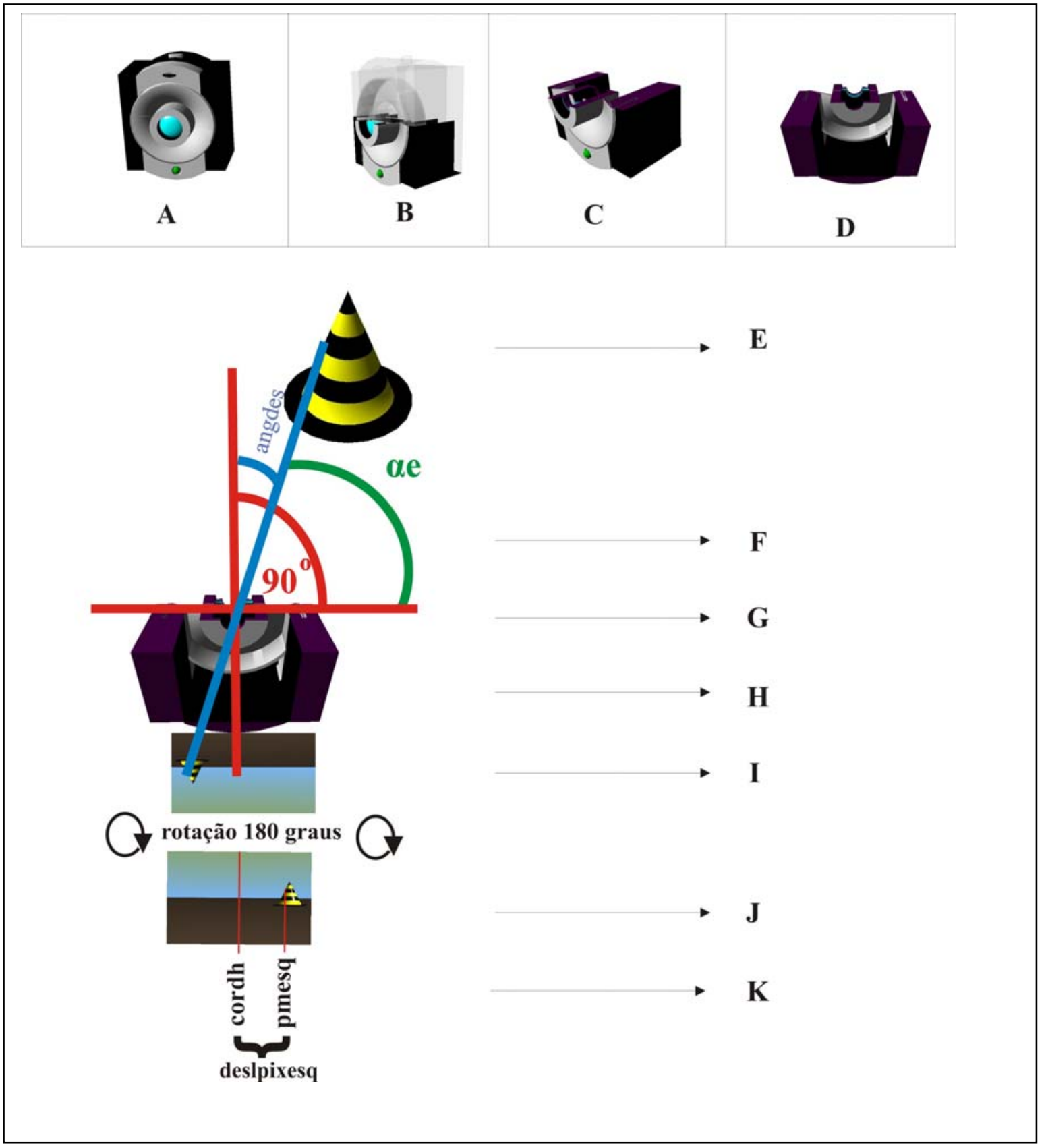

Figura 20. Diagrama genérico para representar o espaço geométrico ocupado. 


\subsubsection{1- Cálculo de $\alpha e$ para pixel situado à direita da imagem}

Figura 21.Diagrama geométrico de uma imagem capturada pela câmera esquerda com pixel de interesse situado na porção direita da imagem.

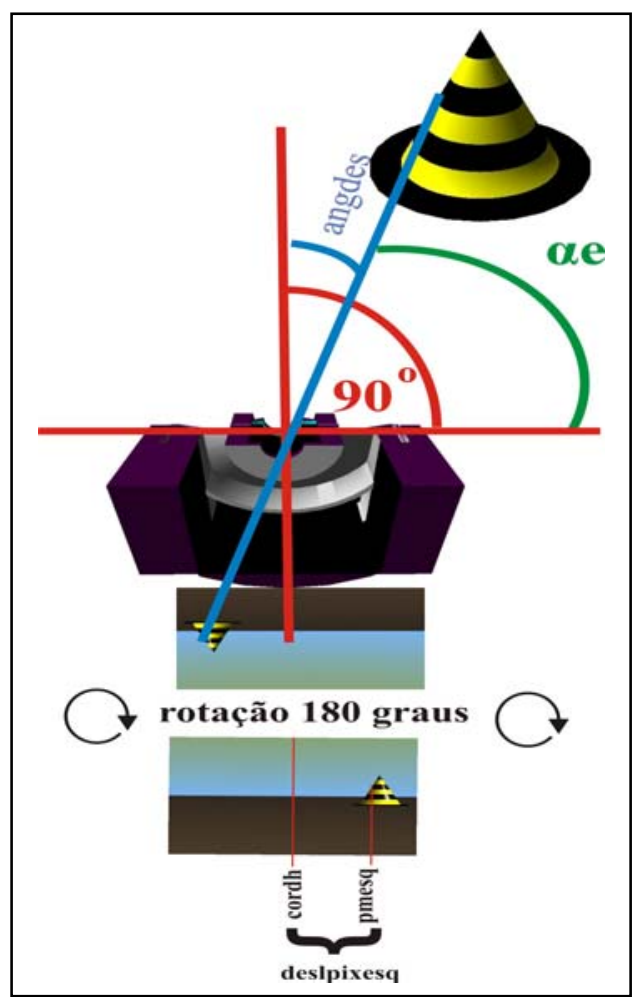

Se o ponto analisado estiver à direita do centro da imagem (coordh $>$ pmesq) para câmera esquerda, o diagrama geométrico será o da figura 21. Neste caso, o deslocamento em pixels (deslpixesq) sobre a incidência de 90 graus será :

deslpixesq $=$ coordh - pmesq, onde

$\operatorname{coordh}=$ coordenada $\mathrm{h}$ do pixel analisado.

O ângulo deslocado (angdesl) entre o centro de 90 graus e o angulo do pixel será :

$$
\begin{aligned}
& \text { angdesl }=\text { deslpixesq } * \text { pixa } \\
& \text { O angulo } \alpha \text { e será } \\
& \alpha e=90-\text { angdesl }
\end{aligned}
$$

Substituindo as equações 3, 4 e 5 podemos decompor $\boldsymbol{\alpha e}$ para escrevê-lo de uma forma mais completa e compatível à rotina “calcula distância” escrita em MatLab no apêndice A:

$$
\begin{aligned}
& \alpha e=90-(\text { deslpixesq } * \text { pix } \alpha) \\
& \alpha e=90-[(\operatorname{coordh}-\text { pmesq }) * \text { pix } \alpha]
\end{aligned}
$$


3.7.3.2 - Cálculo de $\alpha e$ para pixel situado à esquerda da imagem

Figura 22. Diagrama geométrico de uma imagem capturada pela câmera esquerda com pixel de interesse situado na porção esquerda da imagem.

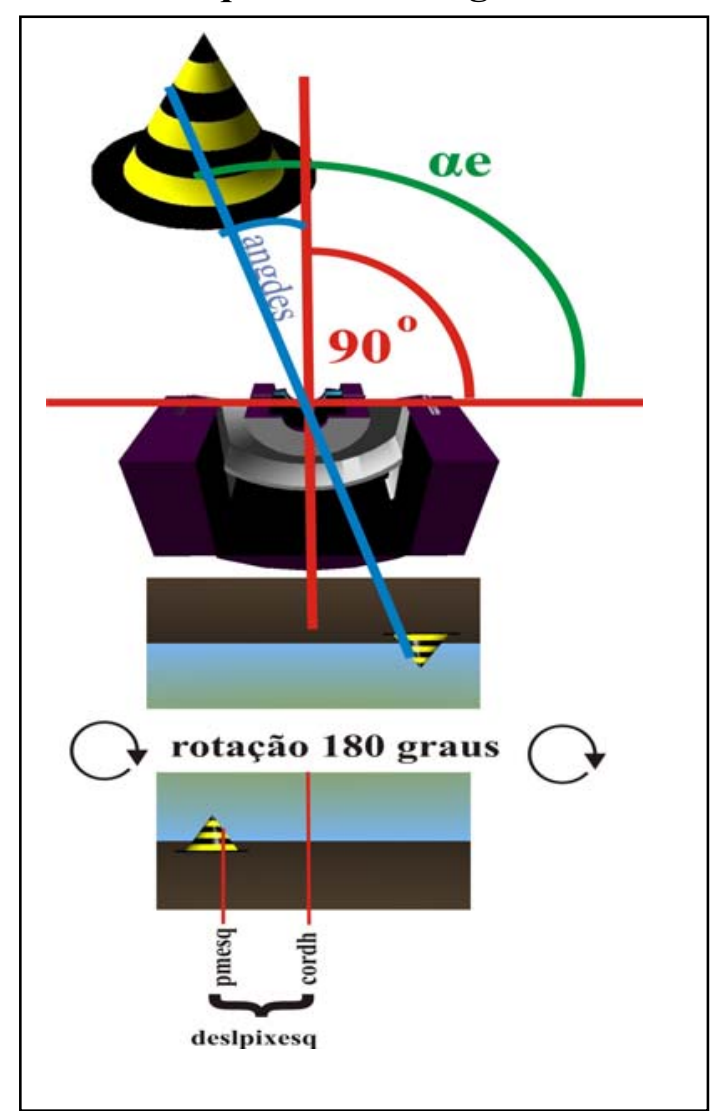

Para câmera esquerda com pixel de interesse à esquerda do centro da imagem, conforme desenho geométrico da figura 22, o deslocamento em pixels (deslpixesq) passará a ser :

$$
\text { deslpixesq }=\text { pmesq }- \text { coordh }
$$

O ângulo deslocado ainda será o mesmo da equação 4 :

$$
\text { angdesl }=\text { deslpixesq }{ }^{*} \text { pix } \alpha
$$

O ângulo $\boldsymbol{\alpha e}$ neste caso será

$$
\alpha e=90+\text { angdesl }
$$

Substituindo as equações 7, 8 e 9 podemos decompor ae para escrevê-lo de uma forma mais completa e compatível à rotina "calcula distância" escrita em MatLab no apêndice A:

$$
\begin{aligned}
& \alpha e=90+(\text { deslpixesq * pix } \alpha) \\
& \alpha e=90+[(\text { pmesq }- \text { coordh }) * \text { pix } \alpha]
\end{aligned}
$$




\subsection{4 - Calculando ad}

Tal qual o $\boldsymbol{\alpha e}$, nas situações onde o pixel se situa no centro horizontal da imagem original, sabemos que o ângulo de incidência do raio luminoso é de 90 graus. Porém neste caso, como demonstrado anteriormente, a imagem da câmera direita tem o tratamento de borda diferente da imagem esquerda para corrigir erros de inserção desta sobre o suporte. Como consequência disso, o centro horizontal da imagem, após o tratamento de correção tem um novo cálculo, e passa a se chamar pmdir.

Semelhante à situação do $\alpha e$, aqui também temos cálculos distintos para a situação onde o pixel analisado se encontra à esquerda ou à direita do centro pmdir.

O formato dos diagramas apresentados, ainda seguem o mesmo formato adotado para a câmera esquerda, representado na figura 20 .

Por similaridade, também é evidente que pmdir possui 90 graus de incidência. A partir daí calculamos o deslocamento em pixels do pixel analisado em relação ao centro, agora chamado de deslpixdir. Em seguida, também calculamos o ângulo de desvio angdesl a partir do deslocamento em pixels deslpixdir.

Uma grande diferença em relação ao cálculo de ae está no desenho geométrico para estimar se o angulo de desvio deve ser somado ou subtraído do ângulo de referência de 90 graus. 
3.7.4.1 - Calculando $\alpha \mathrm{d}$ para pixel situado à direita da imagem

Figura 23.Diagrama geométrico de uma imagem capturada pela câmera direita com pixel de interesse situado na porção direita da imagem.

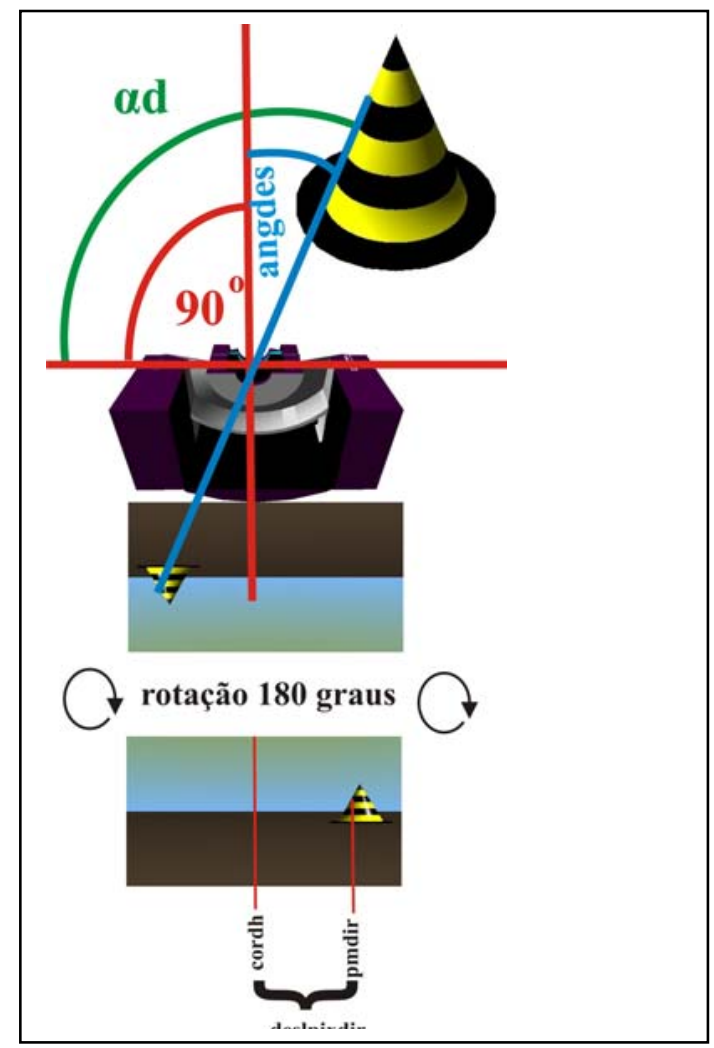

Para câmera direita com pixel de interesse à esquerda do centro da imagem, conforme desenho geométrico da figura 23, o deslocamento em pixels (deslpixdir) passará a ser :

$$
\text { deslpixdir }=\text { coordh }- \text { pmdir }
$$

O ângulo deslocado ainda será o mesmo da equação 4 :

$$
\text { angdesl }=\text { deslpixdir } * \text { pix } \alpha
$$

O ângulo $\boldsymbol{\alpha d}$ neste caso será

$$
\boldsymbol{a d}=90+\text { angdesl }
$$

Substituindo as equações 11, 12 e 13 podemos decompor $\boldsymbol{\alpha d}$ para escrevê-lo de uma forma mais completa e compatível à rotina “calcula distância” escrita em MatLab no apêndice A:

$$
\begin{aligned}
& \boldsymbol{\alpha d}=90+(\text { deslpixdir } * \text { pix } \alpha) \\
& \boldsymbol{\alpha d}=90+[(\text { coordh }- \text { pmdir }) * \text { pix } \alpha]
\end{aligned}
$$




\subsubsection{2 - Calculando ad para pixel situado à esquerda da imagem}

Figura 24. Diagrama geométrico de uma imagem capturada pela câmera direita com pixel de interesse situado na porção esquerda da imagem.

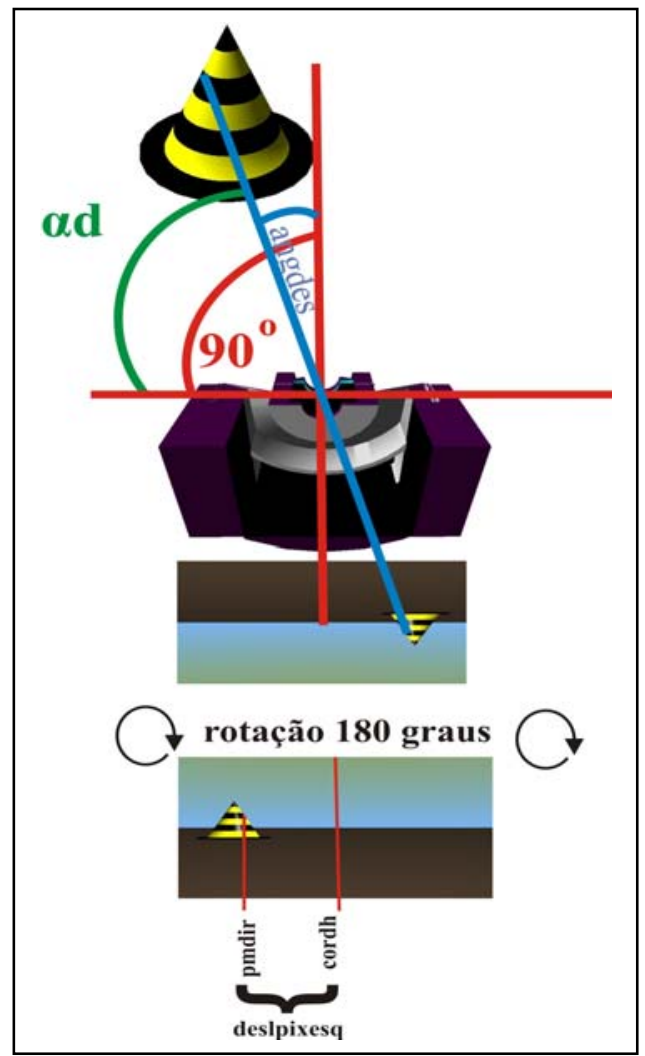

Para câmera direita com pixel de interesse à esquerda do centro da imagem, conforme desenho geométrico da figura 24, o deslocamento em pixels (deslpixesq) passará a ser :

$$
\text { deslpixdir }=\text { pmdir }- \text { coordh }
$$

O ângulo deslocado ainda será o mesmo da equação 4 :

$$
\text { angdesl }=\text { deslpixdir } * \text { pix } \alpha
$$

O ângulo $\boldsymbol{\alpha d}$ neste caso será

$$
\boldsymbol{\alpha d}=90-\text { angdesl }
$$

Substituindo as equações 15, 16 e 17 podemos decompor $\boldsymbol{\alpha d}$ para escrevê-lo de uma forma mais completa e compatível à rotina “calcula distância” escrita em MatLab no apêndice A:

$$
\begin{aligned}
& \boldsymbol{\alpha d}=90-(\text { deslpixdir } * \text { pix } \alpha) \\
& \boldsymbol{\alpha d}=90-[(\text { pmdir }- \text { coordh }) * \text { pix } \alpha]
\end{aligned}
$$




\subsection{5 - Finalização do cálculo da distância}

Revendo o nosso triângulo da figura 25, formado pelas duas câmeras e o ponto analisado do um objeto, podemos concluir que diversos elementos já foram solucionados.

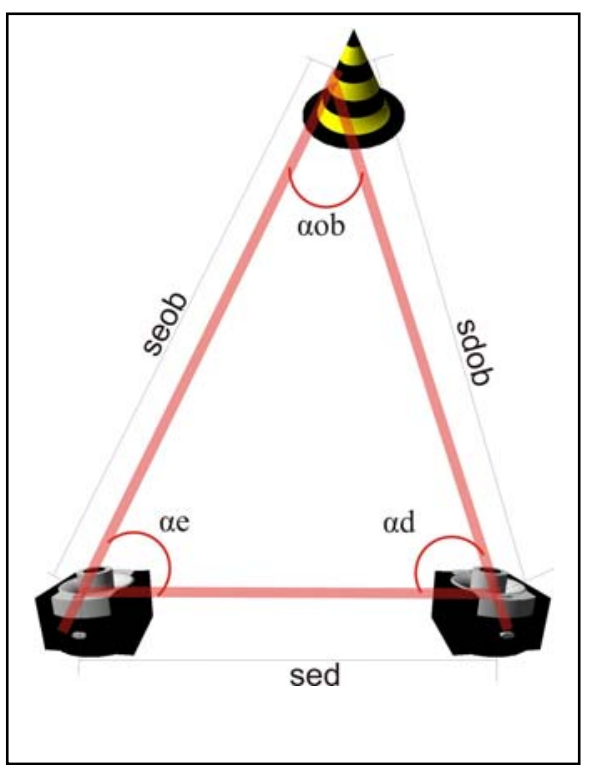

Figura 25. Triângulo entre duas câmeras e ponto analisado de um objeto.

Já possuindo ad, ae, e a distância entre as câmeras sed, podemos achar aob pelo principio de que os ângulos internos de um triângulo é $180^{\circ}$.

Portanto :

$\boldsymbol{\alpha o b}+\boldsymbol{\alpha d}+\boldsymbol{\alpha e}=180$

Como temos $\boldsymbol{\alpha d}$ e $\boldsymbol{\alpha e}$, isolamos e calculamos $\boldsymbol{\alpha o b}:$

$\boldsymbol{\alpha o b}=180-\boldsymbol{\alpha d}-\boldsymbol{\alpha e}$

Agora, com todos os ângulos calculados, a distância seob pode ser calculada pela lei dos senos :

$\operatorname{sed} / \sin (\alpha o b)=\operatorname{seob} / \sin (\alpha d)=\operatorname{sdob} / \sin (\alpha e)$

$\log 0$ :

$\operatorname{seob}=\operatorname{sed}^{*} \sin (\boldsymbol{\alpha d}) / \sin (\boldsymbol{\alpha o b})$

Convertendo grau para Pi-Radiano, que é a unidade adotada no MatLab, temos:

$\operatorname{seob}=\operatorname{sed} * \sin (\boldsymbol{\alpha d} * \boldsymbol{\pi} / \mathbf{1 8 0}) / \sin (\boldsymbol{\alpha o b} * \boldsymbol{\pi} / \mathbf{1 8 0})$ 


\subsection{6 - Aferição do cálculo de distância}

Com o objetivo de aferir a rotina de cálculo de distância, foi tomada um par estéreo de imagens em uma praça em Araraquara-SP conforme ilustrado na figura 26.

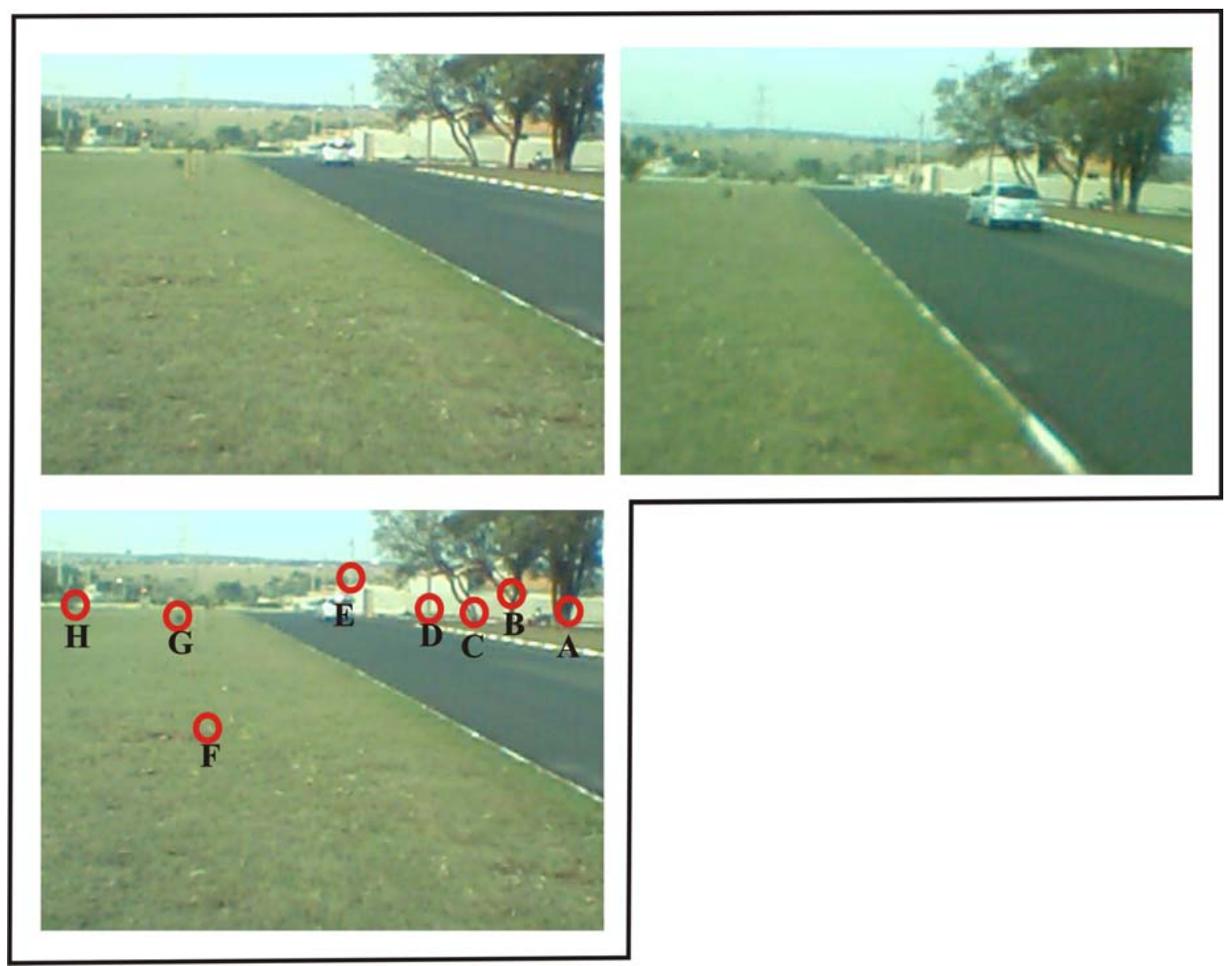

Figura 26. - Teste de campo para rotina de cálculo de distância. No alto são exibidas as imagens estéreo coletadas, e abaixo à esquerda, são evidenciados os pontos de distância estudados.

Sobre esta imagem estéreo foram medidos diversos pontos de referência utilizando uma trena. Estes pontos foram também calculados utilizando uma rotina desenvolvida em MatLab. Nesta rotina podemos clicar em cada ponto de referência em ambas as imagens, e o programa calcula a distância do ponto de referência. O resultado é exibido na tabela 1.

Notamos então que os os pontos B, E, F e H possuem um erro de medida empírica menor que o erro previsto pela discretização da imagem. Os pontos $\mathrm{C}$ e $\mathrm{D}$ possuem o desvio de 1 pixel além do erro previsto e o ponto A possui o erro excedente de 1,2 pixels além do previsto. Surpreendente foi o ponto $\mathrm{G}$, onde o desvio de distância foi o equivalente à coletar 
os dados com o deslocamento de 2,5 pixels. Isso ocorreu pelo artefato de uma estaca de madeira ter camuflada a moita em análise, conforme ilustrado na figura 28.

\section{Tabela 1 - Teste de cálculo de distância}

\begin{tabular}{|l|c|c|c|l|}
\hline \multicolumn{1}{|c|}{ Pontos estudados e descrição } & $\begin{array}{c}\text { Medidas em } \\
\text { campo com } \\
\text { trena }\end{array}$ & $\begin{array}{c}\text { Medidas } \\
\text { calculadas pelo } \\
\text { programa }\end{array}$ & $\begin{array}{c}\text { Erro } \\
\text { obtido }\end{array}$ & $\begin{array}{c}\text { Erro } \\
\text { Previsto para } \\
\text { cada pixel }\end{array}$ \\
\hline $\begin{array}{l}\text { A - Estremo direito de árvores em } \\
\text { feixes }\end{array}$ & $51 \mathrm{~m}$ & $45.2672 \mathrm{~m}$ & $5,732 \mathrm{~m}$ & $2,61 \mathrm{~m}$ \\
\hline $\begin{array}{l}\text { B - Ponto inferior luminoso da } \\
\text { forquilha de árvore }\end{array}$ & $65 \mathrm{~m}$ & $62.4100 \mathrm{~m}$ & $2,6 \mathrm{~m}$ & $4,72 \mathrm{~m}$ \\
\hline $\begin{array}{l}\text { C - Estremo direito de árvore } \\
\text { inclinada }\end{array}$ & $65 \mathrm{~m}$ & $57.0669 \mathrm{~m}$ & $7,9 \mathrm{~m}$ & $4,72 \mathrm{~m}$ \\
\hline D - Poste & $62,8 \mathrm{~m}$ & $56.2536 \mathrm{~m}$ & $6,54 \mathrm{~m}$ & $4,13 \mathrm{~m}$ \\
\hline E - Poste & & & $10,84 \%$ & \\
\hline F - Pedra ao lado de depressão & $7,10 \mathrm{~m}$ & $7.0659 \mathrm{~m}$ & $0,034 \mathrm{~m}$ & $0,045 \mathrm{~m}$ \\
\hline G - Margem direita de Moita & $47,20 \mathrm{~m}$ & $39.0086 \mathrm{~m}$ & $8,191 \mathrm{~m}$ & $2,36 \mathrm{~m}$ \\
\hline
\end{tabular}

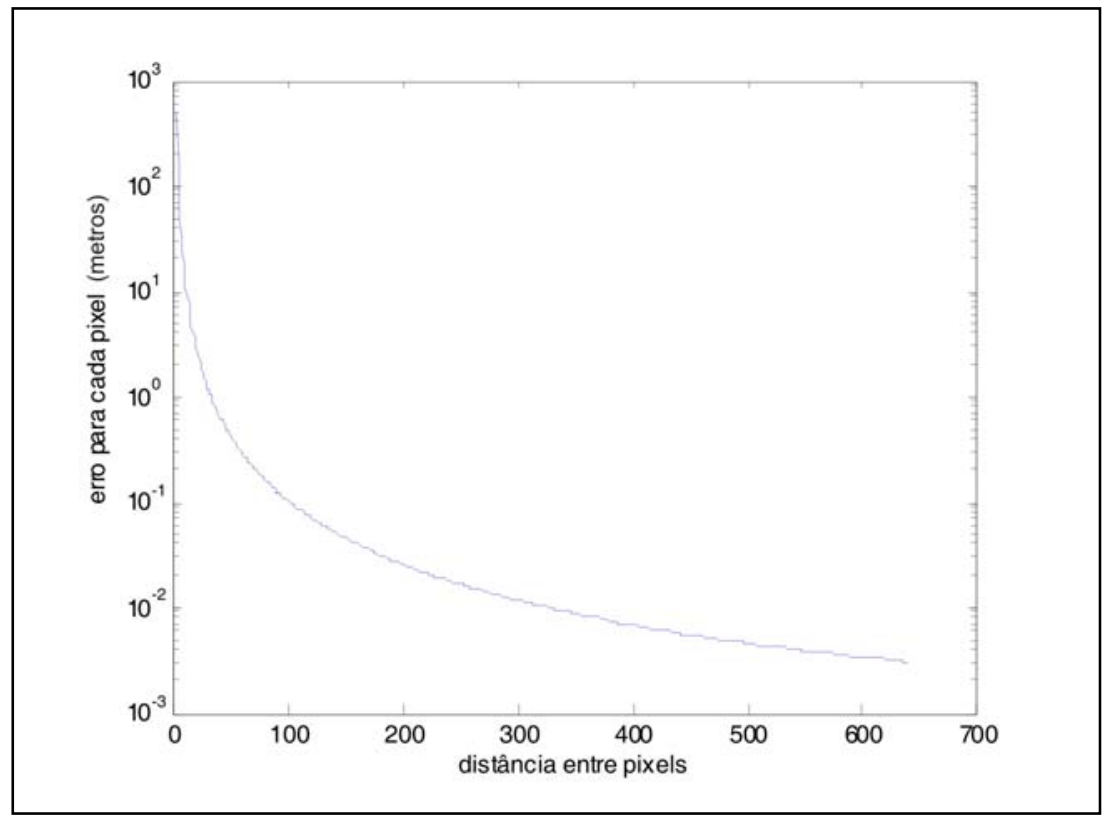

Figura 27. Erro gerado pela discretização da imagem 
O erro previsto para cada pixel depende da distância do pixel analisado à câmera. Quando o pixel candidato à obstáculo está muito perto da câmera há uma margem de erro insignificante quando comparamos à situações onde o pixel em análise está distante.

A figura 27 ilustra como o erro cresce exponencialmente com a distância. Nesta figura temos um gráfico cujo eixo y corresponde ao erro em metros proporcionados pela discretização da imagem. A coordenada x corresponde à distância entre as coordenadas horizontais de um mesmo ponto da imagem visto pela câmera direita e a câmera esquerda. Quando um ponto da imagem está em coordenada muito próxima da câmera esquerda e a câmera direita, o ponto analisado está distante.

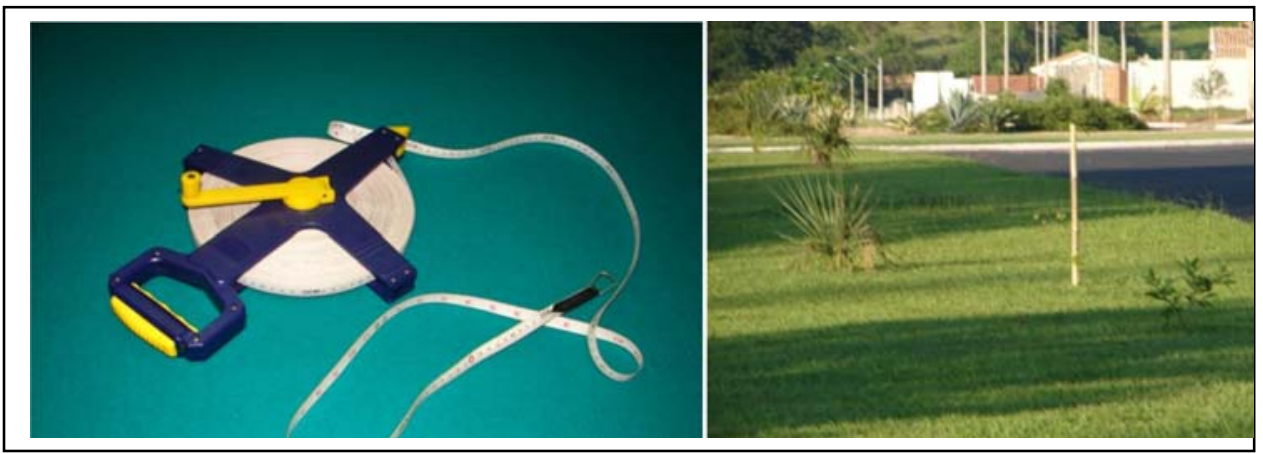

Figura 28. Trena utilizada para verificar distância e estacas de madeiras situadas à frente dos arbustos atribuídas como responsáveis pelo desvio da observação do ponto $G$ da tabela 1 .

O algoritmo para cálculo de erro de discretização entre os pixels pode ser descrito como :

xesq=1;

distância_anterior $=0$; dado do último cálculo de distância

Para $x d i r=1$ até 640 :

distância $=$ distancia $(x$ dir,xesq $)$; distância é a calculada conforme seção 3.7.2

erro(xdir) = Distância - distância_anterior

distância_anterior = distancia.

Fim_xdir

Este mesmo algoritmo proporcionou a tabela A-1 inserida no apêndice B. 


\section{Capítulo 4 Resultados}

\section{1 - Determinação da região de classificação de obstáculos.}

Na figura 29, vemos pontos relativo aos blobs coletados na amostra das imagens estéreo da figuras 1112 e 13 sem nenhum teste de validação (seção 3.6.2). Por isso neste gráfico aparecem pontos dos blobs oclusos e originados por ruídos. O eixo y representa a distância de cada blob da câmera esquerda, o eixo x mostra o vetor predominante do contorno do Blob. Os símbolos de cada dado plotado nesta figura e na figura 30 seguem o diagrama da tabela 2. Esta descrição obedece à classificação realizada manualmente. Nestes gráficos pretendemos visualizar características que permitam classificar os blobs tidos como obstáculos.

Os pontos relativo aos blobs no gráfico da figura 30 já estão filtrados através do teste de validação realizado após o teste de disparidade. Existe uma região do gráfico que pode ser tomada como o espaço de características que define o obstáculo . O retângulo amarelo mostra a região de vetor predominante no qual verificamos que não contém as ondas. Dentro desta região amarela, é classificado como obstáculos aqueles pontos com distância inferior à distância da margem.

Tabela 2 - Código de cores adotados nos gráficos à seguir.

\begin{tabular}{|c|c|c|}
\hline Classe & Cor & Descrição \\
\hline Obstáculo & & Bóias de sinalização presentes nas imagens. \\
\hline Onda & & Oscilações na superfície da água capaz de gerar blobs \\
\hline Luminosidade & & blobs provenientes do brilho do sol sobre a água \\
\hline Margem & & blobs provenientes da margem de fundo do lago \\
\hline Reflexo imagem & & $\begin{array}{l}\text { blobs provenientes de reflexos de nuvens ou margens } \\
\text { sobre a água. }\end{array}$ \\
\hline Nuvem & $\star$ & blobs provenientes das nuvens do céu. \\
\hline Não Classificado & 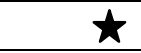 & Blob que não teve sua classificação manual. \\
\hline
\end{tabular}




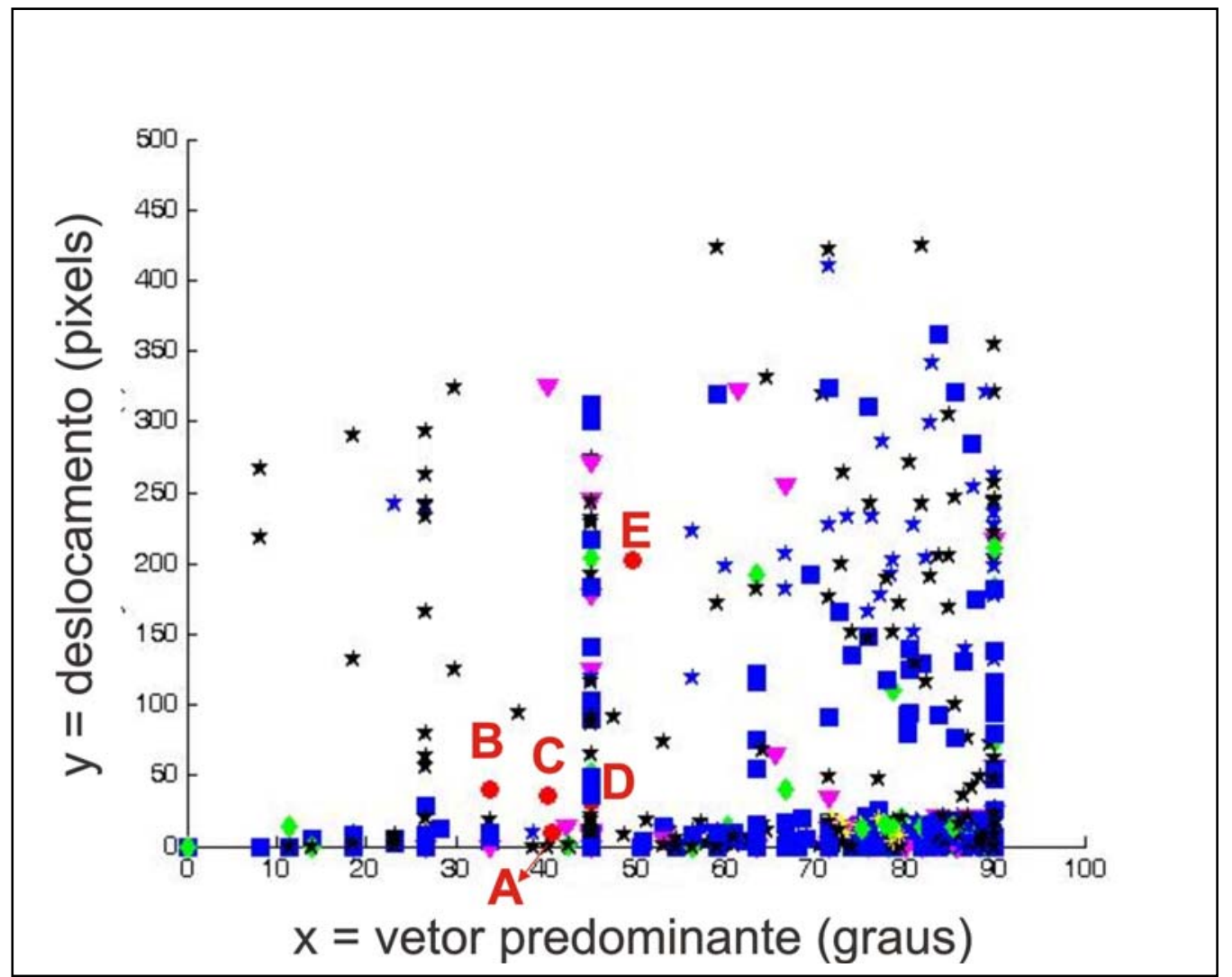

Figura 29. Espaço de características vetor $\mathbf{x}$ deslocamento de pixels, com plotagem dos blobs totais.

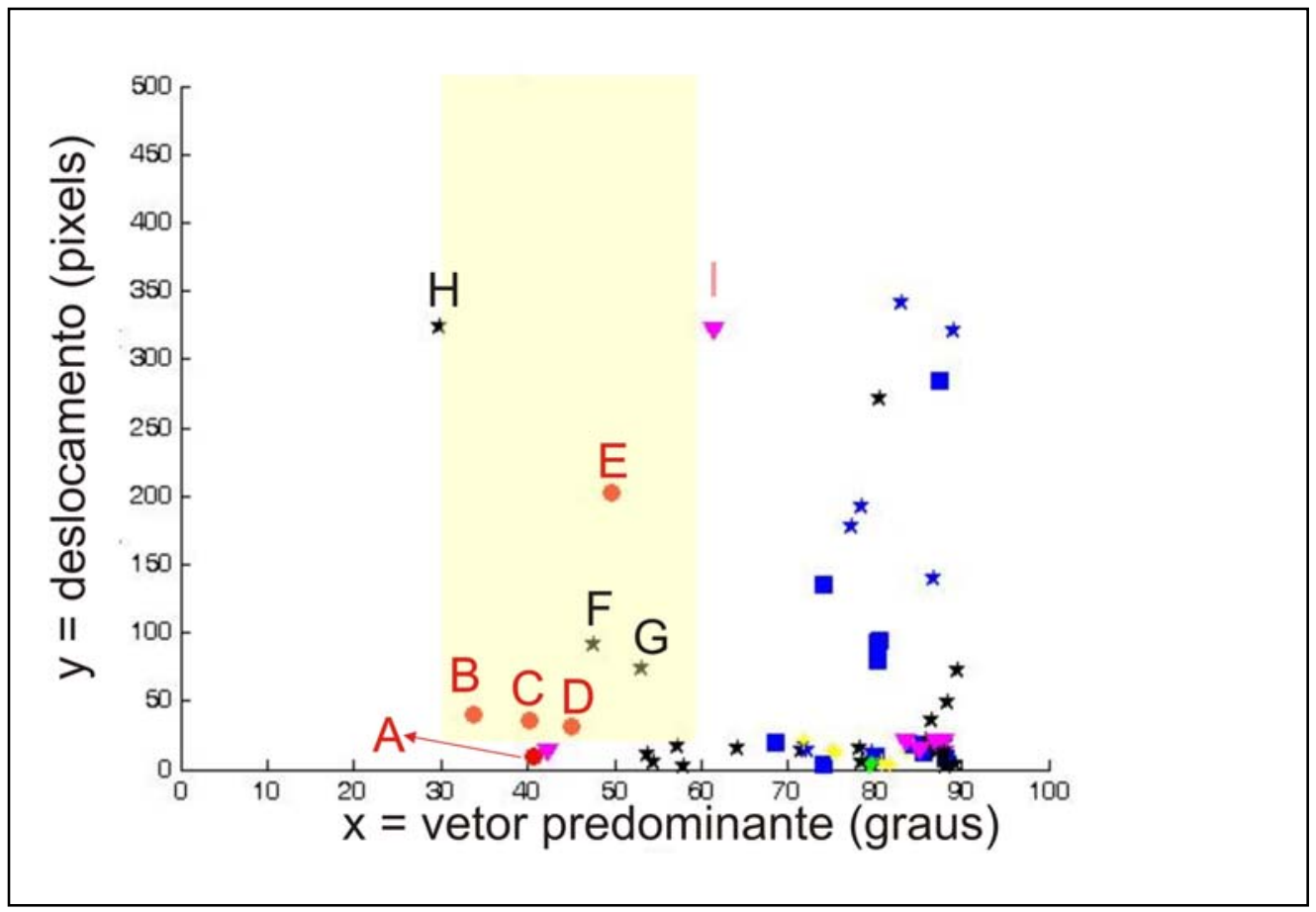

Figura 30. Espaço de características vetor $\mathrm{x}$ deslocamento de pixels, com plotagem dos lobs filtrados por teste de validação. 
Os pontos H e I, por estarem na região amarela, entende-se como tendo o vetor de contorno predominantemente achatado verticalmente, em formato idêntico à uma onda, porém estão na distância relativa à margem de fundo da imagem.

A rotina desenvolvida detectou corretamente todos os obstáculos da figura 11, 12 e 13. A imagem A da figuras 11, teve o ostáculo atribuído como ponto B, e o obstáculo da imagem $\mathrm{B}$ atribuído como ponto $\mathrm{D}$ no gráfico. $\mathrm{O}$ obstáculo da imagem $\mathrm{C}$ não aparece por estar ocluso na imagem esquerda após recorte.

Na figura 13, o obstáculo da imagem $\mathrm{H}$ aparece no gráfico como sendo o ponto $\mathrm{E}$, enquanto o obstáculo da imagem I está ocluso na imagem esquerda. Na imagem $\mathrm{J}$, os obstáculos aparecem como um ponto branco tão pequeno que ocupam praticamente a área de alguns pixel, não sendo sequer considerado uma cadeia blob significativa.

$\mathrm{Na}$ imagem $\mathrm{K}$ da figura 13 o obstáculo escuro foi detectado como sendo o ponto $\mathrm{C}$ do gráfico, enquanto o obstáculo claro, apresentado como o ponto A do gráfico da figura 30, foi reprovado na análise de validade, e foi tomado como falso-negativo pelo programa. Isso se deve ao fato da distância deste obstáculo ser maior do que a informada como sendo a da margem oposta ao lago.

Foram classificados como falso-positivos os pontos F, G, H e I. O ponto F refere-se à um ponto em terra da imagem $\mathrm{F}$ - figura 12 e imagem $\mathrm{J}$ - figura 13. Estes não foram considerados como significativos pelo fato deste campo em terra ser um artefato gerado pela imagem ter sido obtida à margem da lagoa. Deduzimos que quando as câmeras estiverem sobre o barco não haverá este segmento de terra na porção inferior das imagens.

A região do gráfico da figura 30 que é tida como obstáculo, é aquela sobre o retângulo amarelo que :

1) No eixo y relativo à distância em pixels está acima dos 2 pixels. Isso significa que o obstáculo será aquele menor que 496 metros que é a distância atribuída como sendo da margem oposta do lago, em sua direção mais curta. 
2) No eixo $x$ relativo ao vetor de contorno sobre o blob é menor que 70 graus, o que já está em uma boa margem de segurança para separar do blob das ondas que estariam teoricamente muito próximo dos 90 graus.

3) Para que seja plotado no gráfico é necessário que o blob passe no teste de validação de forma que tenha sua validação menor que 30, e também é necessário que ele possua uma área maior que 40 pixels $^{2}$. Estes valores foram os limites obtidos empiricamente para se excluir os blobs inválidos e para se excluir os blobs com área maior do que as ondas encontradas.

Podemos concluir com o gráfico da figura 30 que o espaço de características da distância do blob em função do vetor predominante de contorno como sendo suficientes para separar os obstáculos das ondas. O gráfico por ser bidimensional é muito simples e elegante para tomada de decisões. A análise de área de cada blob, apesar de coletada nestes exemplos, contribuíram muito pouco. Isso porque a distância e vetor predominante de contorno foram suficientes para delimitarem os obstáculos. 


\section{2 - Teste de desempenho e comparação com Snyder et al. (2004)}

Foram coletadas 26 imagens em estéreo às margens da represa do Broa em ItirapinaSP a fim de submeter o método à situações não previstas e testar o desempenho. As imagens estão expostas nas figura 31,32,33. Abaixo de cada imagem, expomos uma imagem com os campos potenciais propostos por Snyder et al. (2004). Na série de imagens das figuras 35, 36 , 37 e 38 as imagens do campo potenciais estão ao lado..

A figura 34 apresenta imagens esquerdas coletadas sobrepostas aos seus blobs. A imagem Ab mostra a imagem A da figura 31, juntamente com seus blobs. Ainda na figura 34, a imagem $\mathrm{Bb}$ mostra a imagem $\mathrm{B}$ da figura 32, com seus respectivos blobs, e a imagem $\mathrm{Cb}$ mostra a imagem $\mathrm{C}$ da figura 33. Os blobs detectados como obstáculos são pintados em verde, mesmo que sajam falso-positivos. A imagem $\mathrm{Cb}$ detecta como obstáculo na porção inferior um contorno que é a fusão da imagem de dois banhistas com ondas. Tanto os banhistas, como as ondas, por estarem contra o sol tiveram o mesmo tom enegrecido. Notamos um pouco mais acima outros dois contornos verdes falso-positivos.

Para obter as imagens com os supostos obstáculos de Snyder, extraímos os campos potenciais através do fluxo ótico pelo método Lucas-Kanade. O médodo de campos potenciais, gera para cada micro-região da imagem um vetor de deslocamento vertical, e outro vetor horizontal . Foram somados os módulos do vetor horizontal e vertical para cada uma destas micro-regiões, e com isso atribuído um valor relativo à esta soma. Estes índices de cada micro-região foram normalizados para 1 byte.

A princípio, as regiões que tiveram maiores vetores de deslocamento, e com isso seriam as melhores candidatas a obstáculos, teriam bytes altos na imagem final. Porém, para evitarmos uma imagem escura demais o que dificultaria a visualização, a invertemos de forma que os obstáculos fiquem representados como manchas escuras em fundo branco.

$$
\operatorname{im}(\mathrm{x}, \mathrm{y})=255-\operatorname{Nim}(\mathrm{x}, \mathrm{y})
$$

Na figura 31, temos acima, a imagem esquerda do par estéreo. Apesar de não haver obstáculos, notamos na imagem de campos potenciais abaixo 19 regiões com concentração de pontos escuros de forma a serem consideradas como obstáculos. 
Estes 19 falsos-positivos detectados pelo método de Snyder et al (2004) são gerados pelo brilho das ondas sobre a superfície como consequência da imagem ser coletada contra o sol. No método proposto, não houveram falsos-positivos.

A figura 32, na imagem abaixo também é de uma região do lago onde não havia obstáculos. Porém, pela imagem haver sido coletada em um ângulo muito mais direto em direção ao sol, o número de falsos obstáculos aumentou. $\mathrm{Na}$ imagem acima, notamos 42 regiões de pontos escuros, que erroneamente seriam classificados como falso-positivos pelo método tradicional, mas que neste método proposto não foram detectados.

A figura 33, vemos na imagem abaixo a presença de 2 banhistas. Pelo método de Snyder et al (2004), existem 4 regiões de pontos escuros que acusam a presença de obstáculos em coordenadas da região dos banhistas, com 26 regiões de obstáculos falsospositivos.

As figuras 35, 36,37 e 38 apresentam uma série de imagens, com o mapa de disparidade ao lado e a interpretação na mesma altura. O balanço geral do desempenho do método de Snyder et al (2004) em comparação com o método proposto, está na tabela 3

No método de Snyder et al (2004) notamos então uma predominância de 914 regiões obstáculos falso positivos contra 68 regiões de obstáculos reais. 7 obstáculos não foram reconhecidos por estarem oclusos no campo de visão da imagem direita do par estéreo.

Todos os obstáculos não detectados, seja por qualquer um dos métodos, foi devido à oclusão. Em outras palavras a totalidade dos casos de não detecção, foi devido à obstáculos presente no campo de uma câmera e que está ausente no campo de outra.

Os casos de falso-positivos encontrados no método desenvolvido foram devido à novos formatos de brilho das ondas. Notamos na imagem da 34-C algumas ondas de formatos mais circulares, que não seguiam o padrão de achatamento vertical. Apesar de tudo, estas ocorrências foram significativamente menor do que na proposta de Snyder et al (2004). No antigo método, a grande maioria dos brilhos de onda foram tomados como obstáculos. 


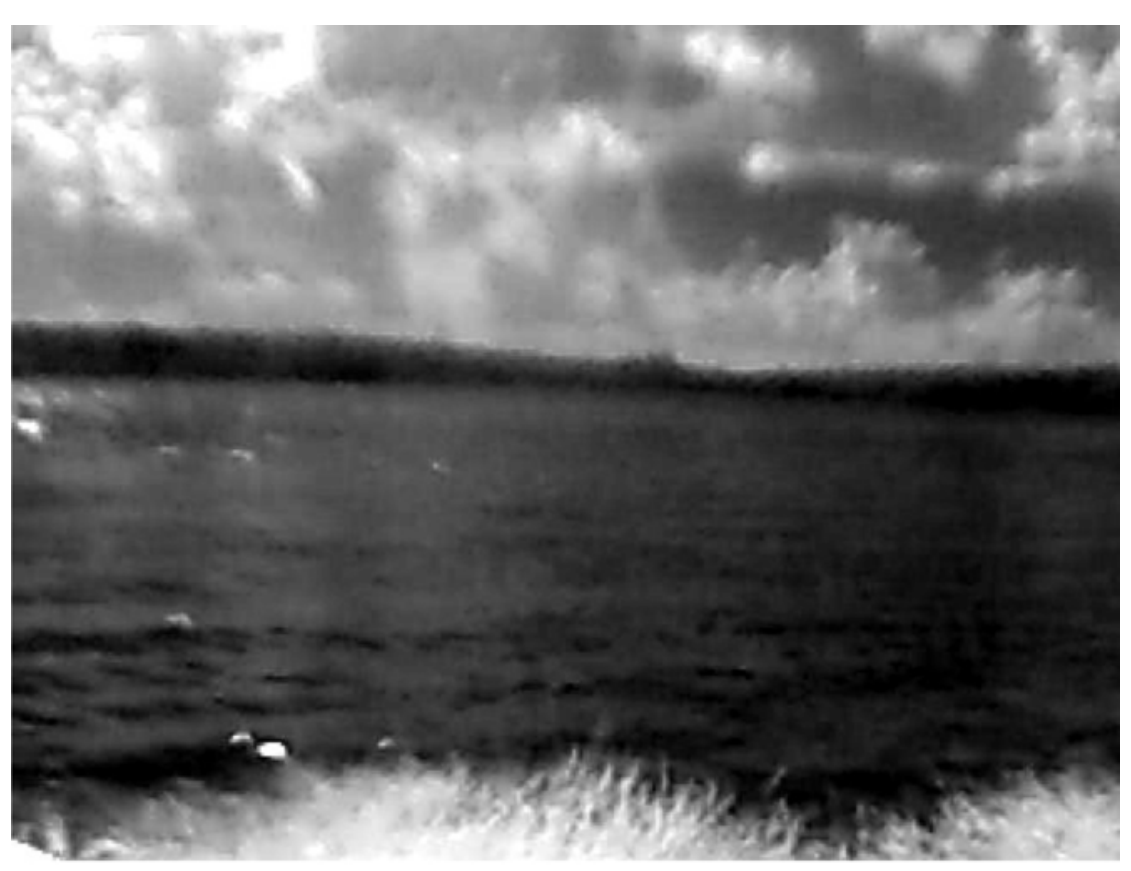

Imagem

A

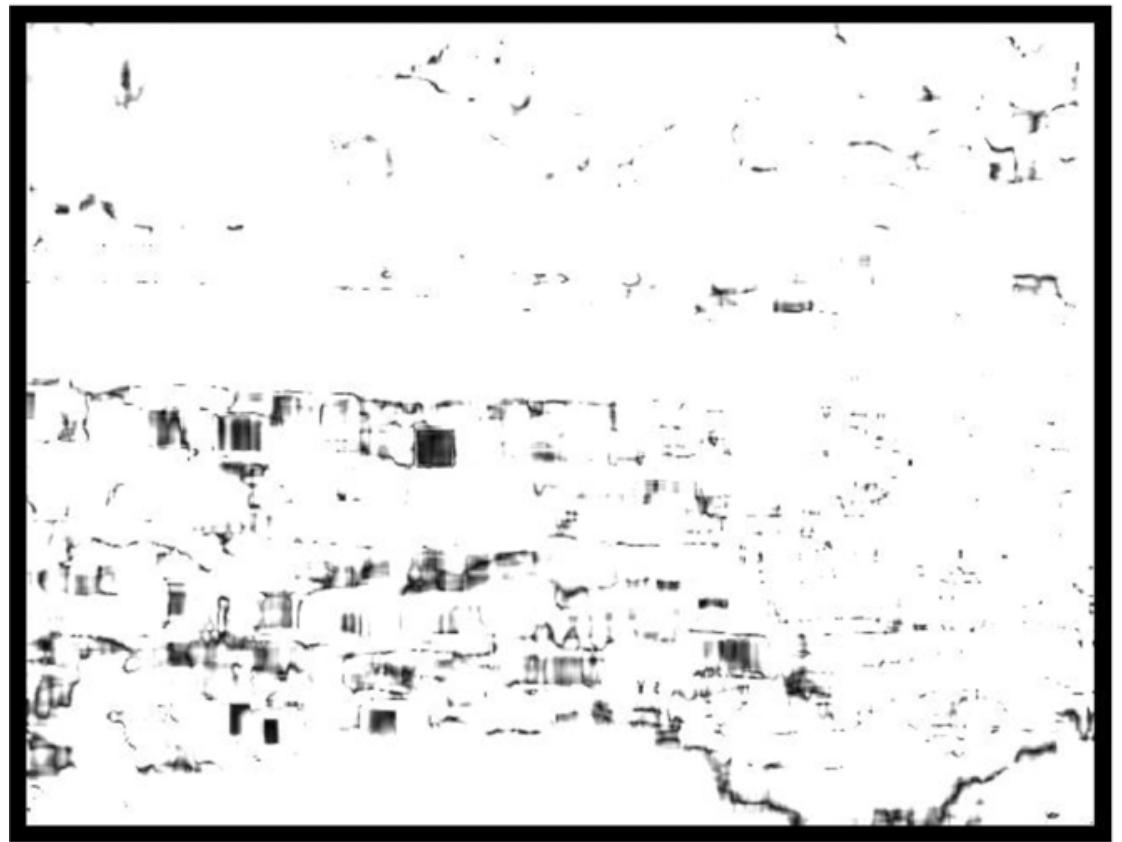

Figura 31. - Resultado de imagens coletadas na represa do Broa-Itirapina-SP com as respectivas imagens de campos potenciais. 


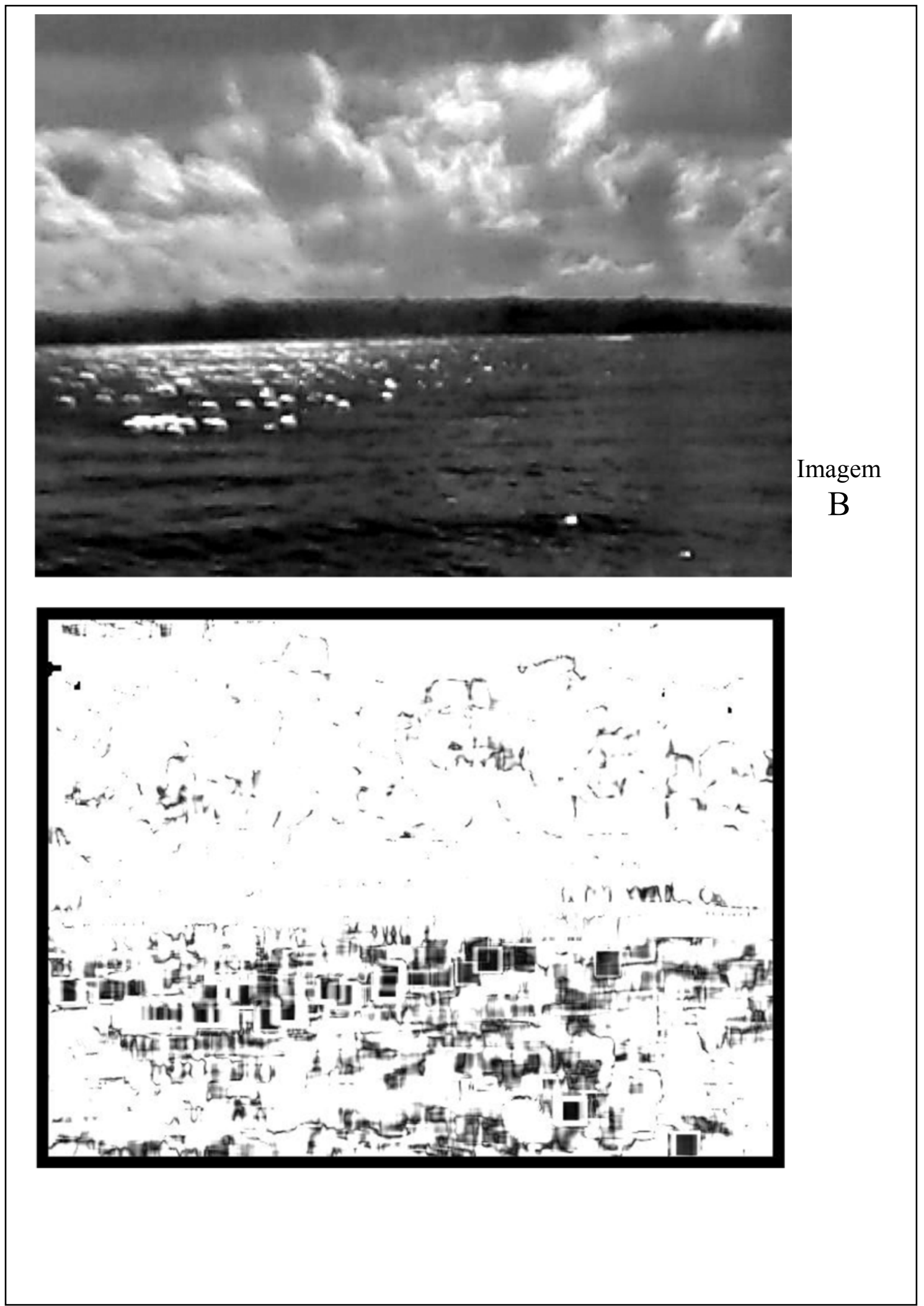

Figura 32.- Resultado de imagens coletadas na represa do Broa-Itirapina-SP com as respectivas imagens de campos potenciais. 


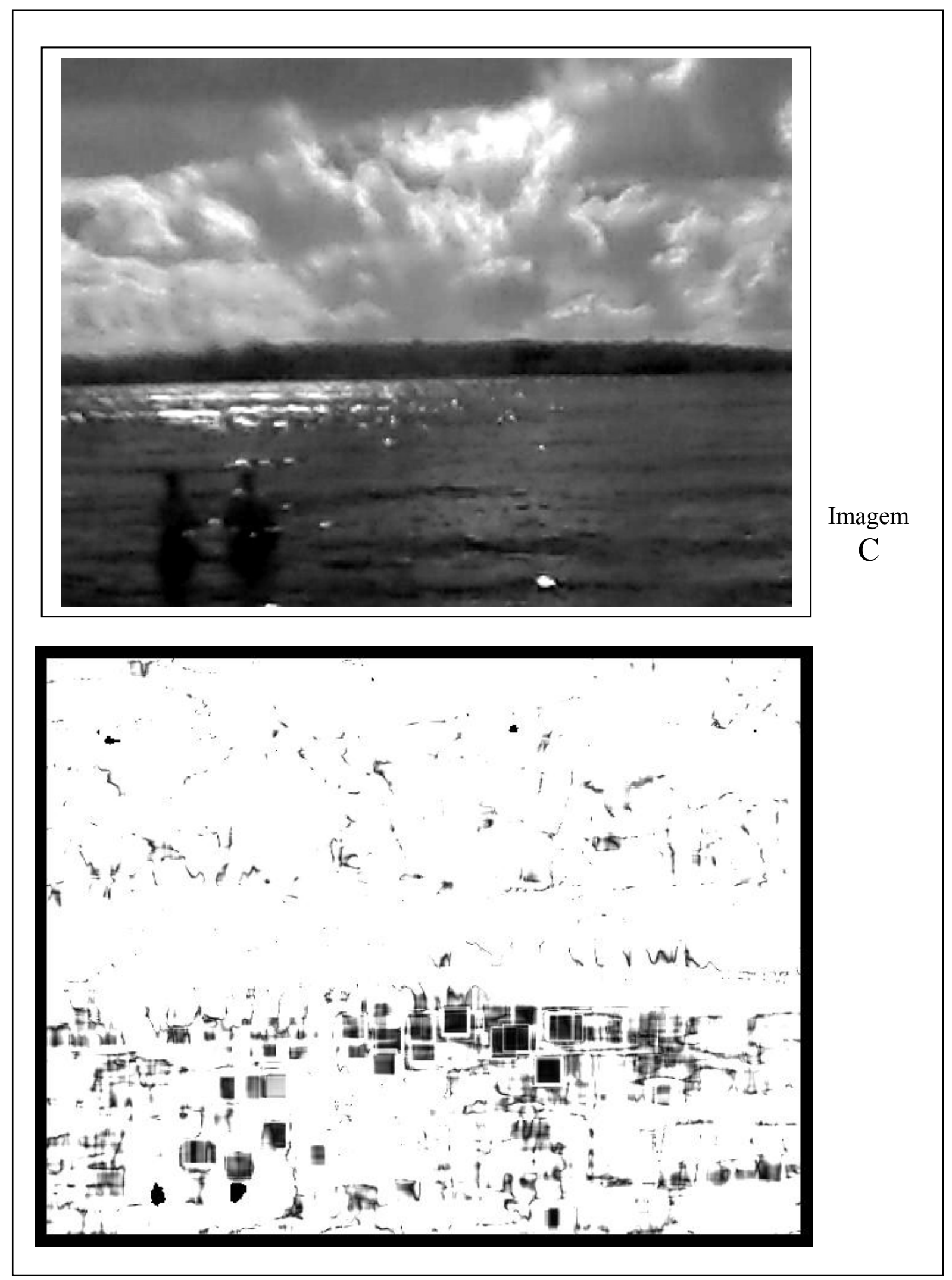

Figura 33. - Resultado de imagens coletadas na represa do Broa-Itirapina-SP com as respectivas imagens de campos potenciais. 


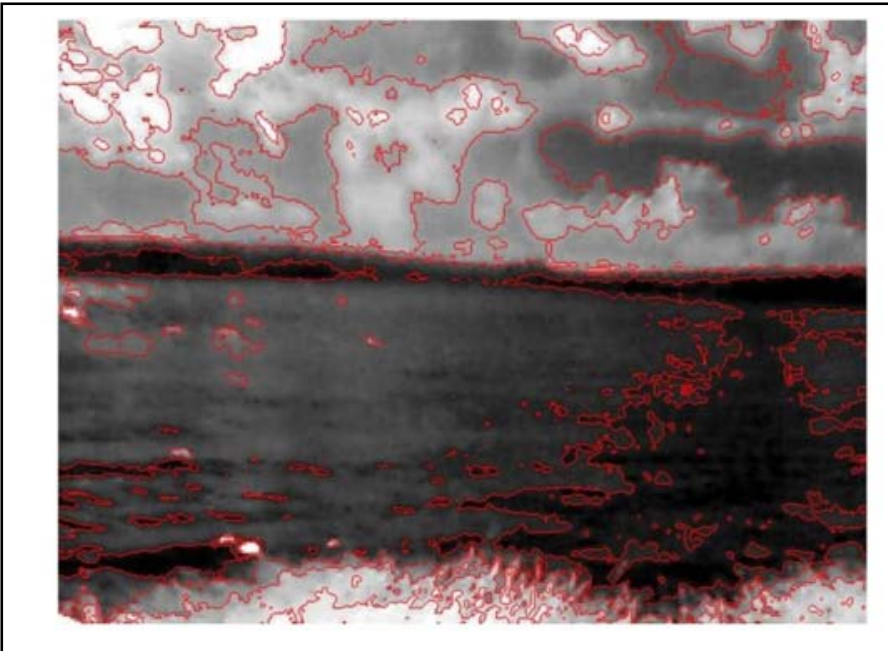

$\mathrm{Ab}$

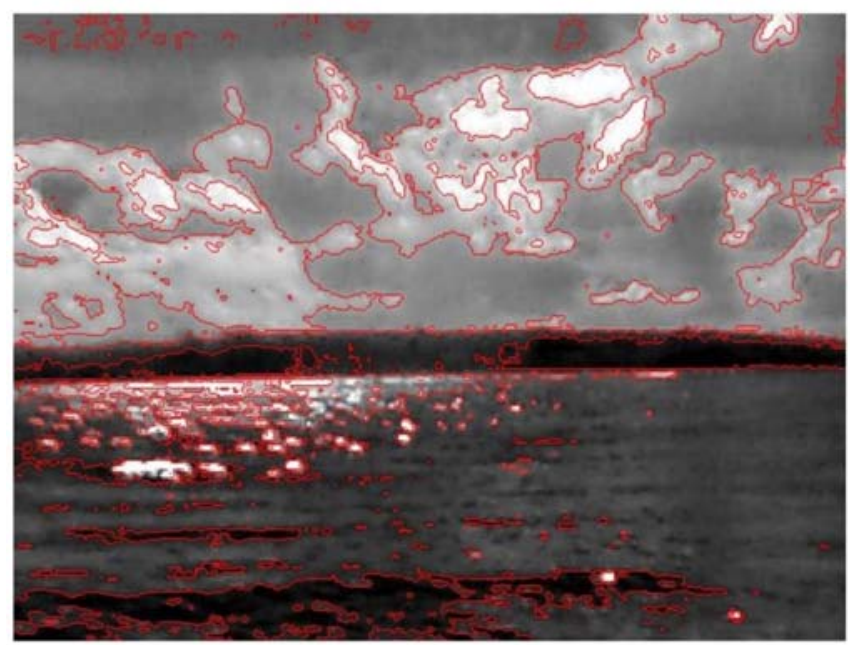

$\mathrm{Bb}$

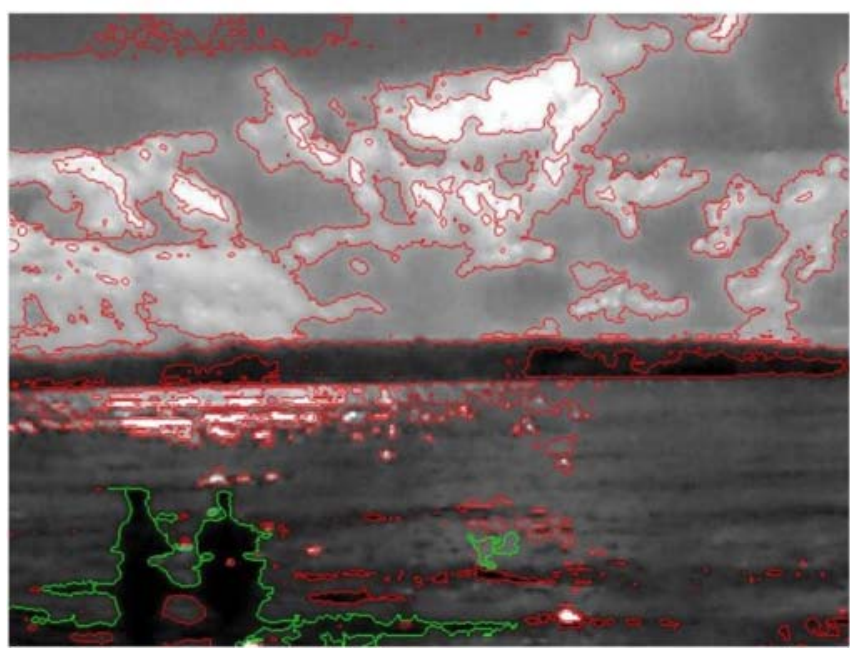

$\mathrm{Cb}$

Figura 34. - Blobs presentes nas imagens coletadas 


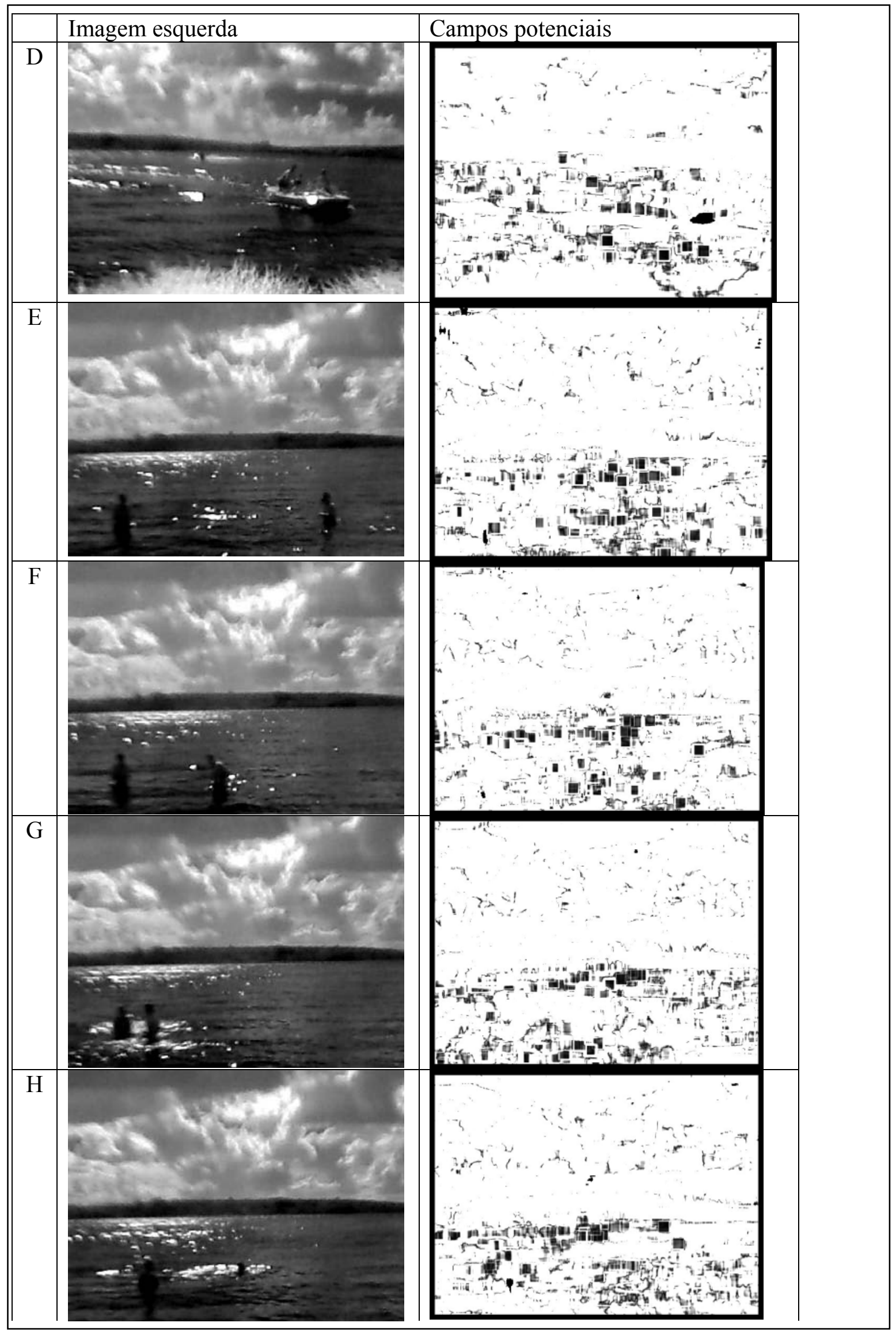


Figura 35. - Resultado de imagens coletadas em Itirapina e comparação de métodos

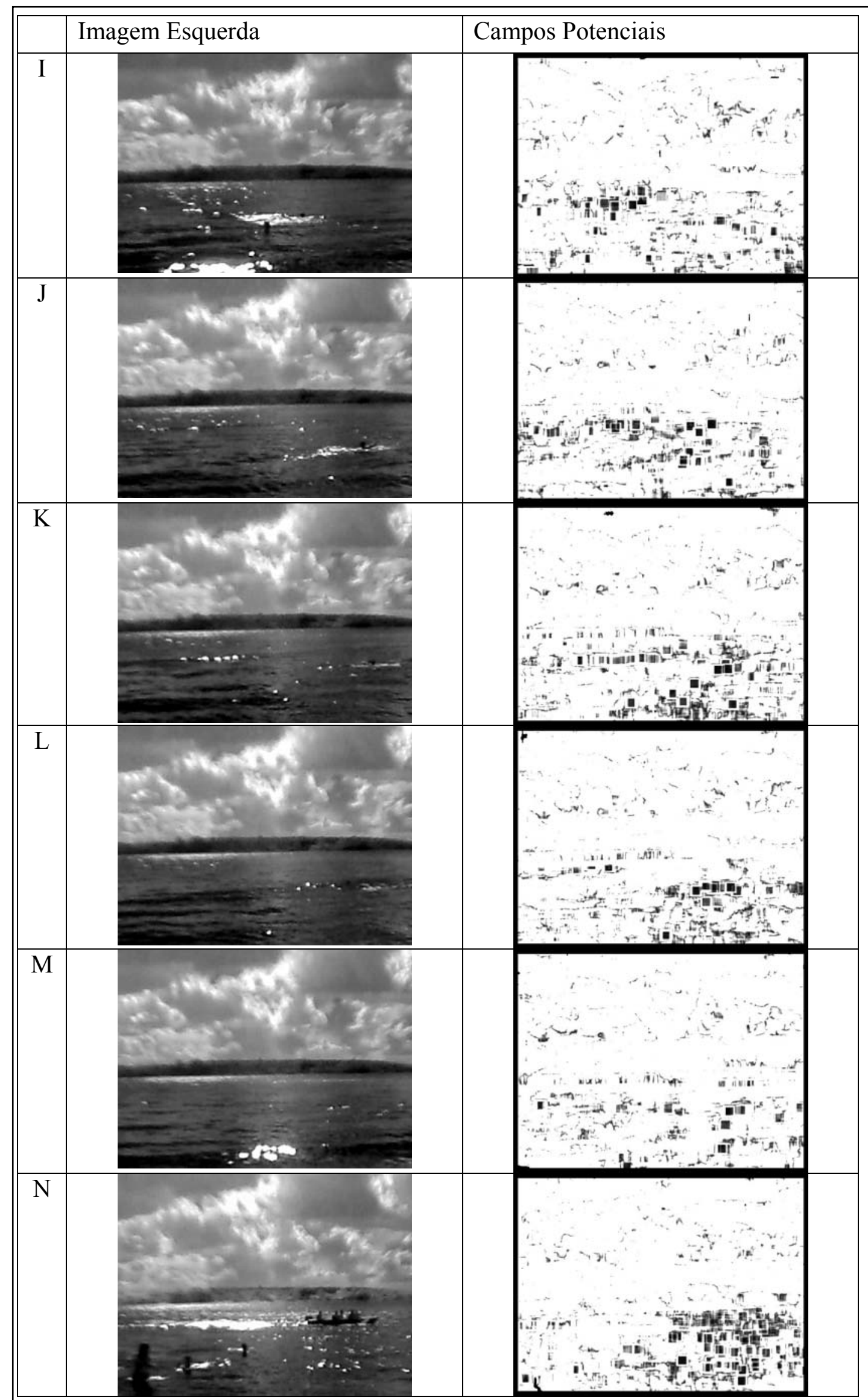


Figura 36. - Resultado de imagens coletadas em Itirapina e comparação de métodos

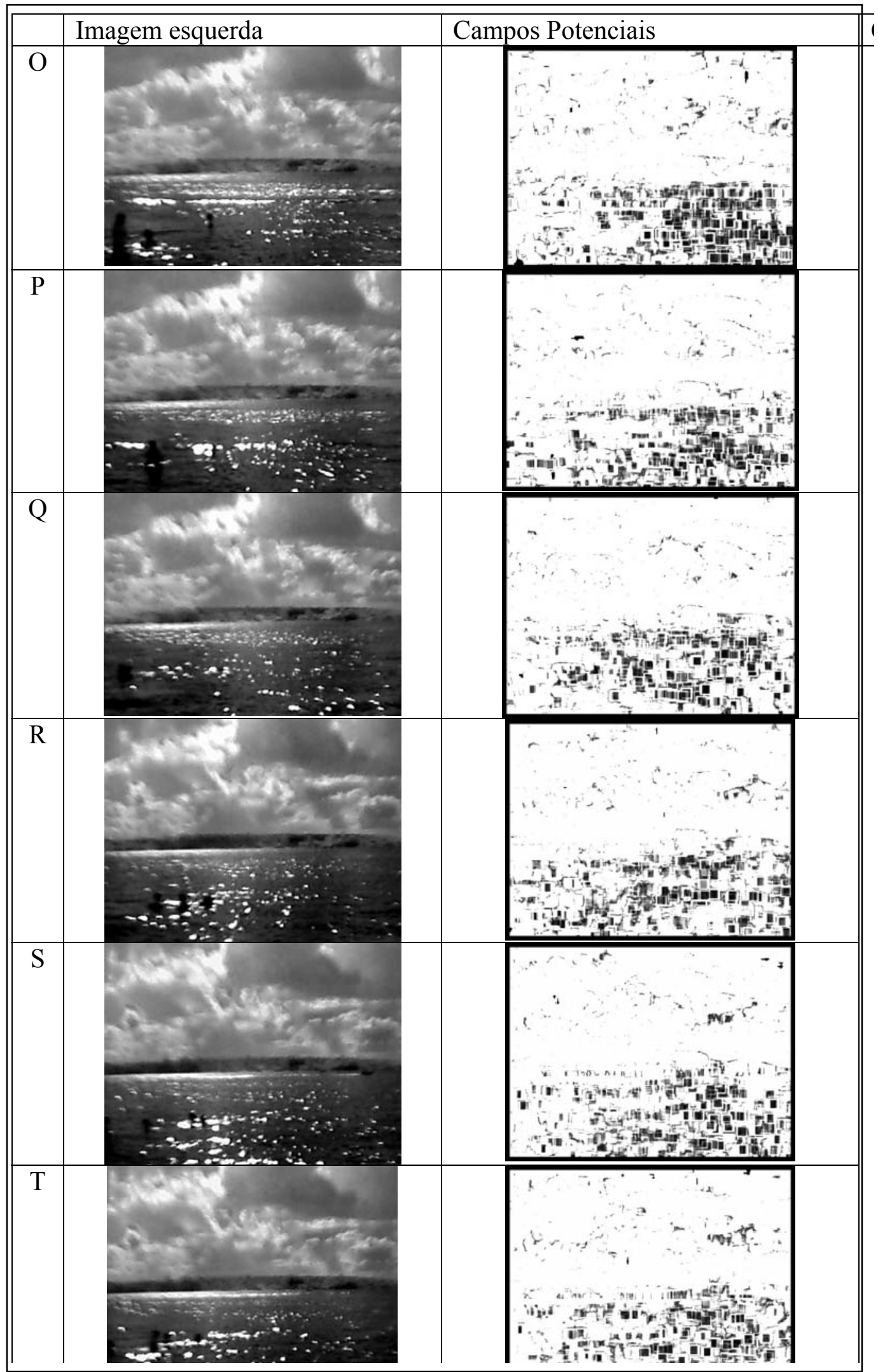

- Figura 37. - Resultado de imagens coletadas em Itirapina e comparação de métodos 


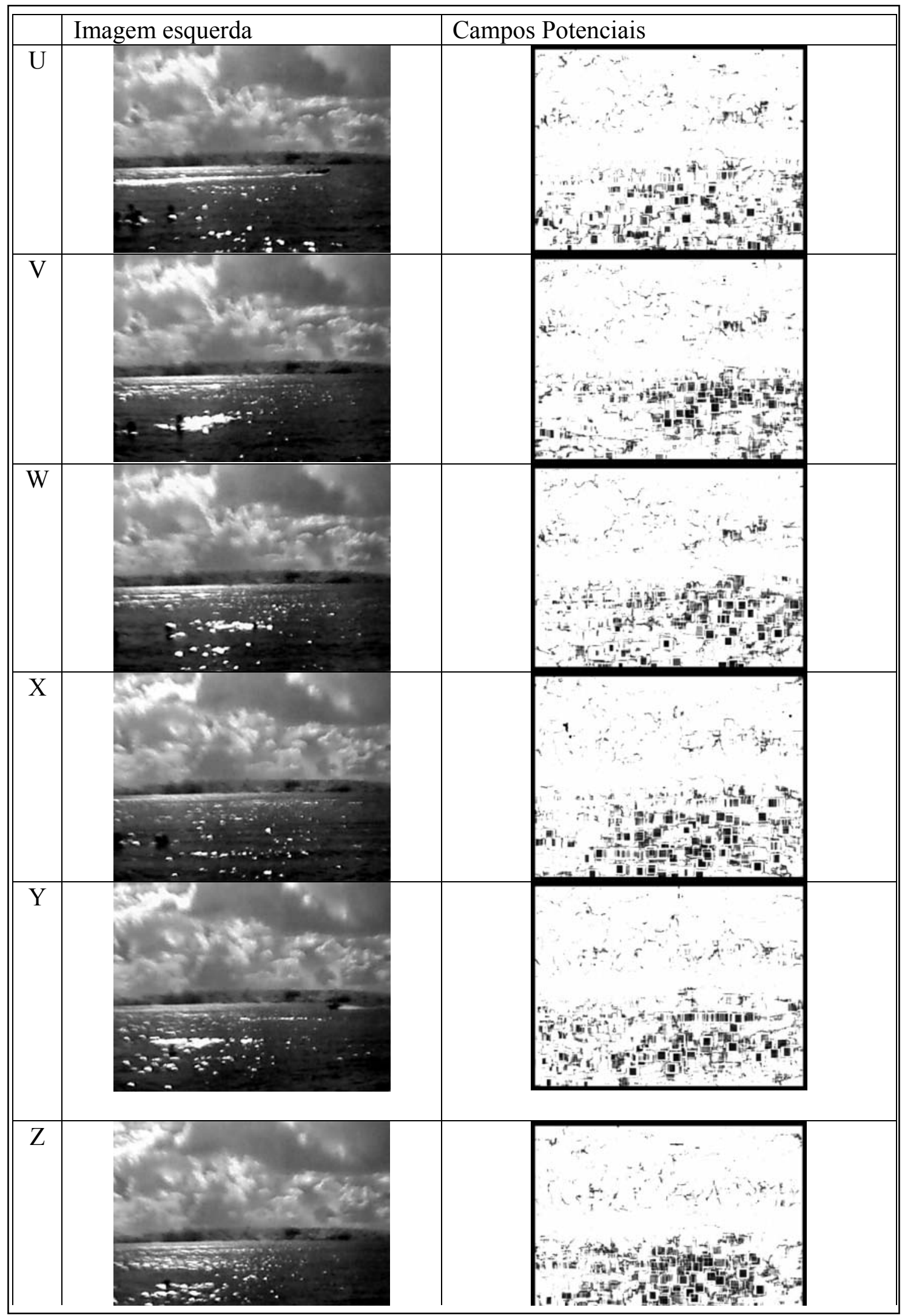

Figura 38. Resultado de imagens coletadas em Itirapina e comparação de métodos 
Tabela 3 - Desempenho do método de Snyder et al (2004) em comparação com o método proposto para imagens contra o sol.

Snyder et al (2004)

Metodo proposto

\begin{tabular}{|c|c|c|c|c|c|c|c|c|}
\hline $\begin{array}{l}\text { Ima- } \\
\text { gem }\end{array}$ & $\begin{array}{l}\text { Obstáculos } \\
\text { presentes }\end{array}$ & $\begin{array}{l}\text { Obstáculos } \\
\text { Oclusos }\end{array}$ & $\begin{array}{l}\text { Obstáculos } \\
\text { Não } \\
\text { Detectados } \\
\text { Snyder et } \\
\text { al (2004) }\end{array}$ & $\begin{array}{l}\text { Obstáculos } \\
\text { Detectados } \\
\text { Snyder et } \\
\text { al (2004) }\end{array}$ & $\begin{array}{l}\text { Falsos } \\
\quad+ \\
\text { Snyder } \\
\text { et al } \\
(\mathbf{2 0 0 4})\end{array}$ & $\begin{array}{l}\text { Obstáculos } \\
\text { Não } \\
\text { Detectados } \\
\text { Método } \\
\text { Proposto }\end{array}$ & $\begin{array}{l}\text { Obstáculos } \\
\text { Detectados } \\
\text { Método } \\
\text { Proposto }\end{array}$ & $\begin{array}{c}\text { Falsos } \\
+\end{array}$ \\
\hline A & 0 & 0 & 0 & 0 & 19 & 0 & 0 & 0 \\
\hline $\mathrm{B}$ & 0 & 0 & 0 & 0 & 42 & 0 & 0 & 0 \\
\hline $\mathrm{C}$ & 2 & 0 & 0 & 2 & 26 & 0 & 2 & 1 \\
\hline $\mathrm{D}$ & 2 & 0 & 0 & 2 & 26 & 0 & 2 & 3 \\
\hline$E$ & 2 & 1 & 1 & 1 & 25 & 0 & 1 & 3 \\
\hline $\mathrm{F}$ & 2 & 0 & 0 & 2 & 13 & 0 & 2 & 0 \\
\hline $\mathrm{G}$ & 2 & 0 & 0 & 2 & 26 & 0 & 2 & 0 \\
\hline $\mathrm{H}$ & 2 & 0 & 0 & 2 & 18 & 0 & 2 & 0 \\
\hline $\mathrm{I}$ & 2 & 0 & 2 & 0 & 19 & 0 & 2 & 2 \\
\hline $\mathrm{J}$ & 1 & 0 & 0 & 1 & 29 & 0 & 1 & 8 \\
\hline $\mathrm{K}$ & 1 & 1 & 1 & 0 & 22 & 1 & 0 & 1 \\
\hline $\mathrm{L}$ & 0 & 0 & 0 & 0 & 19 & 0 & 0 & 4 \\
\hline $\mathrm{M}$ & 1 & 0 & 0 & 1 & 12 & 0 & 1 & 2 \\
\hline $\mathrm{N}$ & 6 & 2 & 2 & 8 & 20 & 0 & 6 & 0 \\
\hline $\mathrm{O}$ & 4 & 1 & 2 & 2 & 47 & 1 & 3 & 0 \\
\hline $\mathrm{P}$ & 4 & 2 & 2 & 2 & 48 & 2 & 2 & 0 \\
\hline$Q$ & 2 & 1 & 1 & 1 & 53 & 1 & 1 & 0 \\
\hline $\mathrm{R}$ & 4 & 1 & 1 & 3 & 54 & 1 & 3 & 0 \\
\hline $\mathrm{S}$ & 4 & 1 & 1 & 3 & 76 & 1 & 3 & 0 \\
\hline $\mathrm{T}$ & 4 & 0 & 1 & 3 & 63 & 0 & 4 & 9 \\
\hline $\mathrm{U}$ & 6 & 1 & 1 & 5 & 32 & 1 & 5 & 16 \\
\hline $\mathrm{V}$ & 4 & 1 & 1 & 3 & 43 & 1 & 3 & 5 \\
\hline W & 3 & 0 & 0 & 3 & 38 & 1 & 2 & 4 \\
\hline$X$ & 2 & 0 & 0 & 2 & 60 & 0 & 2 & 14 \\
\hline $\mathrm{Y}$ & 3 & 1 & 2 & 1 & 36 & 0 & 1 & 0 \\
\hline $\mathrm{Z}$ & 3 & 2 & 2 & 1 & 48 & 0 & 1 & 0 \\
\hline Total & 66 & 15 & 20 & 50 & 914 & 10 & 51 & 72 \\
\hline
\end{tabular}




\section{Capítulo 5 Conclusões}

Para as imagens que foram coletadas propositadamente contra o sol, o método proposto foi significativamente mais eficiente que o método de Snyder. As imagens de campos potenciais obtidas pelo método de fluxo ótico pela proposta de Lucas-Kanade mostraram uma grande quantia de obstáculos falso-positivos, sendo a maioria deles originários pelo brilho das ondas.

Apesar do método desenvolvido ser superior, quando realizamos novos testes de validade externa fomos surpreendidos por brilhos de onda com novos formatos e área. Apesar de tudo, a maioria das ondas foram cortadas pela análise de vetor predominante.

O método abordado possui versatilidade para incorporar novas características dos blobs. Poderia ser extraída por exemplo a cor interna de cada blob. O brilho das ondas possuem coloração muito próximo do branco. Deste modo. se o índice de croma R, G e B forem maiores do que 200, podemos supor que este blob possa entrar em uma região de classificação própria para ondas. Acredita-se que poucos obstáculos reais que tenham a cor branca por inteiro, sem que apareça uma região de uma outra cor.

Os obstáculos que são citados como "não-detectados" são em sua totalidade aqueles que tiveram a imagem oclusa em uma das câmeras, o que é uma limitação natural em análise estéreo por visão.

Estes procedimentos tiveram por função detectar e localizar os obstáculos, e não traçar uma rota de fuga conforme a proposta da teoria de campos potenciais. O planejamento da rota é realizado pelo programa principal do barco, não abordado neste presente trabalho.

No entanto, por ser uma parte do sistema de navegação, tornou-se necessária a determinação muito mais precisa da posição de cada obstáculo para que se envie dados concretos ao sistema. Estas coordenadas do obstáculo não são coletadas no método de campos potenciais. 
Pelo fato do espaço de características para classificação de obstáculos possuir poucos parâmetros, nota-se que a imagem em perspectiva da superfície de um lago consiste de modelo ideal para estudos de reconhecimento de imagens. O método é elegante por reconhecer obstáculos apenas baseando-se em características simples como distância e em forma geral do blob.

Quanto mais aumentamos a amostragem sempre nos deparamos com novas condições que poderiam surpreender o sistema. A superação contínua sempre vai tornando o sistema cada vez mais confiável. Neste caso, como o gráfico de decisões é muito simples, é sempre fácil aumentar os eixos de características. Mesmo que estas características sejam posteriormente reduzidas por mineração de dados, poderíamos ainda reconhecer as diversas classes por análise de cluster.

È importante observar que pela legislação de tráfego em águas brasileiras, toda outra embarcação que se aproximar de uma primeira por boreste (direita), tem o direito à passagem. Deve portanto a primeira embarcação deixar que esta cruze seu caminho, pelo ato chamado na linguagem náutica como “pedir água”. Por decorrência destas normas, é muito importante que em implementações futuras, seja verificada a direção de deslocamento do obstáculo para auxiliar à decisão de desvio. 


\section{Capítulo 6}

\section{Propostas}

Para utilização futura propomos o uso de um módulo GPS GT-3721FW da UniTraqQ International Corp., ilustrado na figura 39, que pode ser conectado a um microcomputador através de seu conversor serial-USB .

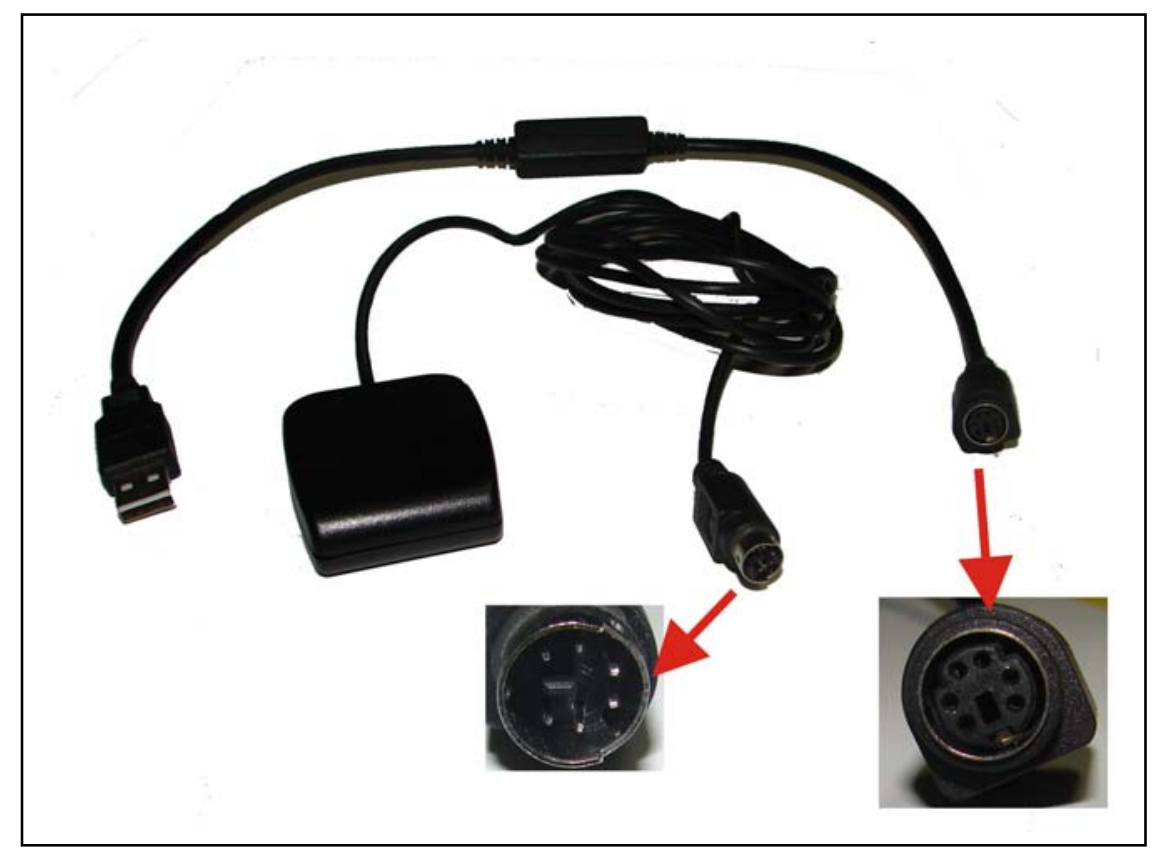

Figura 39. - GPS GT-3721FW da UniTraQ International Corp

Também indicamos para uso futuro uma bússola eletrônica para monitorar a direção em que a imagem é coletada. O modelo proposto é o V2XE da PNI Sensor Corporation ilustrado na figura 40. Esta bússola possui lógica digital com estado alto em $3 \mathrm{~V}$. Para garantir uma comunicação do da bússola com um microcontrolador indicamos o circuito da figura 41, que foi desenhado e simulado para uma futura aplicação.

Para que a bússola e o conversor de tensão se comunicar com a porta USB de um microcomputador é indicado o circuito mostrado na figura 42. Ele tem como componente principal o CI FT232BL da Future Technology Devices International. O fabricante também fornece o drive para ser instalado no microcomputador, para que diferentes linguagens de programação possam ler o sinal USB. 


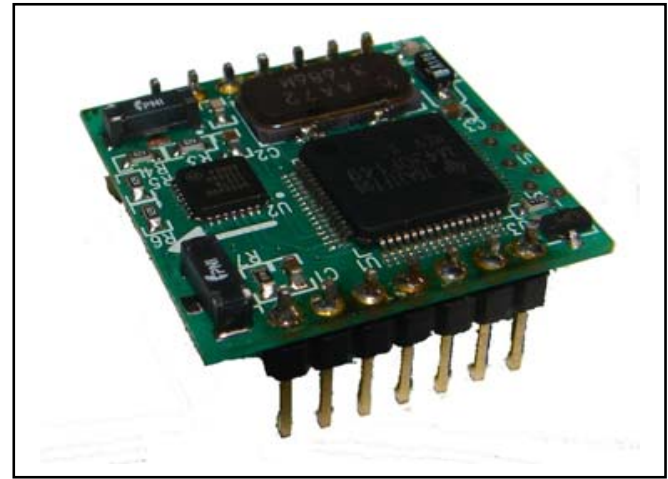

Figura 40. - Bússola V2XE da PNI Sensor Corp

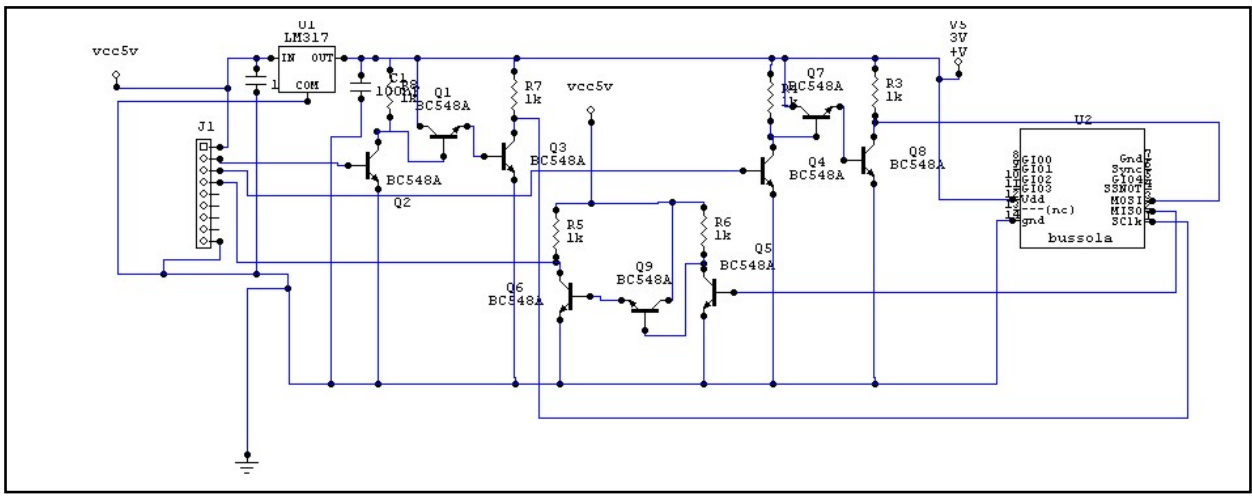

Figura 41. - Circuito de conversão de tensão do sinal digital em 3V da Bússola para o sinal digital TTL em $5 \mathrm{~V}$.

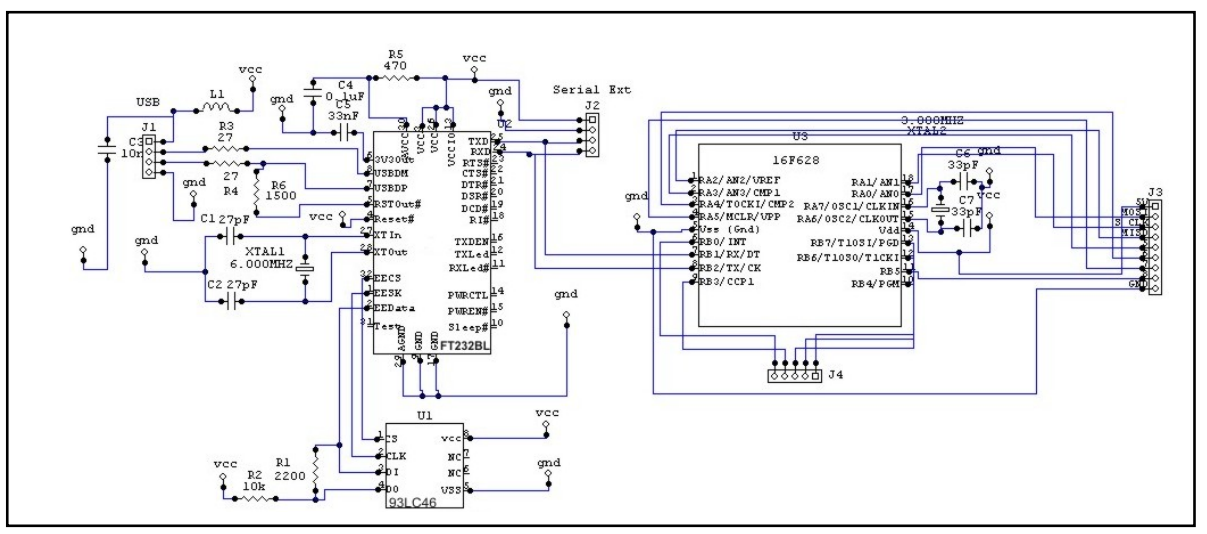

Figura 42. - Circuito para enviar o sinal da bússola para porta USB 


\section{2 - Estimando a distância do barco à margem}

È primordial para nosso método conhecer a distância da margem do fundo de uma imagem ao barco de onde as imagens foram capturadas. Para isso, propomos em uma próxima implementação sejam coletadas uma série de coordenadas por imagem de satélite ao longo do contorno do lago, com intervalo médio de $50 \mathrm{~m}$. Estes pontos são ilustrados na Figura 43.

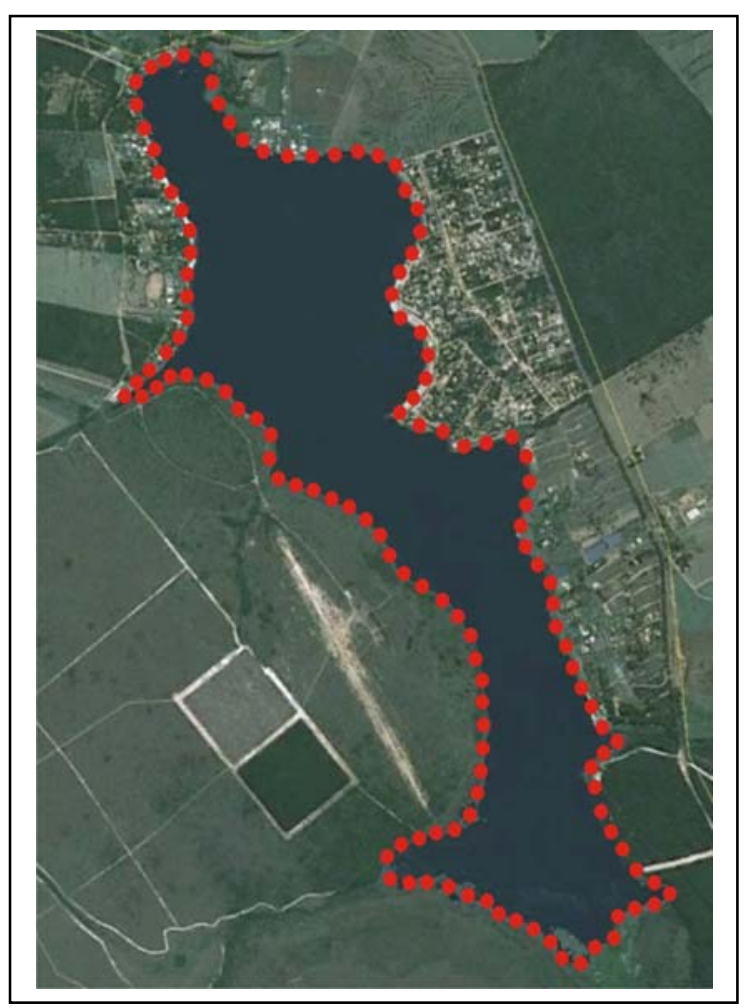

Figura 43. - Represa do Broa em imagem aérea com 164 pontos selecionados ao longo de sua margem.

Sendo estes pontos representados por xmargem e ymargem, o algoritmo proposto para detectar a margem do lago do fundo de uma imagem, tendo a coordenada GPS e o ângulo tomado por uma bússola eletrônica é : 
Para distância_testada = 1 até 630 ; distância testada é o tamanho do eixo ; coordenada polar ; obs. 630 é a tamanho em metro da maior ; distância possível entre duas margens ; convertendo coordenada polar em coordenada cartesiana :

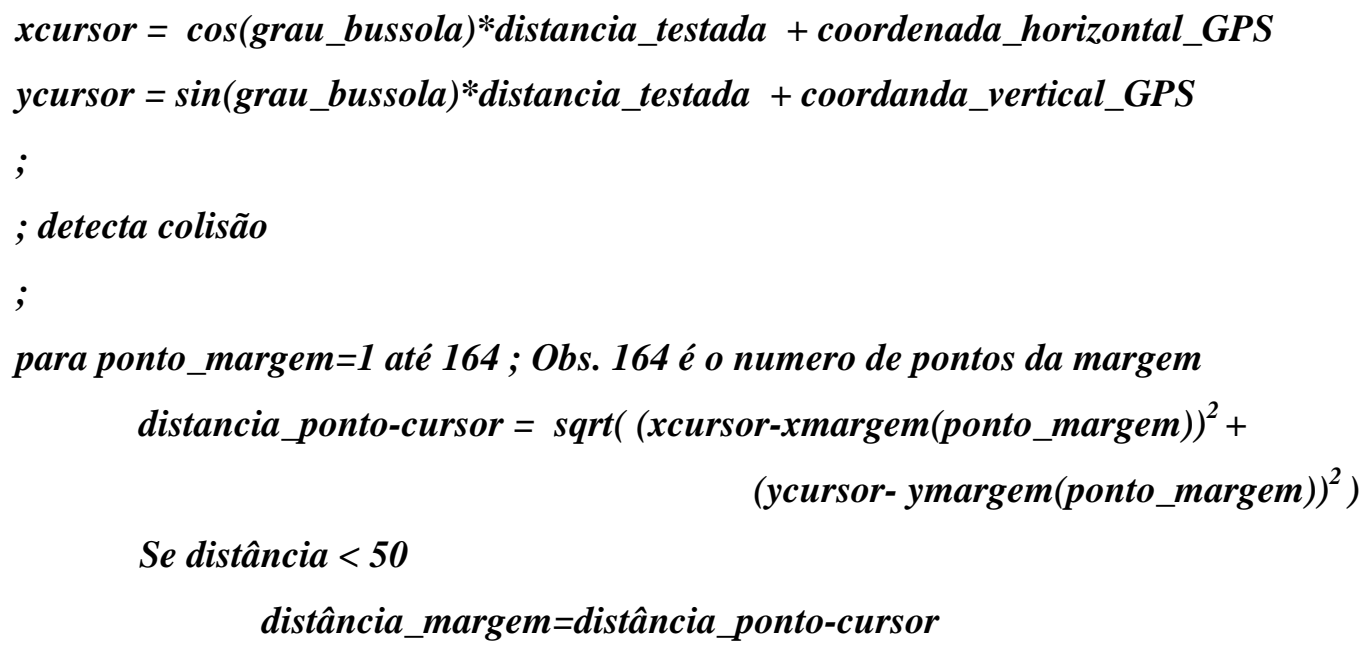

fim distância_testada 


\section{REFERÊNCIAS}

ANTONELLI, G. et al (2001). Real-time path planning and obstacle avoidance for RAIS IEEE Journal of Oceanic Engineering, v.26, n.2, p.216-227

BARISIC, M.; VUKIC, Z.; MISKOVIC, N. (2007). Kinematic simulative analysis of virtual potential field method for AUV trajectory planning. In: MEDITERRANEAN CONFERENCE ON CONTROL AND AUTOMATION, 2007, Athens, Grece [Sl.:s.n]

BHANU, B. et al. (1994). Synergism of binocular and motion stereo for passive Ranging IEEE Transactions on Aerospace and Electronic Systems, v.30, n.3, p.709-721

BOUGUET, J.Y. "Camera Calibration Toolbox for Matlab" disponível on line :

http://www.vision.caltech.edu/bouguetj/calib_doc/. Acessado em 14 de setembro de 2009

BOUXSEIN, P. et al. (2007). A Sonar Simulation used to develop an Obstacle Avoidance System. In: OCEANS 2006 - ASIA PACIFIC, 2007, 2007 16TH IEEE INTERNATIONAL SYMPOSIUM ON THE APPLICATIONS OF FERROELECTRICS, 2007 [Sl.:s.n]

BUI, L. D.; KIM, Y. (2006). An obstacle-avoidance technique for autonomous underwater vehicles based on BK-products of fuzzy relation Fuzzy Sets and Systems, v.157, p.560-577

DOBBINS, T.; SAMWAYS, S. (2003). The use of tactile navigation cues in high speed craft operations The Royal Institution of Naval Architects, [Sl.:s.n]

DUR, E. (2009). Optical Flow-Based Obstacle Detection and avoidance behaviors for mobile robots used in unmanned planetary exploration. in: PROCEEDINGS OF 4TH INTERNATIONAL CONFERENCE ON RECENT ADVANCES SPACE TECHNOLOGIES, 2009, p.638-647

FRANÇA, J. A. et al. (2009). Um novo algoritmo de calibração de um conjunto binocular com um gabarito 1D que realiza deslocamentos irrestritos. In: V WORKSHOP DE VISÃO COMPUTACIONAL ,2009, São Paulo - Brasil [Sl.:s.n]

GAO, J. et al. (2008). A potential field method for bottom navigation of autonomous underwater vehicles. In: PROCEEDINGS OF THE $7^{\text {TH }}$ WORLD CONGRESS ON INTELLIGENT CONTROL AND AUTOMATION, 2008, p.7466- 7470, Chongqing, China

GE, S. S.; CUI, Y. J. (2000). New potential functions for mobile robot path planning IEEE Transactions on robotics and automations, v.16, n.5 p.615-620

GULDNER, J.; UTKIN, V. I. (1995). Sliding mode control for gradient tracking and robot navigation using artificial potential fields IEEE Trans. Robot. Automat., v.11, p.247-254, Apr. 
HANNAL, E.; STRAZNICKY, P.; GOUBRAN ,R. (2008). Obstacle detection for low flying unmanned aerial vehicles using stereoscopic imaging. In: CONFERENCE RECORD - IEEE INSTRUMENTATION AND MEASUREMENT TECHNOLOGY CONFERENCE, 2008, p.113-118, Vancouver Island, Canada

HO ,C. (2010). A stereo vision based target tracking and obstacle avoidance Engineering Materials, v.419-420, p.565-568

HRABAR, S.; SUKHATME, G. (2009). Vision-based navigation through urban canyons Journal of Field Robotics, v.26, n.5, p.431-452

HUBER, E.; KORTENKAMP, D. (1998). Behavior-based approach to active stereo vision for mobile robots Engineering Applications of Artificial Intelligence, v.11, n.2, p.229-243

JOORDENS, M A. (2008). Design of a low cost underwater robotic research platform In: IEEE INTERNATIONAL CONFERENCE ON SYSTEM OF SYSTEMS ENGINEERING, 2008.[S1.:s.n]

KANAKAKIS,V.; VALAVANIS , K. P.; TSOURVELOUDIS , N. C. (2004). Fuzzy-logic based navigation of underwater vehicles Journal of Intelligent and Robotic Systems, v.40 p.45-88

KHANMOHAMMADI, S. et al. (2008). A new artificial intelligence spproach for 2D path planning for underwater vehicles avoiding static and energized obstacles IEEE Congress on Evolutionary

Computation, p.1988- 1995

KOYASU, H.; MIURA, J.; SHIRAI, Y. (2001). Realtime omnidirectional stereo for obstacle detection and tracking in dynamic environments In:IEEE INTERNATIONAL CONFERENCE ON INTELLIGENT ROBOTS AND SYSTEMS, 2001, v.1, p.31-36, Osaka, Japan

KOYASU, H. ; MIURA, J.; SHIRAI, Y. (2003). Mobile robot navigation in dynamic environments using omnidirectional stereo In:PROCEEDINGS - IEEE INTERNATIONAL CONFERENCE ON ROBOTICS AND AUTOMATION, 2003, v.1, p.893-898

LAUREANO, G. T. (2008). Criação de mapas de disparidades empregando análise multi-resolução e agrupamento perceptual. $118 \mathrm{p}$

Dissertação (Mestrado) - Escola de Engenharia de São Carlos, Universidade de São Paulo, São Carlos, 2008.

LI, F.; BRADY, M. (1998). Modeling the ground plane transformation for real-time obstacle detection Computer Vision and Image Understanding v.71, n.1, July, p.137-152

LI, M.; JIA, Y. (2006). Stereo vision system on programmable chip (SVSoC) for small robot navigation In: PROCEEDINGS OF THE 2006 IEEE/RSJ INTERNATIONAL CONFERENCE ON INTELLIGENT ROBOTS AND SYSTEMS, p.1359-1365, 2006, Beijing, China

MANNING, A. (1977). Introdução ao comportamento animal. Rio de Janeiro: Livros Técnicos e Científicos. p.56-67 
MINGXIANG, L.; YUNDE, J. I. A. (2006). Stereo vision system on programmable chip (SVSoC) for small robot navigation. In: PROCEEDINGS OF THE 2006 IEEE/RSJ INTERNATIONAL CONFERENCE ON INTELLIGENT ROBOTS AND SYSTEMS, 2006, p.1359-1365

MOGHADAM, P.; WIJESOMA, W. S.; FENG, D. J. (2008). Improving path planning and mapping based on stereo vision and liar. In:10TH INTL. CONF. ON CONTROL, AUTOMATION, ROBOTICS AND VISION, 2008, p.384-389, Hanoi, Vietnam

MOLTON, N.; BRADY, M. (2000). Practical structure and motion from stereo when motion is unconstrained International Journal of Computer Vision v.39(1), p.5-23

NABBE, B. et al. (2006). Opportunistic use of vision to push back the path-planning horizon. In: PROCEEDINGS OF THE 2006 IEEE/RSJ INTERNATIONAL CONFERENCE ON INTELLIGENT ROBOTS AND SYSTEMS, 2006, p.2388-2393

NARA', S.; TAKAHASHI, S. (2006). Obstacle avoidance control for mobile robots based on vision. In: 2006 SICE-ICASE INTERNATIONAL JOINT CONFERENCE, 2006, p.5335-5338

NOLAN, S. P.; TOAL, D.; EWALD, H. (2005). A novel wideangle ultrasonic sensor utilizing a curved radiator developed for use in an AUV obstacle avoidance system Oceans - Europe p.1101-1106

ODA, N. ; SHIMIZU, H. (2006). Vision based control for power assist motion of wheelchair robots. In: 2006 SICE-ICASE INTERNATIONAL JOINT CONFERENCE, 2006, p.5323-5328

OHNISHI, N.; IMIYA, A. (2007). Corridor navigation and obstacle avoidance using visual potential for mobile robot. In: PROCEEDINGS OF 2007 INTERNATIONAL SYMPOSIUM ON PHYSICAL DESIGN, 2007, p.127-134

PATNAIK, S.; KONAR, A.; MANDAL, A. K. (2002). Building 3-D visual perception of a mobile robot employing extended Kalman filter Journal of Intelligent and Robotic Systems: Theory and Applications, v.34, n.1, p.99-120

PEBODY, M. (2008). Autonomous underwater vehicle collision avoidance for under-ice exploration Proc. IMechE Vol. 222 Part M: J. Engineering for the Maritime Environment p.53-66

POLYCHRONOPOULOS; A. et al. (2004) Dynamic situation and threat assessment for collision warning systems: The EUCLIDE approach. In: IEEE INTELLIGENT VEHICLES SYMPOSIUM, PROCEEDINGS, 2004, p.636-641

QUEK, B. K.; IBAÑEZ-GUZMÁN, J.; LIM, K. W. (2005). Feature-based perception for autonomous unmanned navigation. In:IECON PROC. (INDUSTRIAL ELECTRONICS CONFERENCE) 2005, p.1791-1796

QUNJIE, D.; MINGJUN, Z. (2006). Research on real time path planning method for the underwater robot in unknown environment with random shape obstacle. In: PROCEEDINGS OF THE 2006 IEEE INTERNATIONAL CONFERENCE ON MECHATRONICS AND AUTOMATION, 2006, p.757-761 
REBUT, J. ; TOULMINET, G. ; BENSRHAIR, A. (2004). Road obstacles detection using a selfadaptive stereo vision sensor : a contribution to the ARCOS french project. In: IEEE INTELLIGENT VEHICLES SYMPOSIUMUNIVERSITY OF PARMA, 2004, Parma, Italy. [Sl.:s.n]

RUIZ, A. R. J.; GRANJA, F. S. (2009). A short-range ship navigation system based on Ladar IEEE Transactions on intelligent transportation systems, v.10, n.1, p.186-187

SAURAV, K. (2009). Binocular stereo bision based obstacle avoidance algorithm for autonomous mobile robots. In: 2009 IEEE INTERNATIONAL ADVANCE COMPUTING CONF, 6-7 March 2009 p. 254- 259 Patiala Índia.

STAVARENGO, A. A. (2006). Telemetria de dados e imagens para plataforma autônoma para coleta de dados hidrológicos. $199 \mathrm{p}$

Dissertação (Mestrado) - Escola de Engenharia de São Carlos, Universidade de São Paulo, São Carlos, 2006.

SNYDER, F. D. Et al. (2004). Autonomous river navigation. In: 2004 PROCEEDINGS OF SPIE - THE INTERNATIONAL SOCIETY FOR OPTICAL ENGINEERING, 2004, n.28, p. 221-232

SONGMIN J. et al. (2007). Obstacle recognition for a mobile robot in indoor environments using RFID and stereo vision. In: PROCEEDINGS OF THE 2007 IEEE INTERNATIONAL CONFERENCE ON MECHATRONICS AND AUTOMATION, August 5-8, 2007, Harbin, China, p.2789-2794

STILLER, C. et al. (2000). Multi-sensor obstacle detection and tracking Image and Vision Computing, v.18, n.5, p.389-396

SVASTA , P. M.; HAPENCIUC, I. A. (2009). Autonomous multi-sensor platform with stereo vision. In: ISSE 2009: 32ND INTERNATIONAL SPRING SEMINAR ON ELECTRONICS TECHNOLOGY: HETERO SYSTEM INTEGRATION, THE PATH TO NEW SOLUTIONS IN THE MODERN ELECTRONICS - CONFERENCE PROCEEDINGS, 2009. [Sl.:s.n]

TAN, C. S.; SUTTON R.; CHUDLEY, J. (2007). An integrated collision avoidance system for autonomous underwater vehicles International Journal of Control, v.80, n.7, p.1027-1049

TOAL, D. J. F. et al. (2005). Proximal object and hazard detection for autonomous underwater vehicle with optical fibre sensors Robotics and Autonomous Systems v.53, p.214-229

TSUGAWA, S. (1994). Vision-based vehicles in Japan: Machine vision systems and driving control. IEEE Transactions on Industial Electronics, v.41 n.4 p.398-405

VINCENT, C. Y. ; TJAHJADI, T. (2005). Planar direct method: a new framework for stereo vision based guidance and obstacle detection. In: PROCEEDINGS - INTERNATIONAL CONFERENCE ON IMAGE PROCESSING, ICIP, 2005, v.3, p. 381-384

WALLNER, F.; DILLMANN, R. (1995). Real-time map refinement by use of sonar and active stereo-vision Robotics and Autonomous Systems, v.16, p.47-56 
WEKEL, T.; KROLL-PETERS, O.; ALBAYRAK, S. (2008). Vision based obstacle detection for wheeled robots In: INTERNATIONAL CONFERENCE ON CONTROL, AUTOMATION AND SYSTEMS 2008 OCT. 14-17, 2008 IN COEX, p.1587-1592, Seoul, Korea

WU, X et al. (2006). Line of sight guidance with intelligent obstacle avoidance for autonomous underwater vehicles Oceans, art. n. 4098946 [S1.:s.n]

XU, W. et al. (2006). First results of a novel and low power forward looking sonar technology for small AUV's Oceans, art. n.4099147 [Sl.:s.n]

YAVIN,Y ; ZILMAN ,G. ; MILOH ,T. Ship maneuverability in finite depth water in the vicinity of an obstacle. A stochastic control approach Computers Math. Applic., v.30, n.10, p.103-117, 1995

YE, X. et al Infrared motion guidance and obstacle avoidance of an ICPF actuated underwater microrobot. In: PROCEEDINGS OF THE 2007 IEEE INTERNATIONAL CONFERENCE ON MECHATRONICS AND AUTOMATION August 5 - 8, 2007, Harbin, China, p. 1851- 1856, 2007

YOON, S.; ROH, K. S.; SHIM ,Y. Vision-based obstacle detection and avoidance: application to robust indoor navigation of mobile robots Advanced Robotics, v.22, p.477-492, 2008

ZHANG, Z.; WEISS, R.; HANSON, A. R. Obstacle detection based on qualitative and quantitative 3D reconstruction IEEE Trans on Pattern Analysis and Machine Intelligence, v.19, n.1, p.15- 26, 1997

ZENG, X.; ITO, M.; SHIMIZU, E. - Collision avoidance of moving obstacles for ship with genetic algorithm in: INTERNATIONAL WORKSHOP ON ADVANCED MOTION CONTROL, AMC, pp. 513-518, 2000 


\section{APÊNDICE A - Rotinas Desenvolvidas}

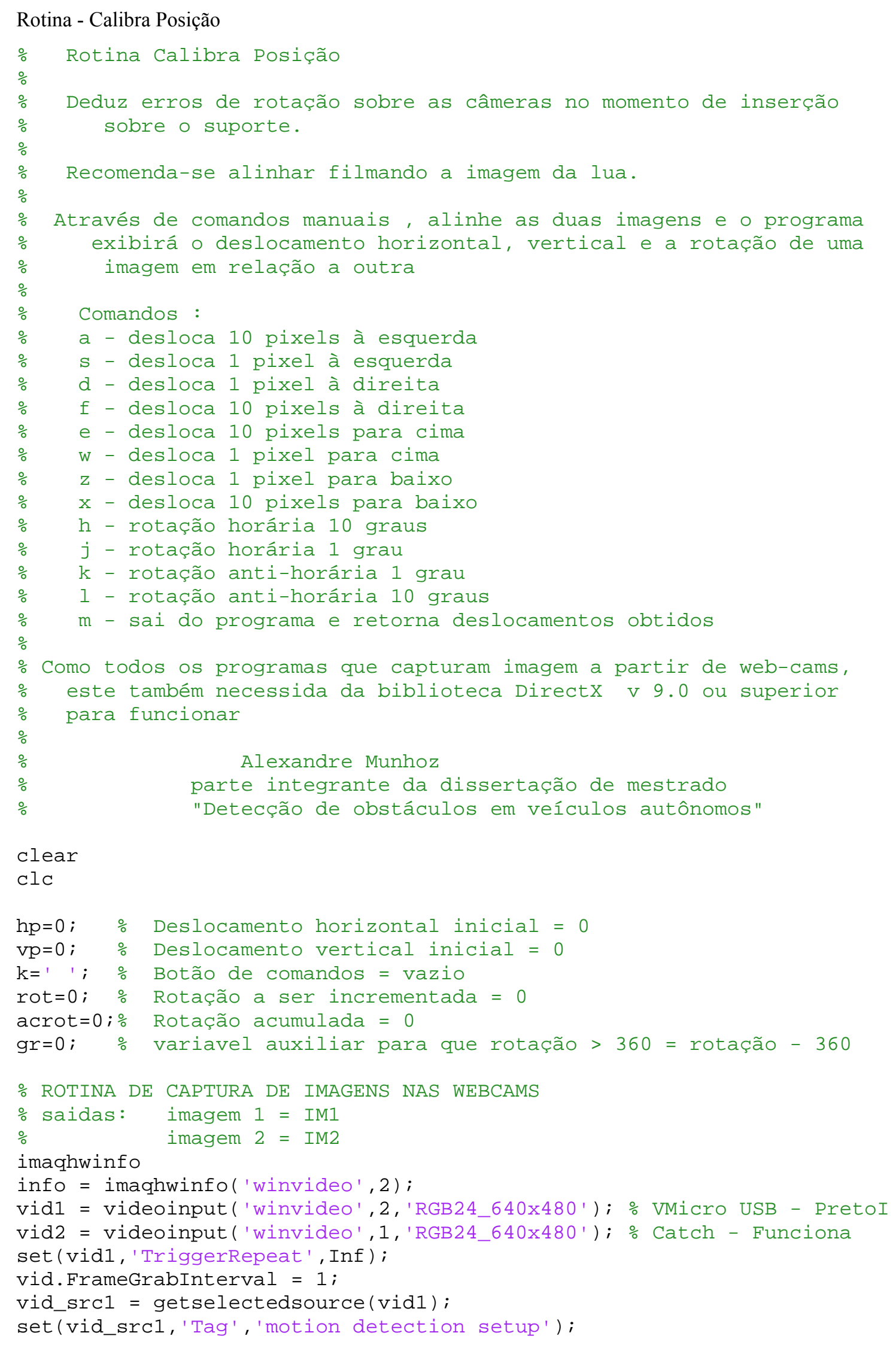




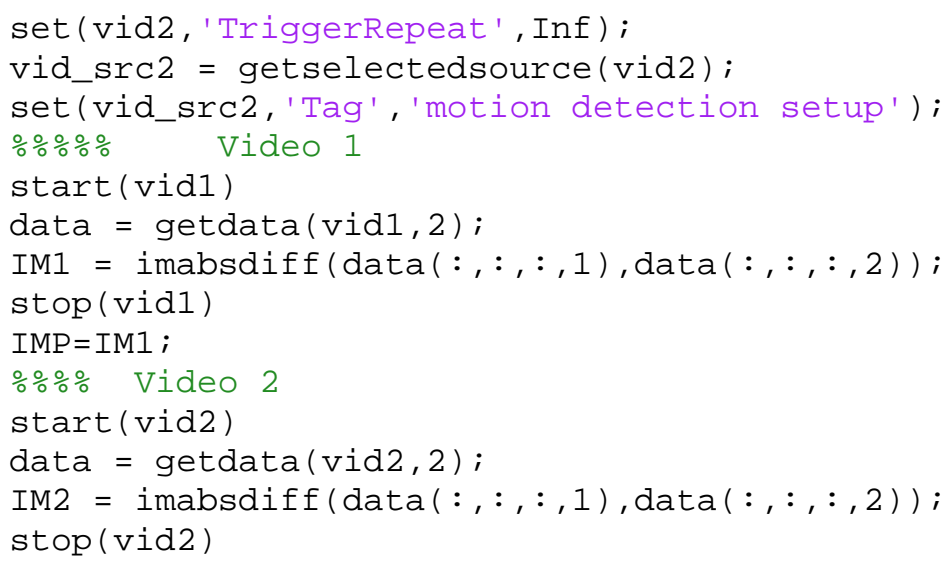

for $h=1: 1: s(2) \%$ Varrendo a imagem na horizontal para Redesar com novo deslocamento $\mathrm{hc}=\mathrm{h}+\mathrm{hp} ; \quad \%$ coordenada horizontal $(\mathrm{hc})=$ looping $(\mathrm{h})+$ deslocamento $(\mathrm{hp})$

if $(v c>=1 \& \& h c>=1 \& \&$ $v c<=s(1) \& \& h c<=s(2)) \%$ se coordenadas não forem $\%$ negativas, nem maior que limites da imagem $\operatorname{IM3}(\mathrm{v},(h * 2)-1,1)=\operatorname{IMP}(\mathrm{vc}, \mathrm{hc}, 1) ; \%$ põe pixel vermelho da imagem $1 \mathrm{em}$ coordenada impar

$\operatorname{IM3}(\mathrm{v},(\mathrm{h} * 2)-1,2)=\operatorname{IMP}(\mathrm{Vc}, \mathrm{hc}, 2) ; \%$ põe pixel verde da imagem 1 em coordenada impar

$\operatorname{IM3}(\mathrm{v},(\mathrm{h} * 2)-1,3)=\operatorname{IMP}(\mathrm{vc}, \mathrm{hc}, 3) ; \%$ põe pixel azul da imagem 1 em coordenada impar

end 
Rotina - Calibra Posição

$\operatorname{IM} 3(\mathrm{v},(\mathrm{h} * 2), 1)=\operatorname{IM} 2(\mathrm{v}, \mathrm{h}, 1) ; \%$ põe pixel vermelho da imagem 2 em coordenada par

$\operatorname{IM} 3(\mathrm{v},(\mathrm{h} * 2), 2)=\operatorname{IM} 2(\mathrm{v}, \mathrm{h}, 2) ; \%$ põe pixel verde da imagem 2 em coordenada par par $\operatorname{IM} 3(v,(h * 2), 3)=\operatorname{IM} 2(v, h, 3) ; \%$ põe pixel azul da imagem 2 em coordenada

end

end

\% Exibindo imagens sobrepostas

figure (3)

imshow(IM3);

$\%$ Exibindo comandos

title (' $[\mathrm{a}]=<-<-\quad[\mathrm{s}]=<-\quad[\mathrm{d}]=->\quad[\mathrm{f}]=->->\quad[\mathrm{e}]=\wedge \wedge \quad[\mathrm{W}]=\wedge \quad[\mathrm{z}]=\mathrm{v}$ $[\mathrm{x}]=\mathrm{vV}[\mathrm{h}]=))$ rot.clock $[\mathrm{j}]=)$ rot.clock $\quad[\mathrm{k}]=($ rot.cont.clock

$[1]=(($ rot. contclock');

$\%$ Lendo comando

k=input ( '- ->>', 's');

if $\mathrm{k}==^{\prime} \mathrm{s}$ ' \% Se comando = s então deslocamento horizontal decrementa 1 end $\mathrm{hp}=\mathrm{hp}-1$

if $\mathrm{k}==^{\prime} \mathrm{d}$ ' \% Se comando = s então deslocamento horizontal incrementa 1 end $h p=h p+1$

if $\mathrm{k}=={ }^{\prime} \mathrm{w}$ ' \% Se comando $=\mathrm{w}$ então deslocamento vertical decrementa 1 $v p=v p-1$

end

if $\mathrm{k}==^{\prime} \mathrm{z}$ ' \% Se comando $=\mathrm{z}$ então deslocamento vertical incrementa 1 end $v p=v p+1$

if $\mathrm{k}==^{\prime} \mathrm{a}$ ' \% Se comando = a então deslocamento horizontal decrementa 10 end $\mathrm{hp}=\mathrm{hp}-10$

if $\mathrm{k}==^{\prime} \mathrm{f}$ ' \% Se comando $=f$ então deslocamento horizontal incrementa 10 end $\mathrm{hp}=\mathrm{hp}+10$

if $\mathrm{k}=={ }^{\prime} \mathrm{e}$ \% Se comando = e então deslocamento vertical decrementa 10 end $\mathrm{vp}=\mathrm{vp}-10$

if $\mathrm{k}==^{\prime} \mathrm{x}$ ' \% Se comando $=x$ então deslocamento vertical incrementa 10 end $\mathrm{vp}=\mathrm{vp}+10$

if $k==^{\prime} j$ ' \% Se comando $=j$ então rotação incrementa 1 rot $=\operatorname{rot}+1$ 
Rotina - Calibra Posição

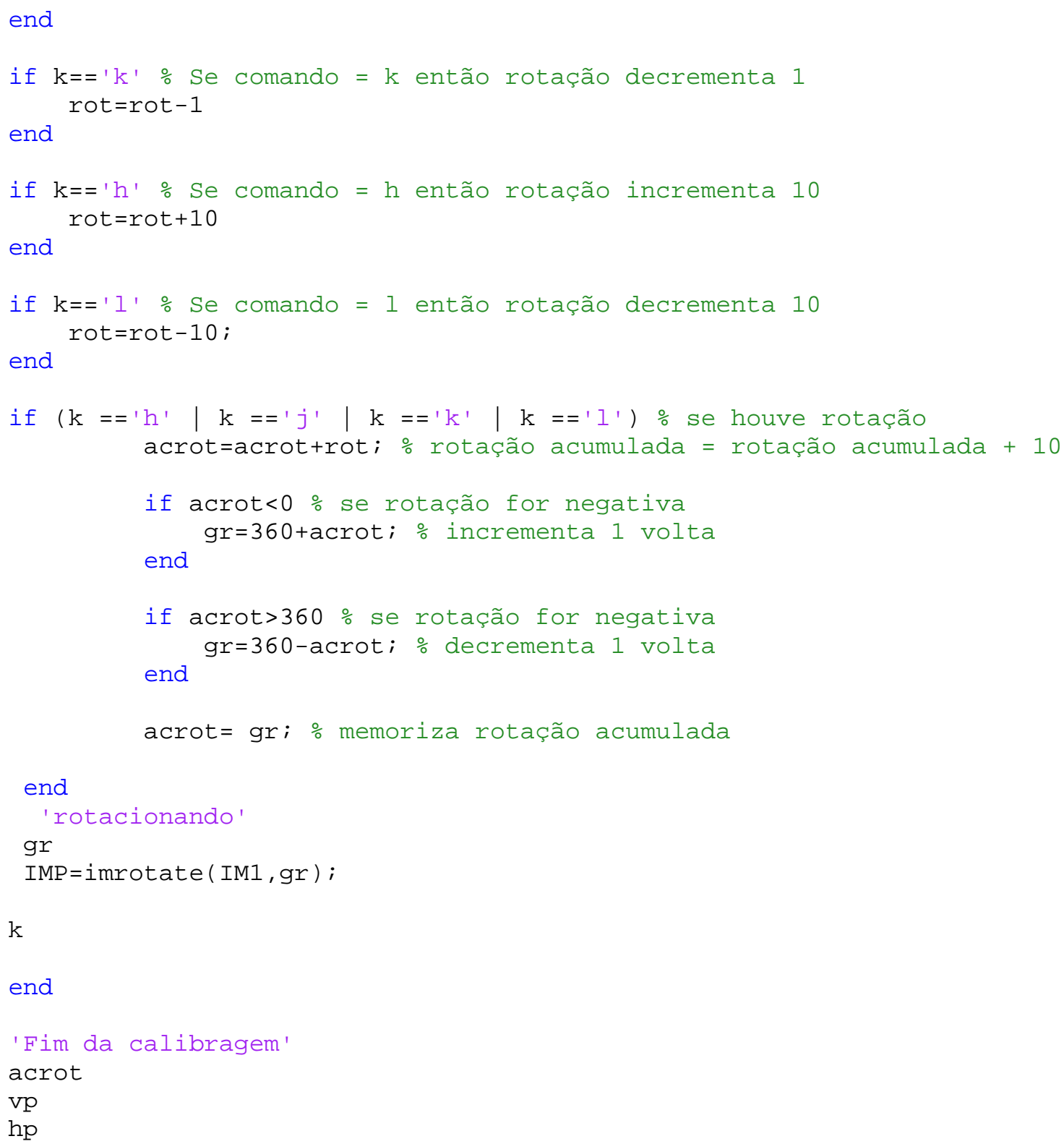




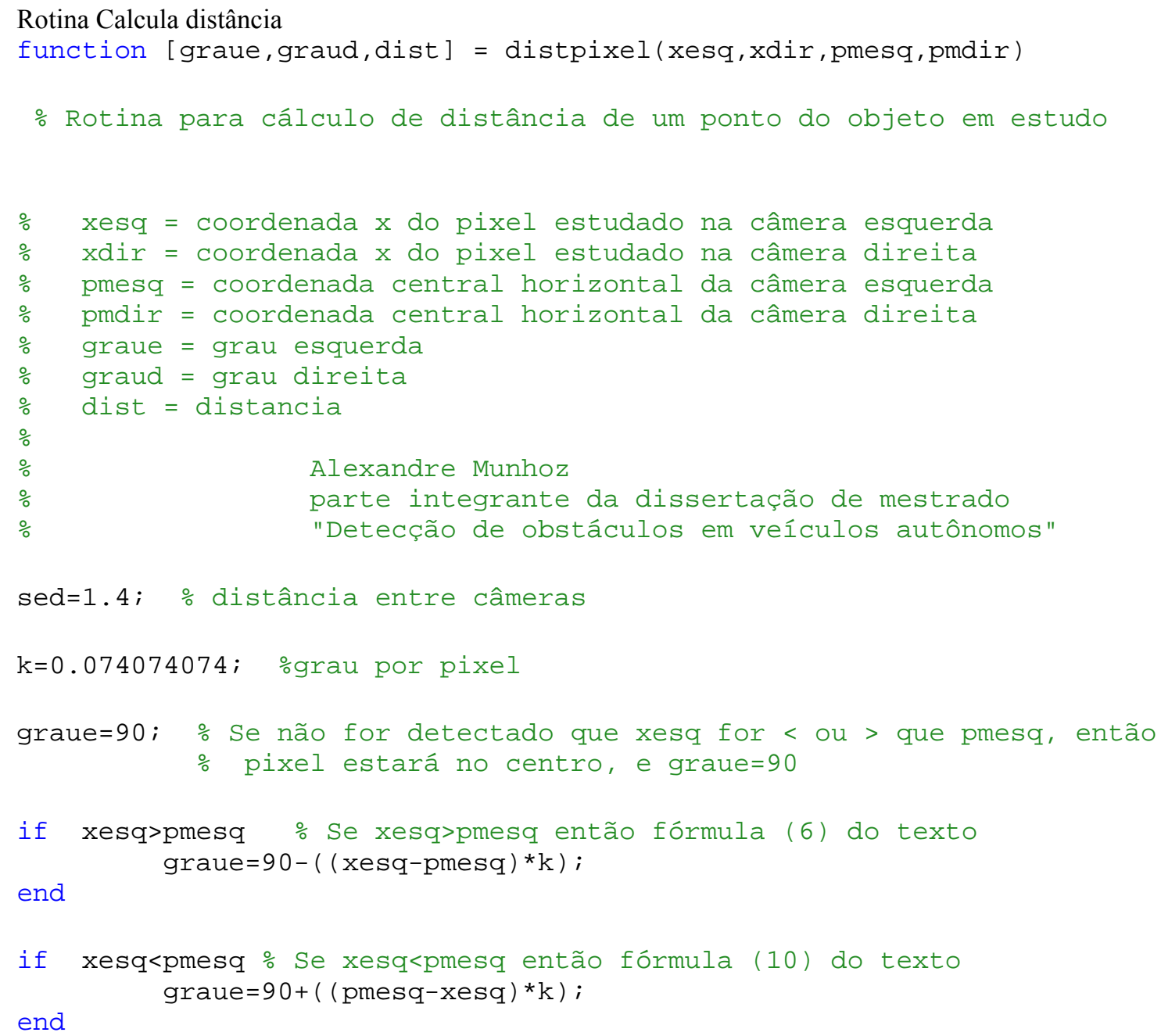

graud=90;

if xdirspmdir \% Se xdir>pmdir então fórmula (14) do texto graud $=90+\left((x d i r-\right.$ pmdir $\left.){ }^{*} k\right)$; end

if xdir<pmdir \% Se xdir<pmdir então fórmula (18) do texto end graud $=90-(($ pmdir $-x d i r) * k)$;

grauob=180-graue-graud; \% Fórmula 19 do texto

seob $=(\operatorname{sed} /(\sin (\operatorname{grauob} *(p i / 180)))) *(\sin (\operatorname{graud} *(p i / 180))) ;$ \% Fórmula 20 do texto

dist $=$ seob;

end 
Rotina de validação

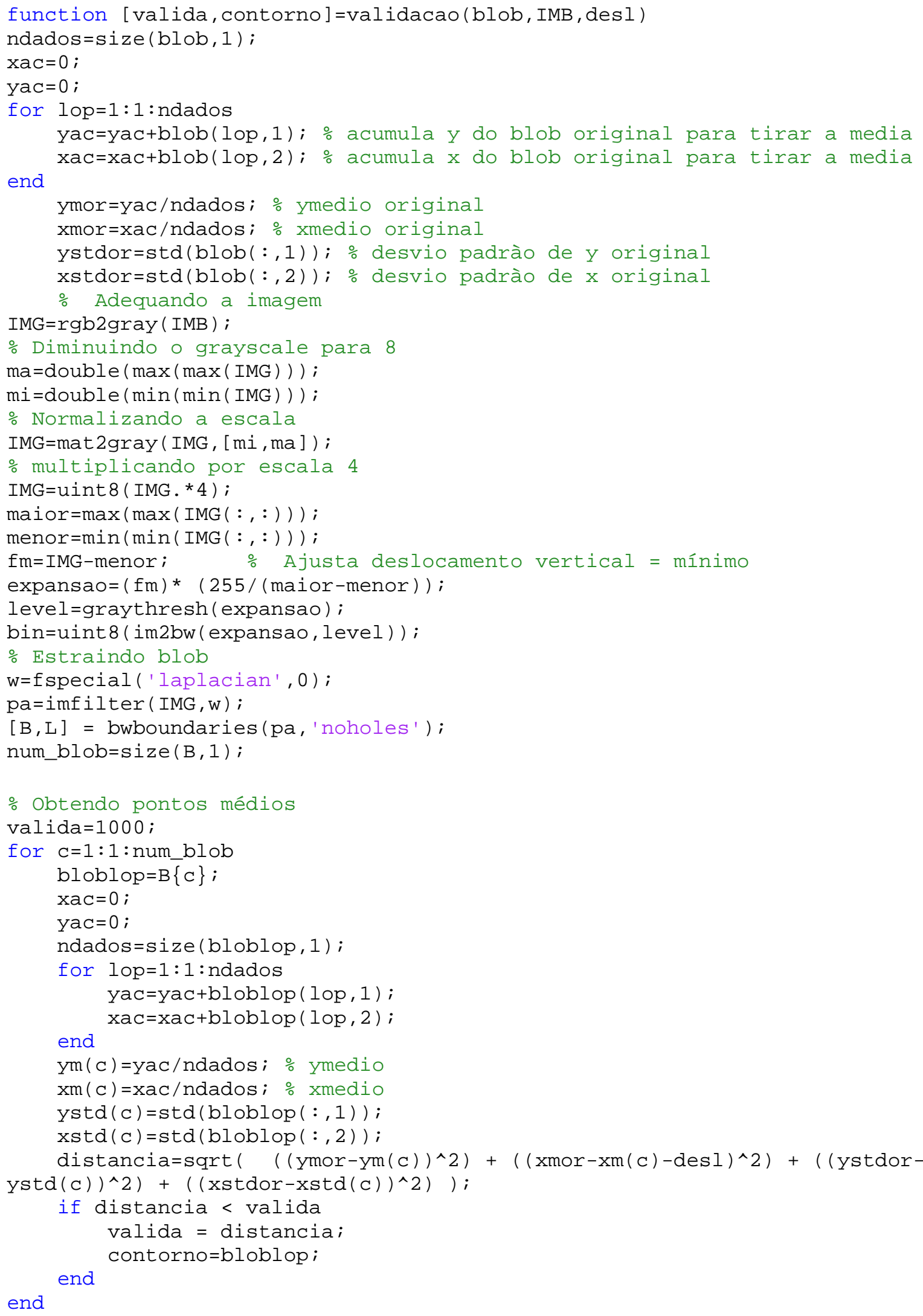




\section{APÊNDICE B - Erros proporcionados pela Discretização da imagem}

Tabela A-1 - Erro proporcionado pela discretização da imagem. Dados calculados para distância em metros com a distância equivalente em pixels.

\begin{tabular}{|c|c|c|}
\hline $\begin{array}{l}\text { Distância } \\
\text { entre } \\
\text { pixels do } \\
\text { ponto } \\
\text { estudado } \\
\text { na } \\
\text { imagem } \\
\text { direita e } \\
\text { esquerda }\end{array}$ & $\begin{array}{l}\text { Distância } \\
\text { do objeto à } \\
\text { câmera } \\
\text { esquerda } \\
\text { (m) }\end{array}$ & $\begin{array}{l}\text { Erro por } \\
\text { cada pixel } \\
\text { desviado } \\
\text { (m) }\end{array}$ \\
\hline 0 & Inf & inf \\
\hline 1 & 992,6565 & Inf \\
\hline 2 & 496,608 & 496,0485 \\
\hline 3 & 331,2581 & 165,3499 \\
\hline 4 & 248,5829 & 82,67521 \\
\hline 5 & 198,9776 & 49,60535 \\
\hline 6 & 165,9072 & 33,07042 \\
\hline 7 & 142,2853 & 23,62188 \\
\hline 8 & 124,5687 & 17,71655 \\
\hline 9 & 110,7891 & 13,77966 \\
\hline 10 & 99,76522 & 11,02384 \\
\hline 11 & 90,74561 & 9,019607 \\
\hline 12 & 83,22918 & 7,516431 \\
\hline 13 & 76,86904 & 6,360142 \\
\hline 14 & 71,41741 & 5,451629 \\
\hline 15 & 66,69259 & 4,724819 \\
\hline 16 & 62,5583 & 4,134286 \\
\hline 17 & 58,91034 & 3,647964 \\
\hline 18 & 55,66764 & 3,242696 \\
\hline 19 & 52,76622 & 2,901418 \\
\hline 20 & 50,15489 & 2,611332 \\
\hline 21 & 47,79221 & 2,362686 \\
\hline 22 & 45,64426 & 2,147947 \\
\hline 23 & 43,68304 & 1,961217 \\
\hline 24 & 41,88522 & 1,797828 \\
\hline 25 & 40,23117 & 1,654046 \\
\hline 26 & 38,70432 & 1,526854 \\
\hline 27 & 37,29052 & 1,413795 \\
\hline 28 & 35,97767 & 1,312849 \\
\hline 29 & 34,75533 & 1,222346 \\
\hline 30 & 33,61443 & 1,140893 \\
\hline 31 & 32,54711 & 1,067323 \\
\hline 32 & 31,54646 & 1,00065 \\
\hline 33 & 30,60642 & 0,940038 \\
\hline 34 & 29,72165 & 0,884774 \\
\hline 35 & 28,8874 & 0,834247 \\
\hline 36 & 28,09947 & 0,787931 \\
\hline 37 & 27,3541 & 0,74537 \\
\hline 38 & 26,64793 & 0,706169 \\
\hline 39 & 25,97795 & 0,669983 \\
\hline 40 & 25,34144 & 0,636512 \\
\hline
\end{tabular}

\begin{tabular}{|c|c|c|}
\hline $\begin{array}{c}\text { Distância } \\
\text { entre pixels }\end{array}$ & $\begin{array}{l}\text { Distância } \\
\text { do objeto à } \\
\text { câmera } \\
\text { esquerda } \\
\text { (m) }\end{array}$ & $\begin{array}{l}\text { Erro por } \\
\text { cada pixel } \\
\text { desviado } \\
\text { (m) }\end{array}$ \\
\hline 320 & 3,482524 & 0,010291 \\
\hline 321 & 3,472293 & 0,010231 \\
\hline 322 & 3,462123 & 0,010171 \\
\hline 323 & 3,452011 & 0,010111 \\
\hline 324 & 3,441959 & 0,010053 \\
\hline 325 & 3,431964 & 0,009994 \\
\hline 326 & 3,422028 & 0,009937 \\
\hline 327 & 3,412148 & 0,00988 \\
\hline 328 & 3,402325 & 0,009823 \\
\hline 329 & 3,392558 & 0,009767 \\
\hline 330 & 3,382847 & 0,009711 \\
\hline 331 & 3,373191 & 0,009656 \\
\hline 332 & 3,363589 & 0,009602 \\
\hline 333 & 3,354042 & 0,009547 \\
\hline 334 & 3,344548 & 0,009494 \\
\hline 335 & 3,335107 & 0,009441 \\
\hline 336 & 3,325719 & 0,009388 \\
\hline 337 & 3,316383 & 0,009336 \\
\hline 338 & 3,307099 & 0,009284 \\
\hline 339 & 3,297866 & 0,009233 \\
\hline 340 & 3,288684 & 0,009182 \\
\hline 341 & 3,279552 & 0,009132 \\
\hline 342 & 3,27047 & 0,009082 \\
\hline 343 & 3,261438 & 0,009032 \\
\hline 344 & 3,252454 & 0,008983 \\
\hline 345 & 3,24352 & 0,008935 \\
\hline 346 & 3,234633 & 0,008887 \\
\hline 347 & 3,225794 & 0,008839 \\
\hline 348 & 3,217003 & 0,008791 \\
\hline 349 & 3,208258 & 0,008745 \\
\hline 350 & 3,19956 & 0,008698 \\
\hline 351 & 3,190908 & 0,008652 \\
\hline 352 & 3,182302 & 0,008606 \\
\hline 353 & 3,173741 & 0,008561 \\
\hline 354 & 3,165226 & 0,008516 \\
\hline 355 & 3,156754 & 0,008471 \\
\hline 356 & 3,148327 & 0,008427 \\
\hline 357 & 3,139944 & 0,008383 \\
\hline 358 & 3,131604 & 0,00834 \\
\hline 359 & 3,123308 & 0,008297 \\
\hline 360 & 3,115054 & 0,008254 \\
\hline
\end{tabular}




\begin{tabular}{|c|c|c|}
\hline 41 & 24,73595 & 0,60549 \\
\hline 42 & 24,15926 & 0,576683 \\
\hline 43 & 23,60938 & 0,549886 \\
\hline 44 & 23,08446 & 0,524917 \\
\hline 45 & 22,58285 & 0,501612 \\
\hline 46 & 22,10302 & 0,479827 \\
\hline 47 & 21,64359 & 0,459432 \\
\hline 48 & 21,20328 & 0,440312 \\
\hline 49 & 20,78092 & 0,422363 \\
\hline 50 & 20,37543 & 0,40549 \\
\hline 51 & 19,98582 & 0,38961 \\
\hline 52 & 19,61117 & 0,374647 \\
\hline 53 & 19,25064 & 0,36053 \\
\hline 54 & 18,90344 & 0,347198 \\
\hline 55 & 18,56885 & 0,334592 \\
\hline 56 & 18,24619 & 0,322662 \\
\hline 57 & 17,93483 & 0,31136 \\
\hline 58 & 17,63418 & 0,300643 \\
\hline 59 & 17,34371 & 0,29047 \\
\hline 60 & 17,06291 & 0,280806 \\
\hline 61 & 16,79129 & 0,271618 \\
\hline 62 & 16,52841 & 0,262874 \\
\hline 63 & 16,27387 & 0,254546 \\
\hline 64 & 16,02726 & 0,246609 \\
\hline 65 & 15,78822 & 0,239038 \\
\hline 66 & 15,55641 & 0,231811 \\
\hline 67 & 15,3315 & 0,224908 \\
\hline 68 & 15,11319 & 0,218309 \\
\hline 69 & 14,90119 & 0,211998 \\
\hline 70 & 14,69524 & 0,205957 \\
\hline 71 & 14,49507 & 0,200171 \\
\hline 72 & 14,30044 & 0,194626 \\
\hline 73 & 14,11113 & 0,189309 \\
\hline 74 & 13,92693 & 0,184207 \\
\hline 75 & 13,74762 & 0,17931 \\
\hline 76 & 13,57301 & 0,174606 \\
\hline 77 & 13,40293 & 0,170085 \\
\hline 78 & 13,23719 & 0,165738 \\
\hline 79 & 13,07563 & 0,161556 \\
\hline 80 & 12,9181 & 0,157531 \\
\hline 81 & 12,76445 & 0,153655 \\
\hline 82 & 12,61452 & 0,149921 \\
\hline 83 & 12,4682 & 0,146322 \\
\hline 84 & 12,32535 & 0,142851 \\
\hline 85 & 12,18585 & 0,139503 \\
\hline 86 & 12,04958 & 0,136272 \\
\hline 87 & 11,91642 & 0,133152 \\
\hline 88 & 11,78629 & 0,130138 \\
\hline 89 & 11,65906 & 0,127226 \\
\hline 90 & 11,53465 & 0,124411 \\
\hline 91 & 11,41296 & 0,121689 \\
\hline 92 & 11,2939 & 0,119056 \\
\hline 93 & 11,1774 & 0,116508 \\
\hline 94 & 11,06336 & 0,114041 \\
\hline 95 & 10,9517 & 0,111651 \\
\hline 96 & 10,84237 & 0,109337 \\
\hline 97 & 10,73527 & 0,107094 \\
\hline 98 & 10,63035 & 0,10492 \\
\hline
\end{tabular}

\begin{tabular}{|c|c|c|}
\hline 361 & 3,106843 & 0,008211 \\
\hline 362 & 3,098673 & 0,008169 \\
\hline 363 & 3,090545 & 0,008128 \\
\hline 364 & 3,082459 & 0,008086 \\
\hline 365 & 3,074414 & 0,008045 \\
\hline 366 & 3,066409 & 0,008005 \\
\hline 367 & 3,058444 & 0,007964 \\
\hline 368 & 3,05052 & 0,007924 \\
\hline 369 & 3,042635 & 0,007885 \\
\hline 370 & 3,03479 & 0,007845 \\
\hline 371 & 3,026983 & 0,007806 \\
\hline 372 & 3,019216 & 0,007768 \\
\hline 373 & 3,011486 & 0,007729 \\
\hline 374 & 3,003795 & 0,007691 \\
\hline 375 & 2,996142 & 0,007653 \\
\hline 376 & 2,988526 & 0,007616 \\
\hline 377 & 2,980947 & 0,007579 \\
\hline 378 & 2,973405 & 0,007542 \\
\hline 379 & 2,9659 & 0,007505 \\
\hline 380 & 2,958431 & 0,007469 \\
\hline 381 & 2,950998 & 0,007433 \\
\hline 382 & 2,943601 & 0,007397 \\
\hline 383 & 2,936239 & 0,007362 \\
\hline 384 & 2,928912 & 0,007327 \\
\hline 385 & 2,92162 & 0,007292 \\
\hline 386 & 2,914363 & 0,007257 \\
\hline 387 & 2,90714 & 0,007223 \\
\hline 388 & 2,899952 & 0,007189 \\
\hline 389 & 2,892797 & 0,007155 \\
\hline 390 & 2,885675 & 0,007121 \\
\hline 391 & 2,878587 & 0,007088 \\
\hline 392 & 2,871532 & 0,007055 \\
\hline 393 & 2,86451 & 0,007022 \\
\hline 394 & 2,85752 & 0,00699 \\
\hline 395 & 2,850563 & 0,006957 \\
\hline 396 & 2,843638 & 0,006925 \\
\hline 397 & 2,836744 & 0,006894 \\
\hline 398 & 2,829882 & 0,006862 \\
\hline 399 & 2,823051 & 0,006831 \\
\hline 400 & 2,816252 & 0,0068 \\
\hline 401 & 2,809483 & 0,006769 \\
\hline 402 & 2,802744 & 0,006738 \\
\hline 403 & 2,796037 & 0,006708 \\
\hline 404 & 2,789359 & 0,006678 \\
\hline 405 & 2,782711 & 0,006648 \\
\hline 406 & 2,776093 & 0,006618 \\
\hline 407 & 2,769505 & 0,006589 \\
\hline 408 & 2,762945 & 0,006559 \\
\hline 409 & 2,756415 & 0,00653 \\
\hline 410 & 2,749914 & 0,006501 \\
\hline 411 & 2,743441 & 0,006473 \\
\hline 412 & 2,736997 & 0,006444 \\
\hline 413 & 2,73058 & 0,006416 \\
\hline 414 & 2,724192 & 0,006388 \\
\hline 416 & 2,717832 & 0,00636 \\
\hline 417 & 2,711499 & 0,006333 \\
\hline & 2,698915 & 0,006305 \\
\hline & & \\
\hline 315 & \\
\hline 375678 \\
\hline 375
\end{tabular}




\begin{tabular}{|c|c|c|}
\hline 99 & 10,52754 & 0,102811 \\
\hline 100 & 10,42678 & 0,100766 \\
\hline 101 & 10,32799 & 0,098782 \\
\hline 102 & 10,23114 & 0,096856 \\
\hline 103 & 10,13615 & 0,094986 \\
\hline 104 & 10,04298 & 0,09317 \\
\hline 105 & 9,951576 & 0,091406 \\
\hline 106 & 9,861884 & 0,089692 \\
\hline 107 & 9,773858 & 0,088026 \\
\hline 108 & 9,687452 & 0,086406 \\
\hline 109 & 9,602621 & 0,084831 \\
\hline 110 & 9,519322 & 0,083299 \\
\hline 111 & 9,437515 & 0,081808 \\
\hline 112 & 9,357158 & 0,080357 \\
\hline 113 & 9,278213 & 0,078944 \\
\hline 114 & 9,200644 & 0,077569 \\
\hline 115 & 9,124414 & 0,07623 \\
\hline 116 & 9,049489 & 0,074925 \\
\hline 117 & 8,975835 & 0,073654 \\
\hline 118 & 8,90342 & 0,072415 \\
\hline 119 & 8,832213 & 0,071207 \\
\hline 120 & 8,762183 & 0,07003 \\
\hline 121 & 8,693301 & 0,068882 \\
\hline 122 & 8,62554 & 0,067762 \\
\hline 123 & 8,558871 & 0,066669 \\
\hline 124 & 8,493268 & 0,065603 \\
\hline 125 & 8,428706 & 0,064562 \\
\hline 126 & 8,365161 & 0,063546 \\
\hline 127 & 8,302607 & 0,062554 \\
\hline 128 & 8,241021 & 0,061585 \\
\hline 129 & 8,180382 & 0,060639 \\
\hline 130 & 8,120667 & 0,059715 \\
\hline 131 & 8,061856 & 0,058812 \\
\hline 132 & 8,003927 & 0,057929 \\
\hline 133 & 7,94686 & 0,057066 \\
\hline 134 & 7,890637 & 0,056223 \\
\hline 135 & 7,835239 & 0,055398 \\
\hline 136 & 7,780647 & 0,054592 \\
\hline 137 & 7,726844 & 0,053803 \\
\hline 138 & 7,673813 & 0,053031 \\
\hline 139 & 7,621536 & 0,052276 \\
\hline 140 & 7,569999 & 0,051538 \\
\hline 141 & 7,519184 & 0,050815 \\
\hline 142 & 7,469077 & 0,050107 \\
\hline 143 & 7,419663 & 0,049414 \\
\hline 144 & 7,370928 & 0,048735 \\
\hline 145 & 7,322857 & 0,048071 \\
\hline 146 & 7,275437 & 0,04742 \\
\hline 147 & 7,228655 & 0,046782 \\
\hline 148 & 7,182497 & 0,046158 \\
\hline 149 & 7,136951 & 0,045546 \\
\hline 150 & 7,092005 & 0,044946 \\
\hline 151 & 7,047647 & 0,044358 \\
\hline 152 & 7,003866 & 0,043782 \\
\hline 153 & 6,960649 & 0,043217 \\
\hline 154 & 6,917986 & 0,042663 \\
\hline 155 & 6,875866 & 0,04212 \\
\hline 156 & 6,834279 & 0,041587 \\
\hline & & \\
\hline 125
\end{tabular}

\begin{tabular}{|c|c|c|}
\hline 419 & 2,692664 & 0,006251 \\
\hline 420 & 2,68644 & 0,006224 \\
\hline 421 & 2,680242 & 0,006198 \\
\hline 422 & 2,674071 & 0,006171 \\
\hline 423 & 2,667926 & 0,006145 \\
\hline 424 & 2,661807 & 0,006119 \\
\hline 425 & 2,655713 & 0,006093 \\
\hline 426 & 2,649646 & 0,006068 \\
\hline 427 & 2,643604 & 0,006042 \\
\hline 428 & 2,637587 & 0,006017 \\
\hline 429 & 2,631595 & 0,005992 \\
\hline 430 & 2,625629 & 0,005967 \\
\hline 431 & 2,619687 & 0,005942 \\
\hline 432 & 2,61377 & 0,005917 \\
\hline 433 & 2,607877 & 0,005893 \\
\hline 434 & 2,602008 & 0,005869 \\
\hline 435 & 2,596164 & 0,005844 \\
\hline 436 & 2,590343 & 0,005821 \\
\hline 437 & 2,584546 & 0,005797 \\
\hline 438 & 2,578773 & 0,005773 \\
\hline 439 & 2,573023 & 0,00575 \\
\hline 440 & 2,567297 & 0,005726 \\
\hline 441 & 2,561594 & 0,005703 \\
\hline 442 & 2,555913 & 0,00568 \\
\hline 443 & 2,550256 & 0,005658 \\
\hline 444 & 2,544621 & 0,005635 \\
\hline 445 & 2,539008 & 0,005612 \\
\hline 446 & 2,533418 & 0,00559 \\
\hline 447 & 2,52785 & 0,005568 \\
\hline 448 & 2,522304 & 0,005546 \\
\hline 449 & 2,51678 & 0,005524 \\
\hline 450 & 2,511278 & 0,005502 \\
\hline 451 & 2,505797 & 0,005481 \\
\hline 452 & 2,500338 & 0,005459 \\
\hline 453 & 2,4949 & 0,005438 \\
\hline 454 & 2,489483 & 0,005417 \\
\hline 455 & 2,484087 & 0,005396 \\
\hline 456 & 2,478712 & 0,005375 \\
\hline 457 & 2,473358 & 0,005354 \\
\hline 458 & 2,468024 & 0,005334 \\
\hline 459 & 2,462711 & 0,005313 \\
\hline 460 & 2,457418 & 0,005293 \\
\hline 461 & 2,452146 & 0,005273 \\
\hline 462 & 2,446893 & 0,005253 \\
\hline 463 & 2,441661 & 0,005233 \\
\hline 464 & 2,436448 & 0,005213 \\
\hline 465 & 2,431255 & 0,005193 \\
\hline 466 & 2,426081 & 0,005174 \\
\hline 467 & 2,420927 & 0,005154 \\
\hline 468 & 2,415792 & 0,005135 \\
\hline 469 & 2,410676 & 0,005116 \\
\hline 470 & 2,405579 & 0,005097 \\
\hline 471 & 2,400502 & 0,005078 \\
\hline 472 & 2,395443 & 0,005059 \\
\hline 473 & 2,390402 & 0,00504 \\
\hline 475 & 2,38538 & 0,005022 \\
\hline 476 & 2,380377 & 0,005003 \\
\hline & & \\
\hline 475392 & 0,004985 \\
\hline 44
\end{tabular}




\begin{tabular}{|c|c|c|}
\hline 157 & 6,793215 & 0,041064 \\
\hline 158 & 6,752664 & 0,040552 \\
\hline 159 & 6,712615 & 0,040049 \\
\hline 160 & 6,67306 & 0,039555 \\
\hline 161 & 6,63399 & 0,039071 \\
\hline 162 & 6,595394 & 0,038595 \\
\hline 163 & 6,557266 & 0,038129 \\
\hline 164 & 6,519595 & 0,03767 \\
\hline 165 & 6,482375 & 0,037221 \\
\hline 166 & 6,445596 & 0,036779 \\
\hline 167 & 6,409251 & 0,036345 \\
\hline 168 & 6,373331 & 0,035919 \\
\hline 169 & 6,337831 & 0,035501 \\
\hline 170 & 6,302741 & 0,03509 \\
\hline 171 & 6,268055 & 0,034686 \\
\hline 172 & 6,233766 & 0,034289 \\
\hline 173 & 6,199866 & 0,033899 \\
\hline 174 & 6,16635 & 0,033516 \\
\hline 175 & 6,133211 & 0,03314 \\
\hline 176 & 6,100441 & 0,032769 \\
\hline 177 & 6,068036 & 0,032405 \\
\hline 178 & 6,035988 & 0,032048 \\
\hline 179 & 6,004292 & 0,031696 \\
\hline 180 & 5,972942 & 0,03135 \\
\hline 181 & 5,941932 & 0,03101 \\
\hline 182 & 5,911257 & 0,030675 \\
\hline 183 & 5,880911 & 0,030346 \\
\hline 184 & 5,850888 & 0,030023 \\
\hline 185 & 5,821184 & 0,029704 \\
\hline 186 & 5,791793 & 0,029391 \\
\hline 187 & 5,762711 & 0,029082 \\
\hline 188 & 5,733932 & 0,028779 \\
\hline 189 & 5,705451 & 0,028481 \\
\hline 190 & 5,677264 & 0,028187 \\
\hline 191 & 5,649367 & 0,027898 \\
\hline 192 & 5,621754 & 0,027613 \\
\hline 193 & 5,594421 & 0,027333 \\
\hline 194 & 5,567365 & 0,027057 \\
\hline 195 & 5,54058 & 0,026785 \\
\hline 196 & 5,514063 & 0,026517 \\
\hline 197 & 5,487809 & 0,026254 \\
\hline 198 & 5,461814 & 0,025994 \\
\hline 199 & 5,436075 & 0,025739 \\
\hline 200 & 5,410588 & 0,025487 \\
\hline 201 & 5,385349 & 0,025239 \\
\hline 202 & 5,360354 & 0,024995 \\
\hline 203 & 5,3356 & 0,024754 \\
\hline 204 & 5,311082 & 0,024517 \\
\hline 205 & 5,286799 & 0,024284 \\
\hline 206 & 5,262745 & 0,024053 \\
\hline 207 & 5,238919 & 0,023826 \\
\hline 208 & 5,215316 & 0,023603 \\
\hline 209 & 5,191934 & 0,023382 \\
\hline 210 & 5,168769 & 0,023165 \\
\hline 211 & 5,145818 & 0,022951 \\
\hline 212 & 5,123078 & 0,02274 \\
\hline 213 & 5,100547 & 0,022532 \\
\hline 214 & 5,07822 & 0,022326 \\
\hline & & \\
\hline 14
\end{tabular}

\begin{tabular}{|c|c|c|}
\hline 477 & 2,370425 & 0,004967 \\
\hline 478 & 2,365477 & 0,004949 \\
\hline 479 & 2,360546 & 0,004931 \\
\hline 480 & 2,355633 & 0,004913 \\
\hline 481 & 2,350738 & 0,004895 \\
\hline 482 & 2,34586 & 0,004878 \\
\hline 483 & 2,341 & 0,00486 \\
\hline 484 & 2,336157 & 0,004843 \\
\hline 485 & 2,331332 & 0,004825 \\
\hline 486 & 2,326524 & 0,004808 \\
\hline 487 & 2,321733 & 0,004791 \\
\hline 488 & 2,316959 & 0,004774 \\
\hline 489 & 2,312202 & 0,004757 \\
\hline 490 & 2,307461 & 0,00474 \\
\hline 491 & 2,302737 & 0,004724 \\
\hline 492 & 2,29803 & 0,004707 \\
\hline 493 & 2,293339 & 0,004691 \\
\hline 494 & 2,288665 & 0,004674 \\
\hline 495 & 2,284007 & 0,004658 \\
\hline 496 & 2,279365 & 0,004642 \\
\hline 497 & 2,274739 & 0,004626 \\
\hline 498 & 2,270129 & 0,00461 \\
\hline 499 & 2,265534 & 0,004594 \\
\hline 500 & 2,260956 & 0,004578 \\
\hline 501 & 2,256393 & 0,004563 \\
\hline 502 & 2,251846 & 0,004547 \\
\hline 503 & 2,247314 & 0,004532 \\
\hline 504 & 2,242798 & 0,004516 \\
\hline 505 & 2,238297 & 0,004501 \\
\hline 506 & 2,233811 & 0,004486 \\
\hline 507 & 2,22934 & 0,004471 \\
\hline 508 & 2,224885 & 0,004456 \\
\hline 509 & 2,220444 & 0,004441 \\
\hline 510 & 2,216018 & 0,004426 \\
\hline 511 & 2,211607 & 0,004411 \\
\hline 512 & 2,20721 & 0,004397 \\
\hline 513 & 2,202828 & 0,004382 \\
\hline 514 & 2,19846 & 0,004368 \\
\hline 515 & 2,194107 & 0,004353 \\
\hline 516 & 2,189768 & 0,004339 \\
\hline 517 & 2,185444 & 0,004325 \\
\hline 518 & 2,181133 & 0,004311 \\
\hline 519 & 2,176837 & 0,004296 \\
\hline 520 & 2,172554 & 0,004282 \\
\hline 521 & 2,168286 & 0,004269 \\
\hline 522 & 2,164031 & 0,004255 \\
\hline 523 & 2,15979 & 0,004241 \\
\hline 524 & 2,155562 & 0,004227 \\
\hline 525 & 2,151349 & 0,004214 \\
\hline 526 & 2,147148 & 0,0042 \\
\hline 527 & 2,142961 & 0,004187 \\
\hline 528 & 2,138788 & 0,004174 \\
\hline 529 & 2,134627 & 0,00416 \\
\hline 530 & 2,13048 & 0,004147 \\
\hline 531 & 2,126346 & 0,004134 \\
\hline 532 & 2,122225 & 0,004121 \\
\hline 533 & 2,118117 & 0,004108 \\
\hline 534 & 2,114022 & 0,004095 \\
\hline
\end{tabular}




\begin{tabular}{|c|c|c|}
\hline 215 & 5,056096 & 0,022124 \\
\hline 216 & 5,034172 & 0,021924 \\
\hline 217 & 5,012444 & 0,021728 \\
\hline 218 & 4,990911 & 0,021533 \\
\hline 219 & 4,969569 & 0,021342 \\
\hline 220 & 4,948416 & 0,021153 \\
\hline 221 & 4,927449 & 0,020967 \\
\hline 222 & 4,906665 & 0,020783 \\
\hline 223 & 4,886064 & 0,020602 \\
\hline 224 & 4,86564 & 0,020423 \\
\hline 225 & 4,845394 & 0,020247 \\
\hline 226 & 4,825321 & 0,020073 \\
\hline 227 & 4,805421 & 0,019901 \\
\hline 228 & 4,785689 & 0,019731 \\
\hline 229 & 4,766126 & 0,019564 \\
\hline 230 & 4,746727 & 0,019399 \\
\hline 231 & 4,727491 & 0,019236 \\
\hline 232 & 4,708416 & 0,019075 \\
\hline 233 & 4,689501 & 0,018916 \\
\hline 234 & 4,670741 & 0,018759 \\
\hline 235 & 4,652137 & 0,018604 \\
\hline 236 & 4,633685 & 0,018452 \\
\hline 237 & 4,615384 & 0,018301 \\
\hline 238 & 4,597233 & 0,018152 \\
\hline 239 & 4,579228 & 0,018005 \\
\hline 240 & 4,561368 & 0,017859 \\
\hline 241 & 4,543652 & 0,017716 \\
\hline 242 & 4,526078 & 0,017574 \\
\hline 243 & 4,508644 & 0,017434 \\
\hline 244 & 4,491347 & 0,017296 \\
\hline 245 & 4,474188 & 0,01716 \\
\hline 246 & 4,457163 & 0,017025 \\
\hline 247 & 4,440271 & 0,016892 \\
\hline 248 & 4,423511 & 0,01676 \\
\hline 249 & 4,406881 & 0,01663 \\
\hline 250 & 4,390379 & 0,016502 \\
\hline 251 & 4,374004 & 0,016375 \\
\hline 252 & 4,357755 & 0,016249 \\
\hline 253 & 4,341629 & 0,016126 \\
\hline 254 & 4,325626 & 0,016003 \\
\hline 255 & 4,309744 & 0,015882 \\
\hline 256 & 4,293981 & 0,015763 \\
\hline 257 & 4,278337 & 0,015644 \\
\hline 258 & 4,262809 & 0,015528 \\
\hline 259 & 4,247397 & 0,015412 \\
\hline 260 & 4,232099 & 0,015298 \\
\hline 261 & 4,216914 & 0,015185 \\
\hline 262 & 4,20184 & 0,015074 \\
\hline 263 & 4,186877 & 0,014964 \\
\hline 264 & 4,172022 & 0,014855 \\
\hline 265 & 4,157275 & 0,014747 \\
\hline 266 & 4,142635 & 0,01464 \\
\hline 267 & 4,1281 & 0,014535 \\
\hline 268 & 4,113669 & 0,014431 \\
\hline 269 & 4,099341 & 0,014328 \\
\hline 270 & 4,085115 & 0,014226 \\
\hline 271 & 4,07099 & 0,014125 \\
\hline 272 & 4,056964 & 0,014026 \\
\hline & & \\
\hline 245
\end{tabular}

\begin{tabular}{|c|c|c|}
\hline 535 & 2,109939 & 0,004082 \\
\hline 536 & 2,105869 & 0,00407 \\
\hline 537 & 2,101812 & 0,004057 \\
\hline 538 & 2,097768 & 0,004044 \\
\hline 539 & 2,093736 & 0,004032 \\
\hline 540 & 2,089716 & 0,00402 \\
\hline 541 & 2,085709 & 0,004007 \\
\hline 542 & 2,081714 & 0,003995 \\
\hline 543 & 2,077732 & 0,003983 \\
\hline 544 & 2,073761 & 0,00397 \\
\hline 545 & 2,069803 & 0,003958 \\
\hline 546 & 2,065856 & 0,003946 \\
\hline 547 & 2,061922 & 0,003934 \\
\hline 548 & 2,057999 & 0,003923 \\
\hline 549 & 2,054089 & 0,003911 \\
\hline 550 & 2,05019 & 0,003899 \\
\hline 551 & 2,046303 & 0,003887 \\
\hline 552 & 2,042427 & 0,003876 \\
\hline 553 & 2,038563 & 0,003864 \\
\hline 554 & 2,03471 & 0,003853 \\
\hline 555 & 2,030869 & 0,003841 \\
\hline 556 & 2,027039 & 0,00383 \\
\hline 557 & 2,023221 & 0,003819 \\
\hline 558 & 2,019413 & 0,003807 \\
\hline 559 & 2,015617 & 0,003796 \\
\hline 560 & 2,011832 & 0,003785 \\
\hline 561 & 2,008058 & 0,003774 \\
\hline 562 & 2,004295 & 0,003763 \\
\hline 563 & 2,000543 & 0,003752 \\
\hline 564 & 1,996802 & 0,003741 \\
\hline 565 & 1,993072 & 0,00373 \\
\hline 566 & 1,989352 & 0,00372 \\
\hline 567 & 1,985643 & 0,003709 \\
\hline 568 & 1,981945 & 0,003698 \\
\hline 569 & 1,978257 & 0,003688 \\
\hline 570 & 1,97458 & 0,003677 \\
\hline 571 & 1,970914 & 0,003667 \\
\hline 572 & 1,967257 & 0,003656 \\
\hline 573 & 1,963611 & 0,003646 \\
\hline 574 & 1,959976 & 0,003636 \\
\hline 575 & 1,95635 & 0,003625 \\
\hline 576 & 1,952735 & 0,003615 \\
\hline 577 & 1,94913 & 0,003605 \\
\hline 578 & 1,945535 & 0,003595 \\
\hline 579 & 1,94195 & 0,003585 \\
\hline 580 & 1,938375 & 0,003575 \\
\hline 581 & 1,93481 & 0,003565 \\
\hline 582 & 1,931255 & 0,003555 \\
\hline 583 & 1,927709 & 0,003545 \\
\hline 584 & 1,924173 & 0,003536 \\
\hline 585 & 1,920647 & 0,003526 \\
\hline 586 & 1,917131 & 0,003516 \\
\hline 587 & 1,913624 & 0,003507 \\
\hline 588 & 1,910127 & 0,003497 \\
\hline 589 & 1,906639 & 0,003488 \\
\hline 590 & 1,903161 & 0,003478 \\
\hline 591 & 1,899692 & 0,003469 \\
\hline 592 & 1,896233 & 0,00346 \\
\hline
\end{tabular}




\begin{tabular}{|c|c|c|}
\hline 273 & 4,043037 & 0,013927 \\
\hline 274 & 4,029207 & 0,01383 \\
\hline 275 & 4,015474 & 0,013733 \\
\hline 276 & 4,001836 & 0,013638 \\
\hline 277 & 3,988292 & 0,013544 \\
\hline 278 & 3,974841 & 0,013451 \\
\hline 279 & 3,961483 & 0,013358 \\
\hline 280 & 3,948216 & 0,013267 \\
\hline 281 & 3,935039 & 0,013177 \\
\hline 282 & 3,921951 & 0,013088 \\
\hline 283 & 3,908952 & 0,012999 \\
\hline 284 & 3,896041 & 0,012912 \\
\hline 285 & 3,883215 & 0,012825 \\
\hline 286 & 3,870476 & 0,01274 \\
\hline 287 & 3,857821 & 0,012655 \\
\hline 288 & 3,84525 & 0,012571 \\
\hline 289 & 3,832762 & 0,012488 \\
\hline 290 & 3,820356 & 0,012406 \\
\hline 291 & 3,808031 & 0,012325 \\
\hline 292 & 3,795787 & 0,012244 \\
\hline 293 & 3,783622 & 0,012165 \\
\hline 294 & 3,771536 & 0,012086 \\
\hline 295 & 3,759528 & 0,012008 \\
\hline 296 & 3,747597 & 0,011931 \\
\hline 297 & 3,735742 & 0,011854 \\
\hline 298 & 3,723964 & 0,011779 \\
\hline 299 & 3,71226 & 0,011704 \\
\hline 300 & 3,70063 & 0,01163 \\
\hline 301 & 3,689073 & 0,011556 \\
\hline 302 & 3,677589 & 0,011484 \\
\hline 303 & 3,666177 & 0,011412 \\
\hline 304 & 3,654837 & 0,011341 \\
\hline 305 & 3,643567 & 0,01127 \\
\hline 306 & 3,632366 & 0,0112 \\
\hline 307 & 3,621235 & 0,011131 \\
\hline 308 & 3,610172 & 0,011063 \\
\hline 309 & 3,599177 & 0,010995 \\
\hline 310 & 3,588249 & 0,010928 \\
\hline 311 & 3,577388 & 0,010861 \\
\hline 312 & 3,566592 & 0,010796 \\
\hline 313 & 3,555862 & 0,01073 \\
\hline 314 & 3,545196 & 0,010666 \\
\hline 315 & 3,534594 & 0,010602 \\
\hline 316 & 3,524056 & 0,010538 \\
\hline 317 & 3,51358 & 0,010476 \\
\hline 318 & 3,503167 & 0,010414 \\
\hline 319 & 3,492815 & 0,010352 \\
\hline & & \\
\hline 290
\end{tabular}

\begin{tabular}{|c|c|c|}
\hline 593 & 1,892783 & 0,00345 \\
\hline 594 & 1,889342 & 0,003441 \\
\hline 595 & 1,88591 & 0,003432 \\
\hline 596 & 1,882487 & 0,003423 \\
\hline 597 & 1,879074 & 0,003414 \\
\hline 598 & 1,875669 & 0,003404 \\
\hline 599 & 1,872274 & 0,003395 \\
\hline 600 & 1,868887 & 0,003386 \\
\hline 601 & 1,86551 & 0,003378 \\
\hline 602 & 1,862141 & 0,003369 \\
\hline 603 & 1,858781 & 0,00336 \\
\hline 604 & 1,85543 & 0,003351 \\
\hline 605 & 1,852088 & 0,003342 \\
\hline 606 & 1,848754 & 0,003334 \\
\hline 607 & 1,845429 & 0,003325 \\
\hline 608 & 1,842113 & 0,003316 \\
\hline 609 & 1,838805 & 0,003308 \\
\hline 610 & 1,835505 & 0,003299 \\
\hline 611 & 1,832215 & 0,003291 \\
\hline 612 & 1,828932 & 0,003282 \\
\hline 613 & 1,825658 & 0,003274 \\
\hline 614 & 1,822392 & 0,003266 \\
\hline 615 & 1,819135 & 0,003257 \\
\hline 616 & 1,815885 & 0,003249 \\
\hline 617 & 1,812644 & 0,003241 \\
\hline 618 & 1,809412 & 0,003233 \\
\hline 619 & 1,806187 & 0,003225 \\
\hline 620 & 1,80297 & 0,003217 \\
\hline 621 & 1,799762 & 0,003209 \\
\hline 622 & 1,796561 & 0,003201 \\
\hline 623 & 1,793368 & 0,003193 \\
\hline 624 & 1,790184 & 0,003185 \\
\hline 625 & 1,787007 & 0,003177 \\
\hline 626 & 1,783838 & 0,003169 \\
\hline 627 & 1,780677 & 0,003161 \\
\hline 628 & 1,777523 & 0,003153 \\
\hline 629 & 1,774378 & 0,003146 \\
\hline 630 & 1,771239 & 0,003138 \\
\hline 631 & 1,768109 & 0,00313 \\
\hline 632 & 1,764986 & 0,003123 \\
\hline 633 & 1,761871 & 0,003115 \\
\hline 634 & 1,758763 & 0,003108 \\
\hline 635 & 1,755663 & 0,0031 \\
\hline 636 & 1,752571 & 0,003093 \\
\hline 637 & 1,749485 & 0,003085 \\
\hline 638 & 1,746407 & 0,003078 \\
\hline 639 & 1,743337 & 0,003071 \\
\hline
\end{tabular}

